Universidad de Lima

Facultad de Economía

Carrera de Economía

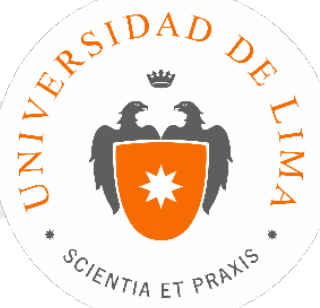

\title{
EL EFECTO DEL PROGRAMA JUNTOS EN EL CONSUMO DE LAS FAMILIAS BENEFICIARIAS DE HUÁNUCO Y LAS CONSECUENCIAS GENERADAS EN LA POBLACIÓN Y LA INADECUADA COBERTURA DE LOS HOGARES, 2007 - 2011
}

Trabajo de investigación para optar el título profesional de Economista

Mayra Ivette Rojas Paredes

20070948

Asesor

Hillman Farfán Ruiz

Lima - Perú

Agosto del 2016 


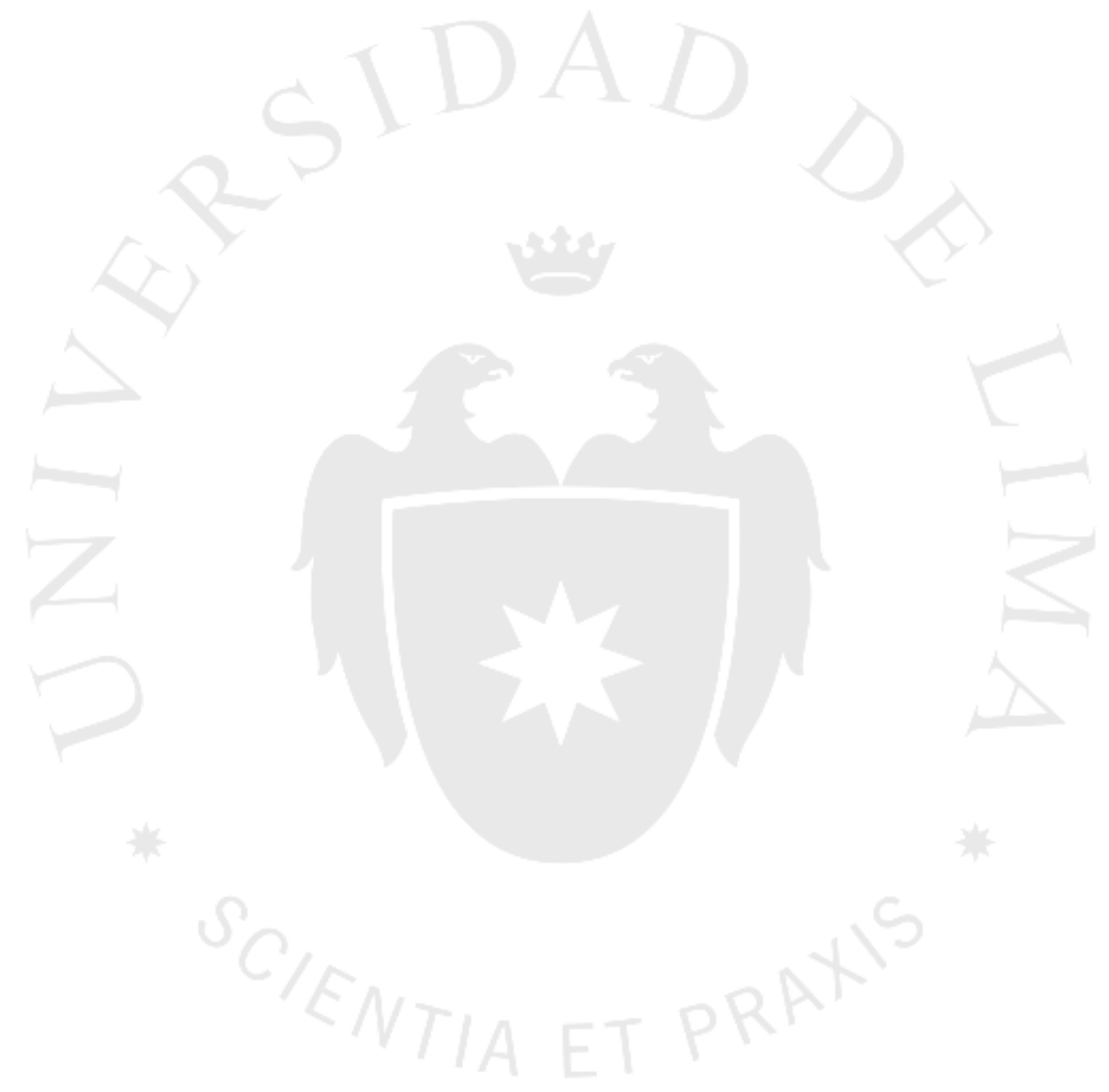


EL EFECTO DEL PROGRAMA JUNTOS EN EL CONSUMO DE LAS FAMILIAS BENEFICIARIAS DE HUÁNUCO Y LAS CONSECUENCIAS GENERADAS EN LA POBLACIÓN Y LA INADECUADA COBERTURA DE LOS HOGARES, 2007 - 2011 


\section{TABLA DE CONTENIDO}

INTRODUCCIÓN 1

CAPÍTULO 1: POBREZA Y PROGRAMAS DE TRANSFERENCIA

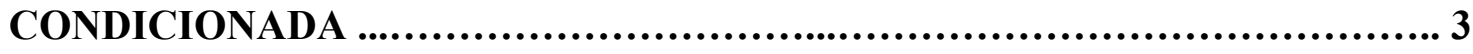

1.1 Marco Teórico ....................................................... 4

1.1.1 Definiciones de pobreza ............................... 4

1.1.2 Metodologías de medición de la pobreza ................... 10

1.2 Evolución de la pobreza en el Perú y la región de

Huánuco.................................................................... 15

1.2.1 Pobreza en el Perú ......................................... 16

1.2.2 Pobreza en Huánuco. ..................................... 25

1.3 Programas de Transferencia Condicionada...................................... 31

1.3.1 México: Programa "Oportunidades" .......................... 37

1.3.2 Brasil: Programa "Bolsa Familia" ............................. 40

1.3.3 Colombia: Programa "Familias en Acción" ..................... 44

CAPITULO 2: PROGRAMA NACIONAL DE APOYO DIRECTO A LOS MAS POBRES "JUNTOS" ............................................................. 48

2.1 El Programa Juntos ............................................. 48

2.1.1 Objetivo del Programa .................................... 48

2.1.2 Diseño del Programa ....................................... 50

2.1.3 Identificación y selección de beneficiarios ................................. 55

2.2 Cobertura y Presupuesto del Programa $\ldots . . \ldots \ldots \ldots \ldots \ldots \ldots \ldots \ldots \ldots \ldots \ldots . \ldots \ldots$

2.3 Resultados del Programa ......................................... 69

2.3.1 Educación ..................................................69 69

2.3.2 Nutrición ............................................... 71

2.3.3 Salud ..................................................... 74

CAPITULO 3: ANÁLISIS DEL CONSUMO DE LOS BENEFICIARIOS Y DE

LA SUBCOBERTURA DEL PROGRAMA JUNTOS EN HUÁNUCO ........... 78

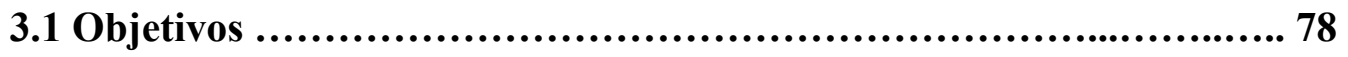

3.1.1 Objetivo General ....................................... 78

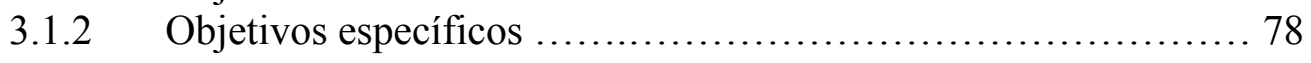


3.2.1 Hipótesis General ............................................... 79

3.2.2 Hipótesis Específicas ...................................... 79

3.3 Análisis de la subcobertura del programa juntos en Huánuco.......... 79

3.4 Análisis del gasto realizado por las familias beneficiarias del programa JUNTOS ......................................................................... 86

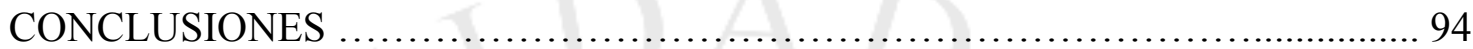

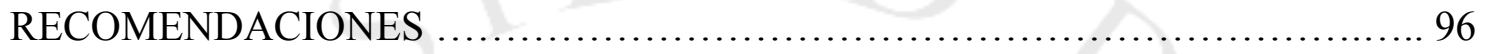

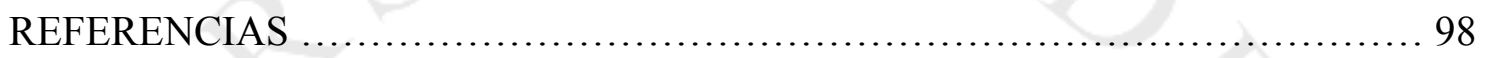

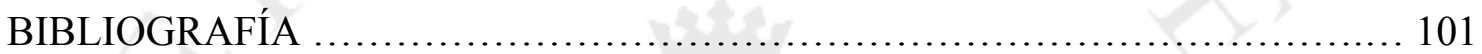

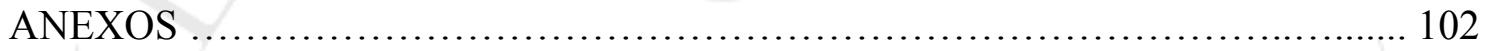




\section{ÍNDICE DE TABLAS}

Tabla 1.1 Perú: Línea de Pobreza Extrema - Canasta Básica de Alimentos per cápita mensual, según niveles geográficos 2007-2011................ 17

Tabla 1.2 Perú: Línea de Pobreza - Canasta Básica per cápita mensual por años de encuesta según ámbitos geográficos 2007-2011........................ 18

Tabla 1.3 Perú: Evolución de la Incidencia de la Pobreza Total, según ámbitos geográficos 2007-2011...................................... 22

Tabla 1.4 Perú: Evolución de la Pobreza Extrema, según ámbitos geográficos

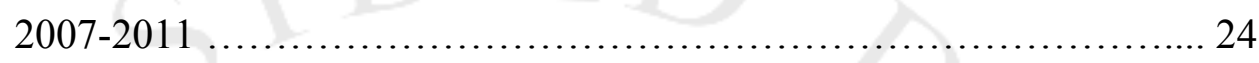

Tabla 1.5 Perú: Incidencia de la Pobreza por grupos de Departamentos 2010 y 2011

Tabla 1.6 Perú: Incidencia de la Pobreza Extrema por grupos de Departamentos

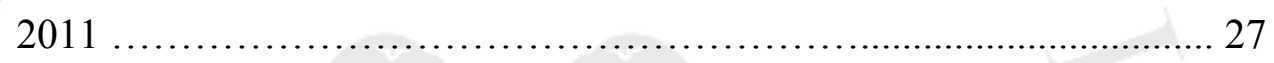

Tabla 1.7 Perú: Tasa neta de matrícula por año 2005-2010 ...................... 30

Tabla 1.8 Perú: Matriz de tamaño de Programa y alcance de las condiciones ..... 35

Tabla 1.9 Impacto de los Programas de Transferencia Condicionada sobre los indicadores de pobreza ....................................... 36

Tabla 1.10 Niveles del SISBEN ......................................... 45

Tabla 1.11 Impacto positivo en el estado nutricional de niños(as) menores de 7 años

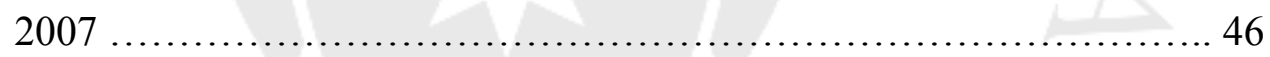

Tabla 2.1 Condiciones del programa JUNTOS.............................. 52

Tabla 2.2 Cobertura del programa JUNTOS por regiones y distritos 2005-2011

Tabla 2.3 Cobertura de hogares y personas del programa JUNTOS 2007-2011

Tabla 2.4 Incidencia de la pobreza por grupo de departamentos 2005 y $2011 \ldots . .64$

Tabla 2.5 Gasto Social Total, en Educación y en Salud 2007-2010 ................... 65

Tabla 2.6 Gasto social en educación y salud 2007-2010 ........................ 66

Tabla 2.7 Ejecución del presupuesto asignado al programa JUNTOS 2007-2011

Tabla 2.8 Porcentaje de ejecución del presupuesto total y de transferencias del programa JUNTOS 2008-2011 68 
Tabla 3.1 Población objetivo del programa JUNTOS de acuerdo a su situación de pobreza. Huánuco 2007

Tabla 3.2 Hogares beneficiarios y no beneficiarios de acuerdo a su calificación para el programa JUNTOS. Huánuco 2007 ........................... 81

Tabla 3.3 Tasa de Subcobertura del programa JUNTOS. Huánuco 2007 ................. 82

Tabla 3.4 Población objetivo del programa JUNTOS de acuerdo a su situación de pobreza. Huánuco 2011 ........................................... 82

Tabla 3.5 Hogares beneficiarios y no beneficiarios de acuerdo a su calificación para el programa JUNTOS. Huánuco 2011 .............................. 83

Tabla 3.6 Tasa de Subcobertura del programa JUNTOS. Huánuco 2011 .......... 84

Tabla 3.7 Categorías de Gasto realizado con las transferencias recibidas del Programa. Huánuco 2012 ...................................... 87

Tabla 3.8 Categorías de Inversiones realizadas. 2012 ......................... 91 


\section{ÍNDICE DE FIGURAS}

Figura $1.1 \quad$ Enfoques de la pobreza, 2010 ................................. 9

Figura 1.2 Medición de la pobreza monetaria, 2011........................... 11

Figura 1.3 Perú: Incidencia de la Pobreza Total según departamento ............. 13

Figura 1.4 Perú: Evolución de las Líneas de Pobreza Total y Pobreza Extrema, 2007-2011 .................................................... 19

Figura 1.5 Perú: Evolución de la Incidencia de la Pobreza Total 2007-2011 ...... 20

Figura 1.6 Perú: Variación de la Pobreza Total, según ámbitos geográficos

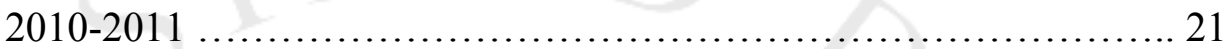

Figura 1.7 Perú: Evolución de la Incidencia de la Pobreza Extrema 2010-2011

Figura 1.8 Perú: Variación de la Pobreza Extrema, según ámbitos geográficos

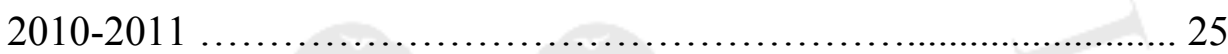

Figura 1.9 Perú: Desnutrición Crónica, según departamento

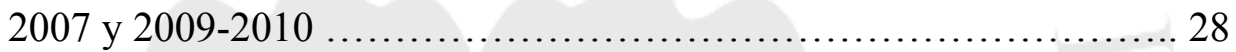

Figura 1.10 México: Evolución de la pobreza 1992-2010 ....................... 38

Figura 1.11 México: Crecimiento de la cobertura del programa Oportunidades

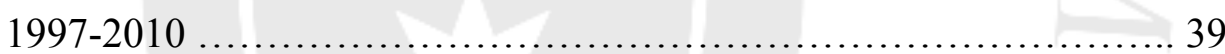

Figura 1.12 Brasil: Evolución de la pobreza extrema 1990-2009 .................. 41

Figura 1.13 Incidencia de la pobreza extrema por dominio 2002-2014 _................. 47

Figura 2.1 Padrón General de Hogares (PGH) del SISFHO ........................ 57

Figura 2.2 Metodología para identificar a potenciales beneficiarios ................... 58

Figura 2.3 Procedimiento para la medición del Índice de Focalización de Hogares

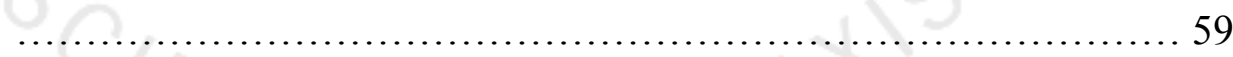

Figura 2.4 Cobertura del programa JUNTOS 2005-2011 .................... 62

Figura 2.5 Inasistencia escolar en beneficiarios y no beneficiarios, en Huánuco 70

Figura 2.6 Incremento general en la tasa de matrícula y asistencia 2007-2011

Figura 2.7 Proporción de niños menores de 5 años con desnutrición crónica (NCHS) en el ámbito del programa Juntos 2007-2011

Figura 2.8 Proporción de menores de 5 años con desnutrición crónica según departamento (Patrón NCHS) Junio 2007-2011 
Figura 2.9 Proporción de menores de 3 años con controles de Crecimiento y Desarrollo (CRED) completo para su edad, en el ámbito del programa Juntos 2007-2011

Figura 2.10 Proporción de mujeres gestantes que recibieron su primer control prenatal en el 1er trimestre de gestación y proporción de mujeres gestantes que recibieron suplemento de hierro en el ámbito del Programa Juntos $2007-2011$............................................... 75

Figura 2.11 Proporción de menores de 3 años con vacunas básicas completas para su edad, en el ámbito del Programa Juntos 2007-2011

Figura 2.12 Proporción de menores de 3 años con vacunas básicas completas para su edad. Total nacional, región de Huánuco 2007-2011 


\section{ÍNDICE DE ANEXOS}

ANEXO 1:Matriz de Coherencia Metodológica

ANEXO 2: Entrevistas

106

ANEXO 3:Metodología para el cálculo del Índice de Focalización de Hogares (IFH)

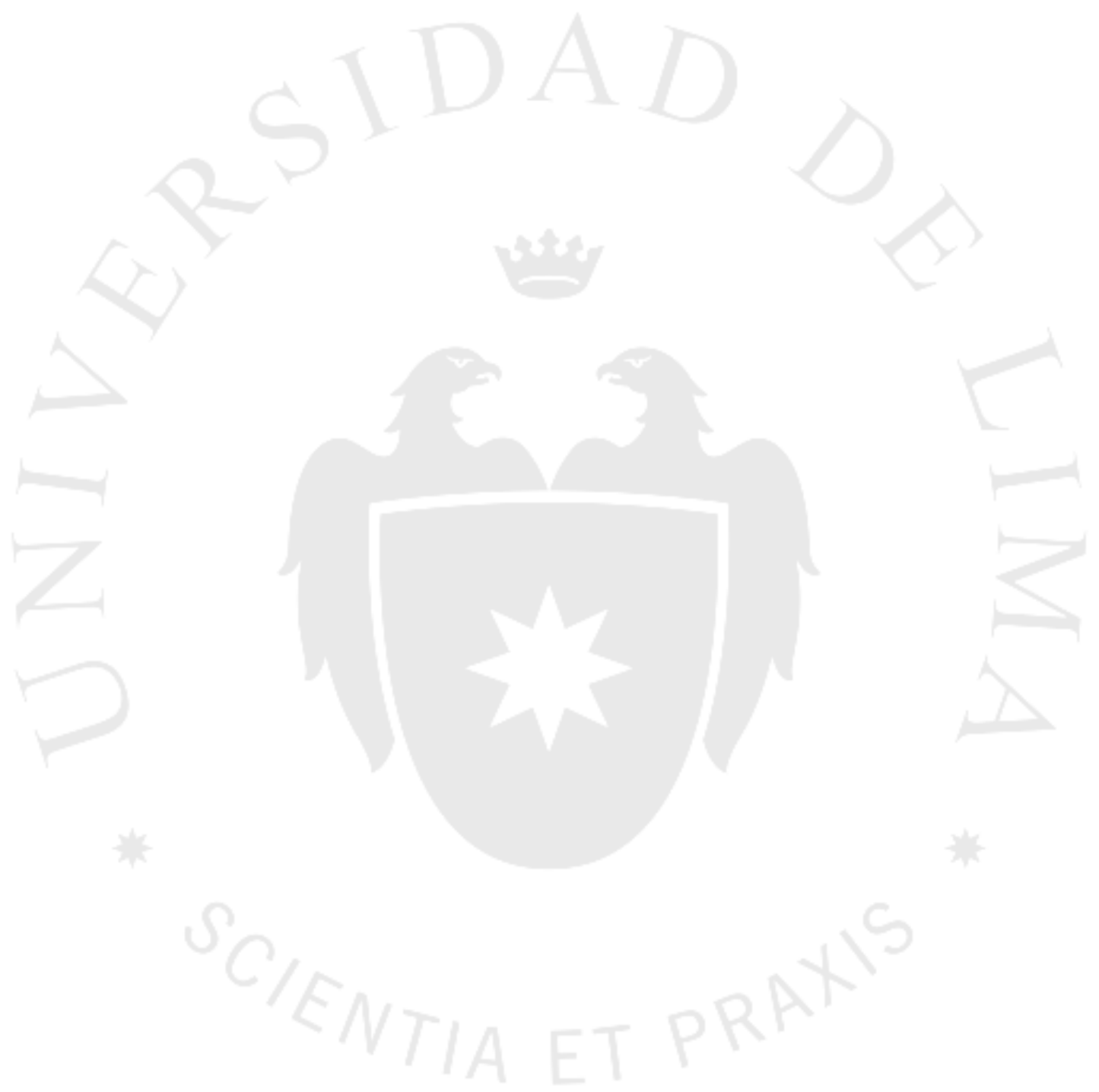




\section{INTRODUCCION}

La pobreza es un fenómeno presente en la sociedad que, a pesar de los diversos esfuerzos para combatirla, no se logra eliminarla por completo. Los Programas de Transferencia Condicionada (PTC) surgen como alternativa a los tradicionales programas sociales de corte paternalista y de alivio a la pobreza.

Dentro de ellos surge JUNTOS, cuyo objeto es buscar, bajo la concepción de la pobreza, entendida como la falta de oportunidades para el desarrollo, la mejora del capital humano y el fin de la pobreza intergeneracional. Sin embargo, el programa presenta algunas limitaciones de diseño por el lado de la selección de las familias, como también a nivel de la difusión de la información y de orientación a los participantes sobre el uso eficiente de las transferencias recibidas.

Los problemas enfrentados han sido principalmente las fuentes de información primaria, pues la información está incompleta, además que diversos indicadores se encuentran a nivel nacional mas no departamental, y para la totalidad del programa y no sectorial (educación, salud, etc.); y, poca disponibilidad de los beneficiarios de hablar sobre su situación bajo el programa.

El objeto principal de esta investigación es estudiar el cambio en los patrones de consumo de las familias beneficiarias del programa Juntos, en Huánuco, en el período 2007-2011, como resultado de las transferencias, y las consecuencias generadas en la población como producto de una inadecuada cobertura de hogares por parte del Programa. Se ha utilizado como hipótesis principal el que las transferencias monetarias realizadas, por el programa JUNTOS en el período 2007-2011, en Huánuco, afectan la economía regional, por la subcobertura del programa respecto de las familias beneficiarias y por los cambios en los patrones de consumo de éstas.

Para la contrastación de las hipótesis se utilizaron métodos cualitativos, como entrevistas a beneficiarios de las comunidades de Churubamba, Ambo y San Rafael y aledañas; y, métodos cuantitativos, como indicadores de subcobertura basados en la información presentada por la Encuesta Nacional de Hogares (ENAHO), de los años 2007 y 2011. 
Lo más resaltante de la investigación realizada es el efecto positivo inmediato que genera el programa en la población de Huánuco: aumenta y mejora el consumo destinado a los hijos de los hogares beneficiarios y ha creado, en algunos usuarios, una cultura de ahorro e inversión a largo plazo.

El primer capítulo presenta las concepciones de pobreza y la metodología de medición, así como su evolución de la pobreza en el Perú y Huánuco, en el periodo de estudio; para presentar los Programas de Transferencia Condicionada así como sus objetivos y alcances a nivel mundial. En el segundo capítulo se describe al programa JUNTOS, sus objetivos, diseño, condicionalidades, así como la identificación y selección de beneficiarios (determinar su elegibilidad) para lo que se describe el Sistema de Focalización de Hogares (SISFOH). Finalmente, en el tercer capítulo se presenta la contrastación de las hipótesis planteadas, así como los resultados a los que se concluye. 


\section{CAPÍTULO 1: \\ POBREZA Y PROGRAMAS DE TRANSFERENCIA CONDICIONADA}

En este primer capítulo, se presenta el marco teórico referente a la pobreza con el fin de mostrar su evolución y explicar la necesidad de emplear programas sociales orientados a combatirla y satisfacer las demandas sociales de la población.

Primero se realizará la definición de pobreza según las concepciones de diferentes autores e instituciones relacionados al estudio de este tema; se presentarán los conceptos operativos de pobreza: absoluta y relativa, así como también las dos concepciones de la misma: la pobreza objetiva y la pobreza subjetiva. Luego, se describirán las metodologías, más utilizadas para medir la pobreza, así como las ventajas y desventajas de su empleabilidad. Los métodos a describir son el de las Necesidades Básicas Insatisfechas (NBI) y la Línea de Pobreza (LP). Se esperaría que ambas metodologías, que parten de una percepción similar sobre la pobreza, llegaran a resultados similares; sin embargo, hay algunos elementos que pueden explicar las diferencias en sus resultados, según su aplicación: la primera se orienta más a la satisfacción de necesidades concretas de la población y la segunda se centra en los ingresos económicos (Programa de las Naciones Unidas para el Desarrollo [PNUD], 1990 p.111). Esta diferencia origina que según el método utilizado, finalmente, se pueda llegar a categorizar en diferente forma a una persona en un nivel de pobreza.

La segunda parte del capítulo se refiere a la evolución de la pobreza durante todo el periodo de análisis de la investigación: primero, a nivel nacional, para luego continuar con la región especificada: Huánuco. Para este fin, se utilizarán tanto los mapas de pobreza presentados por el Instituto Nacional de Estadística e Informática (INEI) que muestra el porcentaje de pobreza por cada región del país ayudando a la mejor focalización de las políticas sociales implementadas por el gobierno dado que permite conocer cuáles son los departamentos a los que necesariamente se deben dirigir los Programas Sociales. También, se presentará otros alcances y resultados respecto al avance que se ha logrado en la lucha contra la pobreza en el país y en las regiones ya mencionadas.

En la última parte del capítulo, se tratará el tema de los programas sociales que funcionan actualmente en el Perú, como los programas sectoriales referentes a la salud, 
nutrición y educación, así como los resultados que se han obtenido hasta la fecha, tanto a nivel nacional como regional. También, se tratan las diferentes experiencias de PTC en países como México, Brasil y Colombia, así como algunos de sus resultados.

\subsection{Marco Teórico}

Los Programas de Transferencia Condicionada (PTC) tienen un objetivo principal que es común a las distintas aplicaciones y ámbitos de trabajo en los países en los que se aplican: romper la pobreza y su transmisión de generación en generación. Para esto primero es esencial entender la concepción envuelta dentro del término pobreza. Es por esto que primero se presentan las distintas definiciones de este fenómeno, para luego aterrizar este concepto a la situación peruana y por último ampliar el tema respecto a los PTC

\subsubsection{Definiciones de Pobreza}

Uno de los objetivos fundamentales de la economía es la distribución de los recursos escasos de la mejor manera para satisfacer las ilimitadas necesidades de las personas. Es por ello, que desde el punto de vista de la pobreza monetaria como de la prestación por parte del Estado, de los servicios básicos como de los servicios fundamentales de la salud y la educación, la pobreza es un concepto económico, aunque también tiene implicancias interdisciplinarias que repercuten en las condiciones de vida de las personas que son objeto de dicho fenómeno.

Definir la pobreza de manera consensuada es una misión imposible, pues son muchos los investigadores e instituciones que estudian este tema y, que, de acuerdo con su experiencia y dentro del campo en el que trabajan, intentan definirla.

Amartya Sen (2000) concibe el desarrollo como "un proceso de expansión de las libertades fundamentales" (p.19), y no solamente como la consecuencia del crecimiento económico, el desarrollo tecnológico o la modernización de la sociedad. Si bien éstas pueden ser un medio para expandir las libertades de las personas, éstas dependen también de otros aspectos tal como la institucionalidad económica y social, y de los derechos políticos y humanos. 
Para Amartya Sen (2000), el desarrollo requiere:

La eliminación de las principales fuentes de privación de libertad: la pobreza y la tiranía, la escasez de oportunidades económicas y las privaciones sociales sistemáticas, el abandono en que pueden encontrarse los servicios públicos y la intolerancia o el exceso de intervención de los Estados represivos. (p. 19-20)

Se puede interpretar a partir de esa concepción que la pobreza representa un impedimento para la libertad de las personas evitando que puedan alcanzar su pleno desarrollo. En ese sentido, Sen (2000) tiene una concepción sobre la pobreza, entendida como:

La privación de capacidades básicas y no meramente como la falta de ingresos, que es el criterio habitual con el que se identifica la pobreza. La perspectiva de la pobreza basada en las capacidades no entraña el rechazo de la razonable idea de que la falta de renta puede ser una importante razón por la que una persona está privada de capacidades. (p. 114)

La falta de renta puede limitar a las personas en el desarrollo de sus capacidades, mas no es el único factor que permite la generación de dichas capacidades. Es por ello, que el eje central de la definición de la pobreza sigue siendo la privación para desarrollar al máximo las capacidades de todas las personas.

Por su parte, el PNUD (1990) presenta su concepción de la pobreza como la falta de satisfactores adecuados para un mínimo de necesidades que se consideran básicas y que para cubrirlas es necesario un esfuerzo productivo directo: alimentación, cumpliendo los requerimientos de nutrición y que no supone solamente satisfacer la necesidad de agua y alimentos sino también los medios y la energía para prepararlos y consumirlos; mantenimiento de la salud, entendida como el acceso a servicios de salud y a medicamentos y también a la adecuada higiene del hogar; vivienda, con espacios de acuerdo al tamaño de la familia, de materiales que aseguren su protección y que cuente con los servicios de saneamiento básicos como agua potable, desagüe, luz, etc.; educación básica, de acuerdo a la situación socio-cultural y sea facilitadora de trabajo productivo; disponibilidad y acceso a los servicios básicos de información, recreación y cultura; vestimenta y calzado de acuerdo al 
hábitat; transporte público; y, comunicaciones fundamentales. De lo anterior se puede interpretar que para esta institución, pobreza significa la existencia de necesidades básicas que no se encuentran satisfechas y que afectan la calidad de vida de las personas; esta concepción se encuentra estrechamente relacionada al método de las NBI para la medición de la pobreza que se describe más adelante. Se excluye de esta concepción otras necesidades consideradas por la psicología como básicas: afecto, realización personal, entre otras, pues su satisfacción no requiere de esfuerzos productivos directos. (p.19-20)

Francisco Verdera (2007) afirma que existen en la actualidad, y con un grado desigual de desarrollo, hasta cuatro enfoques principales sobre la pobreza (p. 22):

- Activos de los pobres, una variante de la teoría del capital humano, popularizada por Becker (1964) y que se ha extendido a la noción de capital social;

- Reconocimiento de derechos (o titularidades) y capacidades de Amartya Sen;

- Exclusión social, difundida por la OIT, que puede verse como la contraparte tanto del enfoque de activos (falta de activos) como el de derechos (falta de reconocimiento de derechos); y,

- Estructural, que considera la pobreza como derivada de la estructura social de la economía, y en el que se inscriben los estudios sobre el impacto del ajuste y las reformas liberales sobre la pobreza.

Por su parte, Rosa Flores (1995), en un documento presentado por el Fondo de Compensación y desarrollo Social (FONCODES) y por el INEI, define la pobreza como "la insatisfacción de un conjunto de necesidades consideradas esenciales por un grupo social especifico, y que reflejan el estilo de vida de esta sociedad".

Esta definición es similar a la presentada anteriormente por el PNUD, pero la diferencia se encuentra en que las necesidades que se consideran básicas son definidas por una sociedad en específico las que a la vez reflejan la forma de vivir que lleva este grupo social, además, no hace alusión a la necesidad de esfuerzos productivos como si lo menciona el PNUD. Aquí también se evidencia el carácter relativo de la pobreza, pues al referirse a un conjunto social en específico, puede ser que la percepción de pobreza de un país, región o área sea distinta a la de otros, incluso también en el tiempo, siendo que no es lo mismo, la 
pobreza que existe en el África Subsahariana y la de Estados Unidos, o la pobreza que existía en el siglo XVIII con la que existe actualmente.

Ahora, en un sentido operacional, en una publicación del INEI (s.f.) se define la pobreza como:

(...) una condición de privación para acceder a una canasta de bienes y servicios básicos con los cuales se pueda vivir adecuadamente en términos de los estándares prevalecientes de necesidades y satisfactores, determinados por una sociedad de acuerdo a su nivel de desarrollo. (párr. 4)

Es decir que en este sentido, no son las necesidades esenciales insatisfechas las que definen que una persona sea pobre o no, sino el hecho de estar privado del acceso a un conjunto de bienes y servicios básicos que no le permiten tener un adecuado nivel de vida o que carecen de los medios necesarios para su supervivencia. Otra vez identificamos en esta concepción el relativismo que presenta la pobreza, pues el nivel de vida adecuado está en términos de un estándar determinado por una sociedad, lo que puede variar ampliamente dependiendo del grupo social que se estudie.

En resumen, la pobreza es un fenómeno que se manifiesta a través de distintas situaciones como: subconsumo, al no acceder a la canasta mínima; desnutrición, pues no se consumen las calorías necesarias; condiciones de vivienda inadecuadas, bajo nivel educativo, desempleo, insuficientes o nulos ingresos y la inexistencia de oportunidades de crecimiento y desarrollo. Es un fenómeno interdisciplinario.

Hay dentro de la pobreza dos tipos de concepciones: la subjetiva y la objetiva. De acuerdo al PNUD (1990), se puede decir que:

La pobreza adquiere su valor relativo por cuanto ésta está en función de las condiciones sociales y económicas heterogéneas de cada contexto regional, nacional o local (...) Es la percepción que tiene el propio grupo sobre su condición de pobreza según sus patrones socioculturales. (p. 20) 
La perspectiva subjetiva define la pobreza como una sensación personal que depende de lo que considere y prefiera una persona como indispensable para vivir de manera adecuada. Bajo esta concepción, las definiciones de pobreza que pueden existir son infinitas pues dependen del juzgamiento que cada persona realice. Por ejemplo, algunos habitantes de una comunidad indígena de la selva peruana que realizan actividades agrícolas y de caza para su autoconsumo, pueden no considerarse pobres, debido principalmente a que no tienen conocimiento de lo que existe más allá de los límites de su comunidad y bajo su perspectiva tiene todo lo que le permite vivir apropiadamente, mientras que bajo las definiciones de pobreza serían considerados en la categoría de pobreza, sea por la insatisfacción de necesidades que se consideran esenciales o por la incapacidad de acceder a una canasta mínima de consumo. Sin embargo, un habitante de Estados Unidos que trabaja, vive en una casa alquilada, no posee auto propio y sus hijos acuden a una escuela pública puede de acuerdo a su concepción considerarse pobre, en tanto que de acuerdo a las definiciones de pobreza que se presentan no podría ser categorizada como pobre pues cubre las necesidades esenciales para vivir o porque puede acceder a la canasta básica de consumo que le permite vivir de manera adecuada.

El concepto objetivo de la pobreza depende de los criterios que cada investigador utiliza en la identificación de individuos pobres. El estándar utilizado para medir la pobreza es resultado de un grupo de procedimientos que determinan finalmente el umbral bajo el que se calificará a una persona como pobre o no pobre (INEI 2011 p. 5) Bajo esta concepción se puede identificar dos enfoques: la pobreza relativa y la absoluta.

El concepto de pobreza relativa utiliza un referente o estándar social, pues la pobreza está aquí definida no por el nivel absoluto de ingresos, riqueza o gasto que posea una persona, sino por el que tiene en relación a los otros miembros de su grupo social. Es decir que el concepto de pobreza puede variar entre sociedades, pues para un individuo de la India no ser pobre significaría tener los suficientes ingresos para su alimentación, salud y educación, sin la necesidad de tener mayores bienes materiales, para un habitante europeo, ser pobre significaría no tener un auto nuevo, una casa más grande o salir de viaje en las vacaciones, ello debido al distinto estándar que existe entre ambas sociedades.

En contraposición, en el segundo enfoque, que tiene carácter universal, el bienestar de cada persona está definido por su nivel total de gasto, en base a los estándares mínimos 
que fija la sociedad como adecuados para el nivel de desarrollo de la misma. Es así que se considera pobres a aquellos que no superan este umbral de consumo mínimo o que no pueden acceder a las condiciones establecidas como aceptables para desarrollarse dentro de su grupo social. En este enfoque, se puede hacer uso de la Línea de Pobreza para diferenciar a las poblaciones en situación de pobreza, pues ésta determina una canasta mínima de consumo, con la cual se puede categorizar a una persona como pobre o no pobre. A partir de esta metodología también se puede reconocer la pobreza extrema, cuyo estándar es mucho menor al definido por la LP.

La figura 1.1 puede servir de resumen sobre los enfoques de la pobreza y los métodos existentes para su medición, que se detallan más adelante.

Figura 1.1

Enfoques de pobreza, 2010

\section{Enfoques de la pobreza}

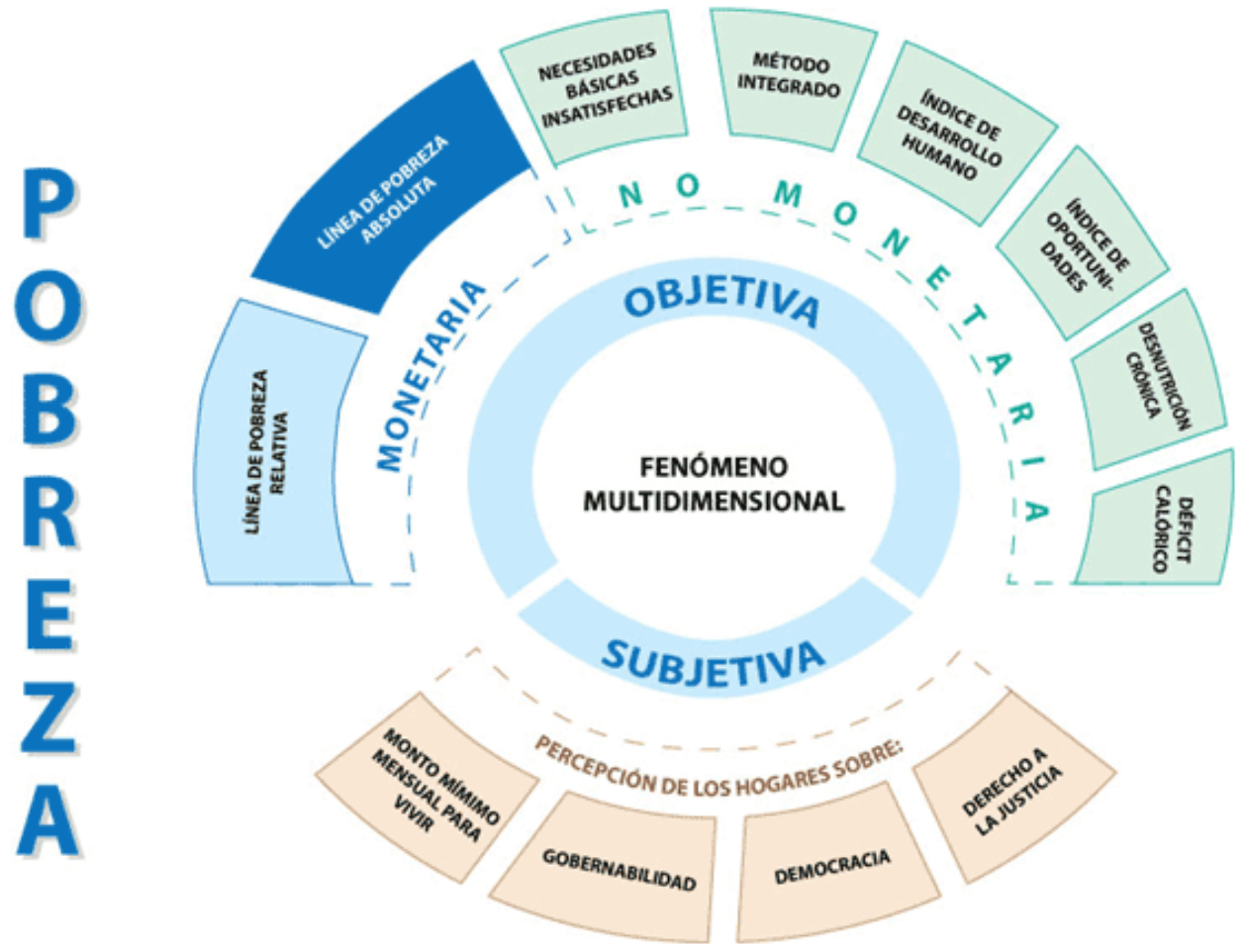

Fuente: INEI. Perú en cifras - Pobreza. Lima: INEI. Recuperado de: http://www.inei.gob.pe/perucifrasHTM/infsoc/pob03.gif 


\subsubsection{Metodologías de medición de la pobreza}

Para medir la pobreza, existen diversas metodologías que analizan los distintos aspectos de la misma. Los métodos más utilizados por las instituciones encargadas de la medición de este fenómeno para la focalización de la política social en el Perú son: el método indirecto o Línea de Pobreza (LP), para medir la pobreza monetaria, y el método de las Necesidades Básicas Insatisfechas (NBI), para la medición de la pobreza no monetaria.

\section{Línea de Pobreza (LP)}

De acuerdo al PNUD (1990), el primer método se basa en el nivel de gasto o ingreso que tienen los hogares, definiendo el costo de una canasta de bienes y servicios que sea suficiente para la satisfacción de las necesidades básicas, y a aquellas personas que no posean los ingresos para adquirirla se les considera en la categoría de pobres. (p. 21)

La Línea de Pobreza define una canasta básica de consumo de bienes y servicios representativa de la sociedad para la que se elabora. Ello permite identificar la Línea de Pobreza crítica, determinada por el costo total de la canasta, a valor de mercado y al menor costo, lo cual incluye el gasto que se realiza en alimentación, educación, vivienda, salud, vestimenta, entre otros. Se considera Línea de Pobreza Extrema cuando sólo se considera el gasto realizado en alimentos que cubran las necesidades calóricas mínimas. Para el Perú, la LP la elabora el INEI, y la composición que tienen ambas canastas está de acuerdo al área geográfica, considerando el consumo de dicha región (Flores 1995). Estas líneas de pobreza se comparan con el gasto real que efectúan los hogares y aquellas personas cuyo gasto no sea al menos igual que al determinado por dichas líneas, se les ubica en la categoría de pobres y pobres extremos, respectivamente.

\section{Según Jorge Reyes (1995)}

El método de LP consiste en calcular el ingreso necesario para cubrir el costo de una canasta básica de consumo, constituida por una canasta alimentaria y otra de bienes y servicios no alimentarios. La canasta alimentaria se define como aquella que reúne el conjunto de alimentos cuya composición cubre las necesidades nutricionales mínimas de la población, considerando los hábitos de consumo predominantes, la disponibilidad efectiva de los alimentos en el mercado, y los precios relativos de los mismos. (p. 96) 
Si bien la definición es en esencia la misma, este autor no define la LP en base al gasto de la canasta sino que utiliza el ingreso percibido por los hogares para contraponerlo al ingreso que se necesita para cubrir la canasta básica de consumo. Se puede observar también que la canasta de la Línea de Pobreza Extrema es la base para la construcción de la canasta de la Línea de Pobreza crítica, pues a la primera se le adiciona otros bienes y servicios no alimentarios como salud, vivienda, educación, etc. Aquí son los ingresos del hogar los que se comparan con la LP y aquellos que estén por debajo de esta línea se consideran pobres o pobres extremos de acuerdo a la que se esté utilizando.

Figura 1.2

Medición de la pobreza monetaria, 2011

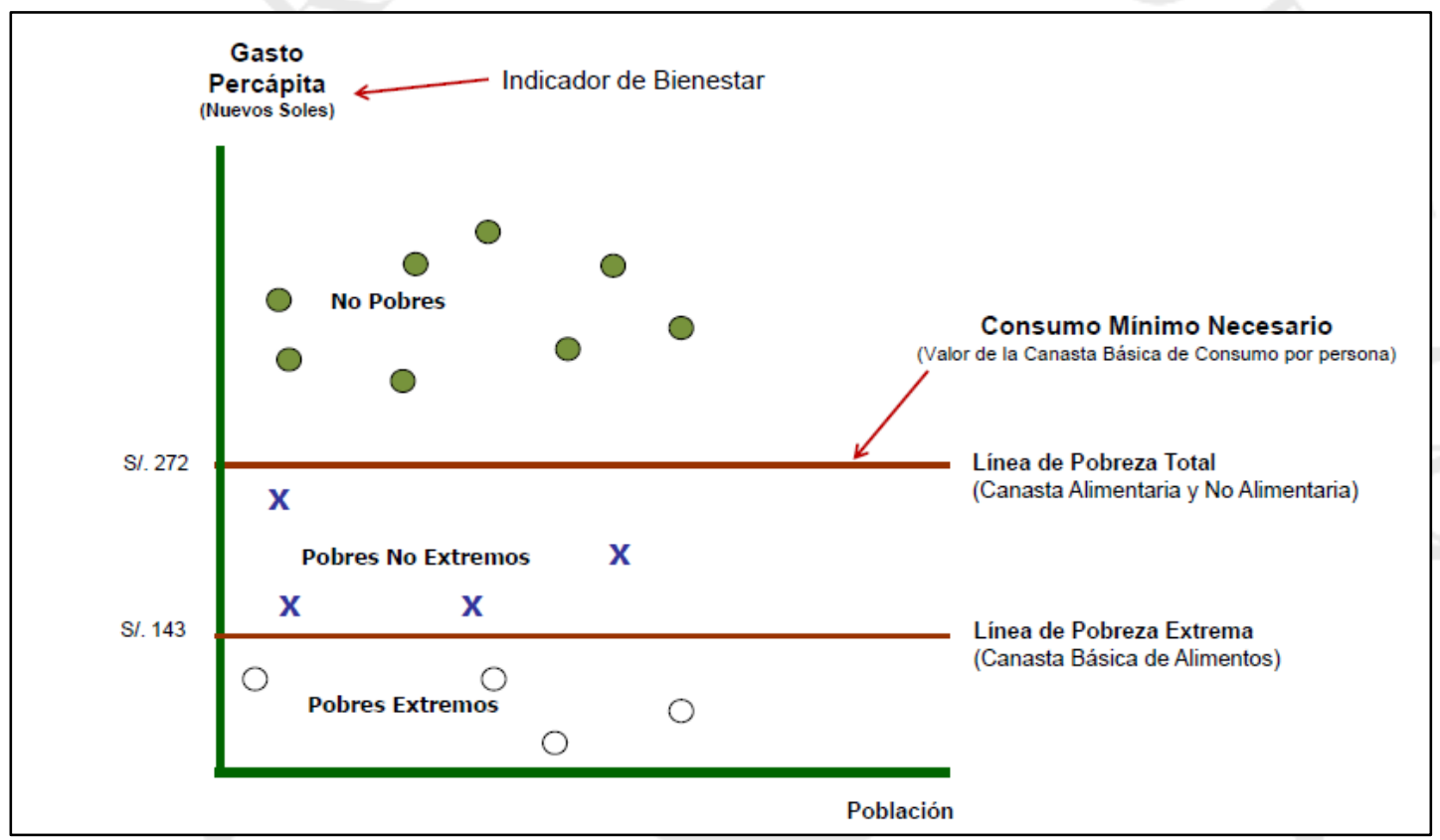

Fuente: INEI. "Evolución de la pobreza al 2011” pp. 2. Lima: INEI. Recuperado de: http://www.inei.gob.pe/documentosPublicos/Pobreza2010/Presentacion18 Mayo 2011.pdf

\section{Necesidades Básicas Insatisfechas (NBI)}

Este método especifica las necesidades consideradas básicas para vivir y "las normas de satisfacción mínima para cada una de ellas" (PNUD, 1990, p. 21). A aquellos que no logran alcanzar el valor mínimo determinado para estas necesidades se les considera en situación de pobreza. Además, en base a esta metodología, se han elaborado "mapas de pobreza" que jerarquizan las áreas geográficas en relación a los niveles de vida que presentan 
y, a la vez, presentan la incidencia de la pobreza y las características dentro de los grupos pobres. (PNUD, 1990, p. 21).

El último mapa de pobreza que se elaboro fue para el año 2010, lo que resulta bastante útil para realizar una observación comparativa de la evolución de la pobreza por departamentos. Así, por ejemplo, se puede observar que Huancavelica, que en el año 2005, era el único departamento con un $90 \%$ de incidencia de pobreza, para el 2010 , se redujo considerablemente esa cifra situándose en $60 \%$, es decir, que se redujo su nivel de pobreza en aproximadamente $30 \%$. Pero así también, se puede ver que otros departamentos como Apurímac, tenían en promedio el mismo porcentaje de incidencia de pobreza desde el 2001 hasta el 2010, es decir que en 10 años no han podido salir de ese nivel.

Este método es directo, según el cual, se deben satisfacer efectivamente las necesidades básicas por lo que resulta indispensable definir las necesidades esenciales de los hogares tanto en salubridad, educación, vivienda, empleo, servicios básicos, etc. En base a ello, se fija un nivel mínimo de satisfacción de estas necesidades que un hogar debe cumplir para no ser considerado pobre. Los estándares utilizados para medir la pobreza en base a las necesidades no satisfechas son: (Reyes, 1995, p. 96)

1. Viviendas inadecuadas por sus materiales

2. Hacinamiento crítico por habitación

3. Falta de servicios para la eliminación de excretas

4. Inasistencia a escuelas primarias de los menores

5. La capacidad económica del hogar, que relaciona el nivel educativo del jefe del hogar con la tasa de dependencia económica. 
Figura 1.3

Perú: Incidencia de la Pobreza Total según departamento, 2001, 2005 y 2010 (en porcentaje)

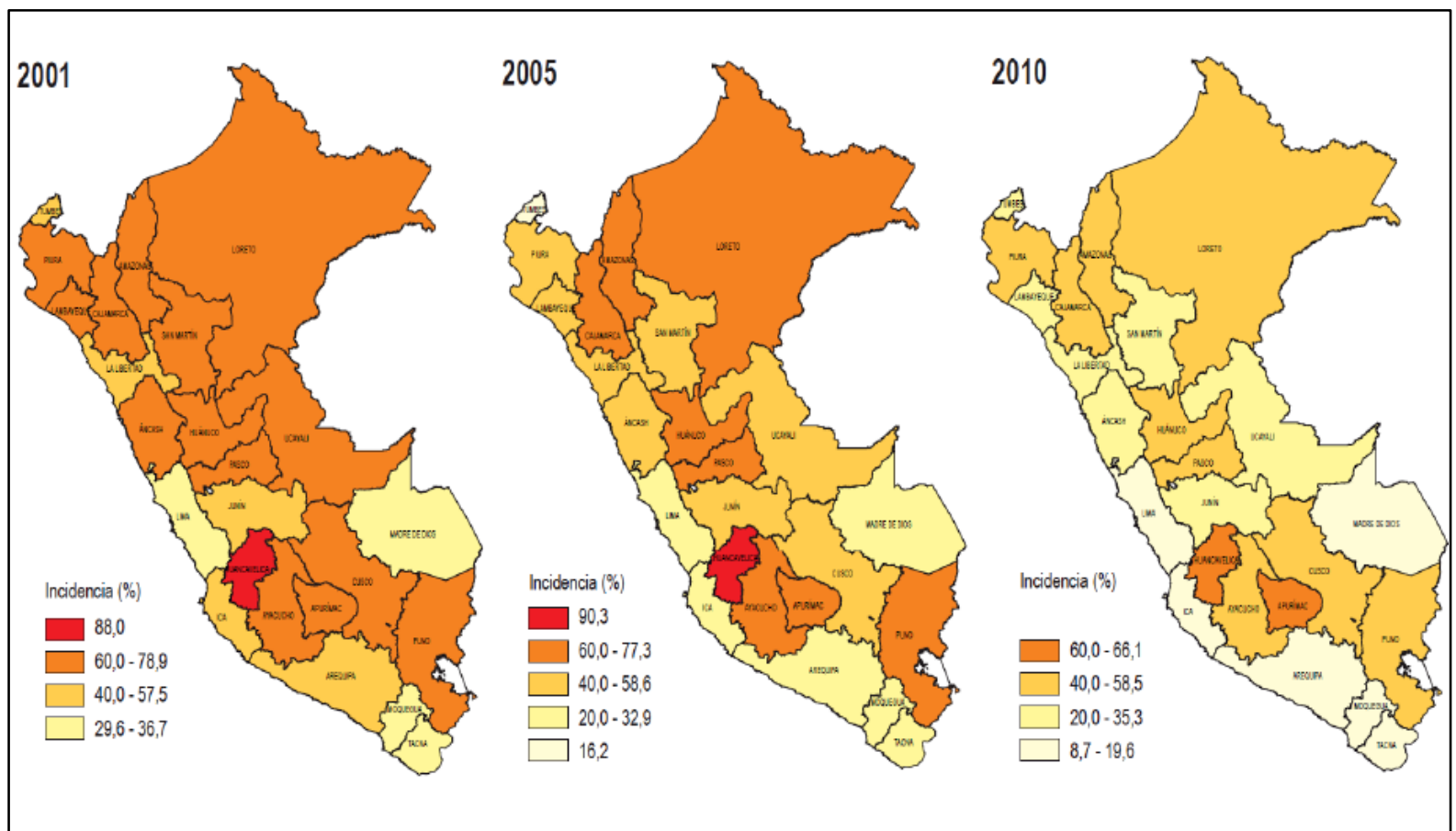

Fuente: INEI - Encuesta Nacional de Hogares 2001, 2005 y 2010 en INEI. "Evolución de la Pobreza en el Perú al 2010". Lima: INEI. http://www.inei.gob.pe/documentosPublicos/Pobreza2010/Presentacion18 Mayo 2011.pdf

La ventaja que presenta esta metodología es que permite tanto identificar como cuantificar a la población que se encuentra en situación de pobreza, incluso en zonas no tan grandes.

Si bien inicialmente se utilizó el método de las NBI en sustitución de la LP debido a la ausencia de información, especialmente en áreas geográficas más pequeñas y lejanas, finalmente se constató, tanto teórica como empíricamente, que ambos métodos no son sustitutos sino que, por el contrario, se complementan el uno con el otro.

Boltvinik (1990) presenta una importante comparación entre ambos métodos y sus implicancias en el tipo de políticas que adopta el Estado para combatir la pobreza: 
(...) en términos de sus implicaciones de política, las mediciones de LP definen poblaciones-objetivo con ingresos insuficientes y que, por tanto, requieren atenderse a través de políticas salariales, de empleo y de generación de ingresos. En cambio, las poblaciones-objetivo identificadas por el método de NBI requieren créditos para vivienda, servicios de agua y de eliminación de excretas, educación y otras políticas similares. Mientras el primer enfoque lleva a la definición de lo que suele llamarse políticas económicas, el segundo lleva a la definición de políticas sociales. (p.43)

Tal como se mencionó en el párrafo anterior, un método no reemplaza al otro, sino que, por el contrario, se complementan entre sí. Lo mencionado por Boltvinik lo demuestra, pues mientras que la LP le sirve al Estado como una medida base para la formulación de políticas económicas que tengan impacto en el salario y el empleo de las personas económicamente activas del hogar, el método de NBI lleva al Estado a definir acciones en favor del desarrollo social de los hogares en situación de pobreza, traducidas en la política social que debe dirigir las instituciones encargadas.

Para el caso peruano, la institución encargada de medir la pobreza es el INEI, y lo hace bajo el enfoque absoluto a través de la Línea de Pobreza. A partir del año 2007, se introdujeron cambios en la metodología utilizada, en aspectos tales como la composición de la canasta básica de alimentos, los hábitos de consumo, los requerimientos calóricos, la tabla de conversión de alimentos y la muestra de la población de referencia para los hábitos de consumo. (INEI, 2012, p. 3). Estos cambios en la metodología de medición fueron duramente criticados porque se decía que escondían las verdaderas cifras de la pobreza y que, por el contrario, lo que se presentaba era un resultado manipulado para favorecer al gobierno imperante en ese periodo.

Ahora que se presentaron algunas definiciones de pobreza y su medición, es necesario analizar la pobreza dentro del Perú y específicamente, en la región en la que se enfoca el presente trabajo: Huánuco. 


\subsection{Evolución de la pobreza en el Perú y la región de Huánuco}

En el Perú, la institución encargada de la medición de la pobreza es el Instituto Nacional de Estadística e Informática (INEI) y lo hace a través del enfoque absoluto dentro de la concepción objetiva de la pobreza. En marzo de 2012, el INEI presentó la actualización de la metodología de medición que utilizan (INEI, 2012, p.5). La razón de esta actualización es que los indicadores de pobreza que se han presentado hasta el año 2010, se han basado en la Encuesta Nacional de Hogares de 1997, año en el cual se definió la línea de pobreza base, que se mantuvo constante; pero, en la última década, la sociedad y la economía del país han sufrido importantes cambios y se puede encontrar información actualizada que se puede incorporar para medir la pobreza.

El INEI (2013) clasifica los cambios más significativos, por sus implicancias en la medición de la pobreza monetaria en cinco aspectos:

1. Cambios en la estructura de la población urbano/rural

Los indicadores que se presentaban en años anteriores tenían como base la estructura de población urbano/rural resultante del Censo de Población y Vivienda de 1993, en la que se observaba que la relación entre población urbana y rural era de aproximadamente el doble. Pero hacia los últimos años, con los grandes cambios económicos, esta estructura se modificó, representando ahora $72 \%$ y $28 \%$ respectivamente, y con estos nuevos resultados se hicieron nuevas proyecciones poblacionales hasta el 2015. (p. 6)

2. Cambios en los patrones de consumo

Se observa también que la Canasta Básica de alimentos contenía productos que o no eran consumidos por la población o estaban ausentes en la Canasta Básica. Tomando la información contenida en la Encuesta Nacional de Hogares del 2010, se han identificado nuevos patrones de consumo de alimentos, considerando aquellos con relativa homogeneidad y contribución, tanto en la frecuencia como en el gasto que realizan los hogares en éstos. (p. 6) 
3. Cambios en los requerimientos calóricos

El requerimiento calórico se basaba en las normas internacionales de 1985 que proponía la Organización Mundial de la Salud (OMS), la FAO y las Naciones Unidas, mientras que ahora se basan en los informes de estas instituciones para el periodo 2001-2004. Además se consideraron aspectos que caracterizan a un poblador peruano como la adaptación a los requerimientos calóricos a la esta población. (p. 7)

4. Cambios en la estimación del gasto en los hogares

Los cambios en este aspecto se realizaron respecto a los métodos de imputación sobre los elementos para los que no existen valores monetarios y respecto a los componentes del gasto, excluyendo los gastos de capital como los destinados a mejorar la vivienda, pero se incorpora el valor de uso de bienes durables dado que satisfacen una necesidad. (p.8)

5. Nueva población de referencia

Como la población de referencia se calculó en base al año 1997, en la actualidad y debido a los cambios que se suscitaron en la última década, la población de referencia se amplió y contenía hogares que no estaban ahora debajo o cercanos a la línea de pobreza. Una vez realizados los cambios por el INEI mejorando la medición para obtener resultados más precisos, se recalculó su evolución desde el año 2007. (p.8)

\subsubsection{Pobreza en el Perú}

La LP se construye a partir de la Canasta Básica de Alimentos y se le adiciona la Canasta Básica de bienes y servicios que es el componente no alimentario; el valor monetario de este componente se hace indexando sus precios al Índice de Precios al Consumidor (IPC) que calcula mensualmente el INEI. 
Tabla 1.1

Perú: Línea de Pobreza Extrema - Canasta Básica de Alimentos per cápita mensual, según niveles geográficos, 2007-2011

(nuevos soles corrientes)

\begin{tabular}{|c|c|c|c|c|c|c|}
\hline \multirow{2}{*}{ Ámbitos geográficos } & \multirow{2}{*}{2007} & \multirow{2}{*}{2008} & \multirow{2}{*}{2009} & \multirow{2}{*}{2010} & \multirow{2}{*}{2011} & \multirow{2}{*}{$\begin{array}{c}\begin{array}{c}\text { Variación } \\
\text { Porcentua }\end{array} \\
2011 / 2010\end{array}$} \\
\hline & & & & & & \\
\hline Nacional & 113 & 128 & 131 & 134 & 143 & 6.4 \\
\hline Urbana & 119 & 135 & 138 & 142 & 151 & 6.2 \\
\hline Rural & 95 & 109 & 112 & 114 & 121 & 6.7 \\
\hline \multicolumn{7}{|l|}{ Ámbito geográfico } \\
\hline Lima Metropolitana & 139 & 156 & 160 & 165 & 173 & 4.6 \\
\hline Resto urbano & 105 & 119 & 122 & 125 & 135 & 7.8 \\
\hline Rural & 95 & 109 & 112 & 114 & 121 & 6.7 \\
\hline \multicolumn{7}{|l|}{ Dominios } \\
\hline Costa urbana & 107 & 122 & 123 & 128 & 138 & 7.5 \\
\hline Costa rural & 96 & 110 & 111 & 110 & 120 & 8.5 \\
\hline Sierra urbana & 98 & 114 & 117 & 120 & 127 & 6.4 \\
\hline Sierra rural & 95 & 109 & 114 & 115 & 121 & 6.1 \\
\hline Selva urbana & 115 & 125 & 128 & 129 & 144 & 11.6 \\
\hline Selva rural & 94 & 109 & 109 & 113 & 121 & 7.7 \\
\hline Lima Metropolitana & 139 & 156 & 160 & 165 & 173 & 4.6 \\
\hline
\end{tabular}

Fuente: INEI - Encuesta Nacional de Hogares (ENAHO): 2007-2011 en INEI. "Informe Técnico. Evolución de la Pobreza 2007-2011". Lima: INEI. Recuperado de:

http://www.inei.gob.pe/DocumentosPublicos/Pobreza InformeTecnico.pdf

La tabla 1.1 muestra la evolución de la Línea de Pobreza Extrema desde el 2007 hacia el 2011, a través de la Canasta Básica de Alimentos (CBA) en términos per cápita. Se puede apreciar que tanto a nivel nacional como en las zonas urbanas y rurales, el valor monetario de la CBA aumento en promedio S/. 26 siendo la parte urbana la que experimento un mayor aumento y, en especial, en la canasta de alimentos de Lima Metropolitana. 
Tabla 1.2

Perú: Línea de Pobreza - Canasta Básica per cápita mensual por años de encuesta según ámbitos geográficos, 2007-2011

(nuevos soles corrientes)

\begin{tabular}{|c|c|c|c|c|c|c|}
\hline \multirow[t]{2}{*}{ Ámbitos geográficos } & \multirow[t]{2}{*}{2007} & \multirow[t]{2}{*}{2008} & \multirow[t]{2}{*}{2009} & \multirow[t]{2}{*}{2010} & \multirow[t]{2}{*}{2011} & $\begin{array}{l}\text { Variación } \\
\text { Porcentual }\end{array}$ \\
\hline & & & & & & $2011 / 2010$ \\
\hline Nacional & 238 & 250 & 252 & 260 & 272 & 4.7 \\
\hline Urbana & 263 & 274 & 274 & 284 & 296 & 4.5 \\
\hline Rural & 176 & 187 & 189 & 193 & 203 & 5.1 \\
\hline \multicolumn{7}{|l|}{ Ámbito geográfico } \\
\hline Lima Metropolitana & 309 & 322 & 324 & 335 & 348 & 3.6 \\
\hline Resto urbano & 229 & 239 & 239 & 246 & 260 & 5.4 \\
\hline Rural & 175 & 187 & 189 & 193 & 203 & 5.1 \\
\hline \multicolumn{7}{|l|}{ Dominios } \\
\hline Costa urbana & 244 & 255 & 253 & 263 & 277 & 5.4 \\
\hline Costa rural & 195 & 206 & 205 & 207 & 220 & 6.2 \\
\hline Sierra urbana & 208 & 220 & 221 & 227 & 238 & 4.8 \\
\hline Sierra rural & 172 & 184 & 188 & 191 & 200 & 4.8 \\
\hline Selva urbana & 229 & 236 & 237 & 242 & 259 & 7.0 \\
\hline Selva rural & 174 & 187 & 186 & 192 & 202 & 5.3 \\
\hline Lima Metropolitana & 309 & 322 & 324 & 335 & 348 & 3.6 \\
\hline
\end{tabular}

Fuente: INEI - Encuesta Nacional de Hogares (ENAHO): 2007-2011 en INEI. “Informe Técnico. Evolución de la Pobreza 2007-2011". Lima: INEI. Recuperado de:

http://www.inei.gob.pe/DocumentosPublicos/Pobreza InformeTecnico.pdf

Este aumento gradual va acorde a la evolución de la inflación, que durante el periodo de estudio mostró un comportamiento estable y sin afectar de manera negativa y significativa los precios de los alimentos básicos.

Su evolución a nivel nacional fue positiva y aumentó en promedio S/. 32, monto mayor que la evolución de la LP Extrema. Al igual que ésta, la LP creció más en el área urbana para todo el periodo, mientras que la variación del 2010 al 2011 tuvo su mayor incremento en el área rural (5.1\%). 
En la figura 1.4, se puede apreciar cómo ha sido la evolución de ambas Líneas de Pobreza, en el periodo 2007 a 2011.

Figura 1.4

Perú: Evolución de las Líneas de Pobreza Total y Pobreza Extrema, 2007-2011 (nuevos soles por persona mensual)

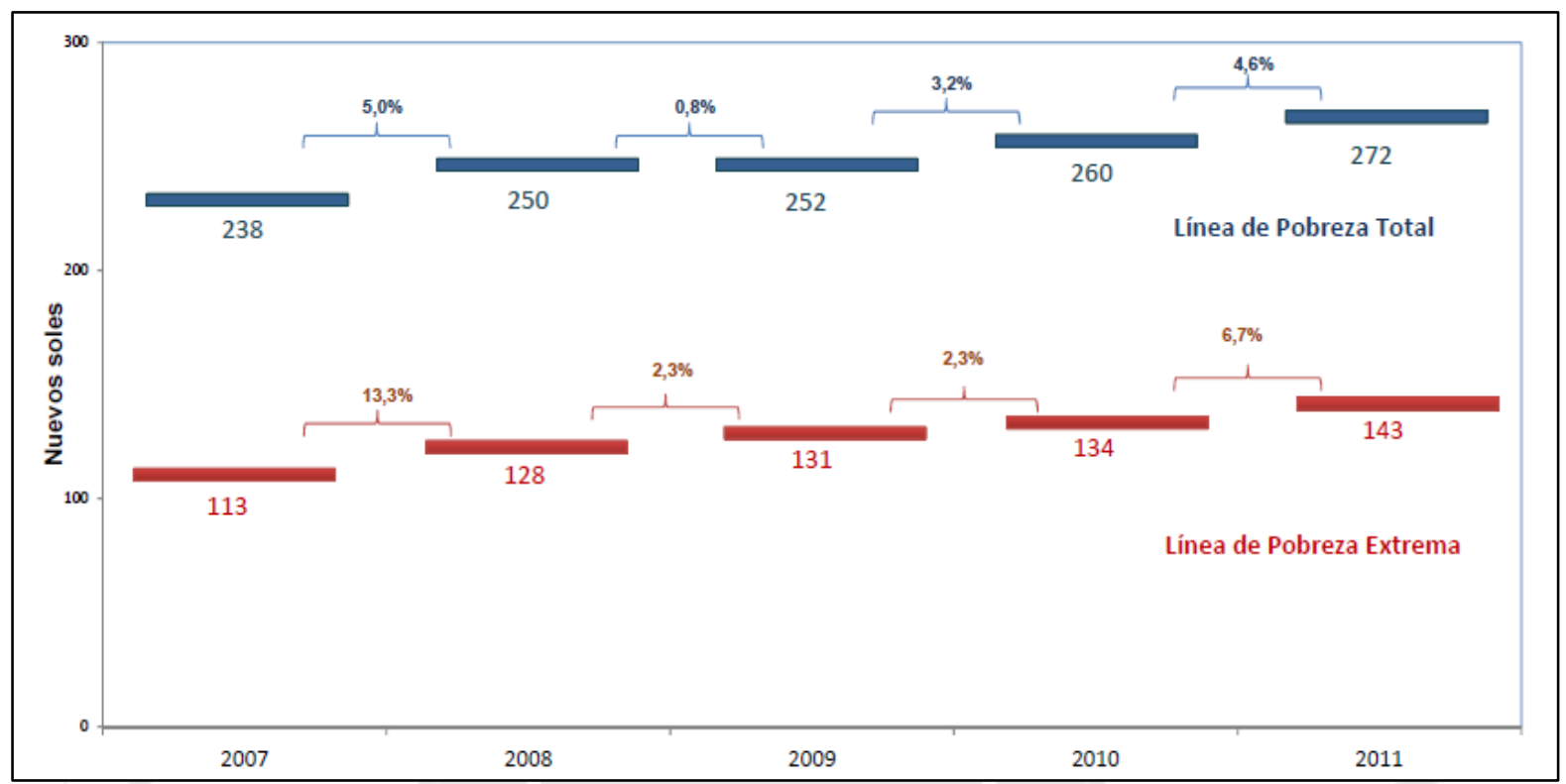

Fuente: INEI. “Evolución de la Pobreza al 2011" Lima: INEI. Recuperado de: http://www.inei.gob.pe/DocumentosPublicos/Pobreza_ExposicionJefe.pdf pp. 8

La LP Extrema, para el 2011, estaba en S/. 143, es decir, que para que una persona sea considerada como extremadamente pobre debería tener un gasto sólo por componentes alimentarios menor a S/.143 mensuales; mientras que la LP Total tiene un valor de S/. 272, con lo que aquellas personas cuyo gasto en la canasta básica tanto de alimentos como de otros bienes y servicios para satisfacer sus necesidades mínimas era menor que el monto antes mencionado, son consideradas como pobres no extremos.

Por la incidencia de la pobreza, se puede ver que aproximadamente el $28 \%$ de la población nacional era pobre, es decir, que de cada 100 personas, existían 28 personas cuyo gasto no alcanzaba a cubrir el costo de la canasta básica de consumo. 
En la figura 1.5, se puede observar que, del año 2010 al 2011, la variación de esta incidencia fue de 3\% mientras que, desde el año 2007 al 2011, disminuyó en 14.6\%, lo que representa una reducción anual de aproximadamente $3 \%$.

\section{Figura 1.5}

Perú: Evolución de la Incidencia de la Pobreza Total, 2007-2011

(porcentaje respecto del total de población)

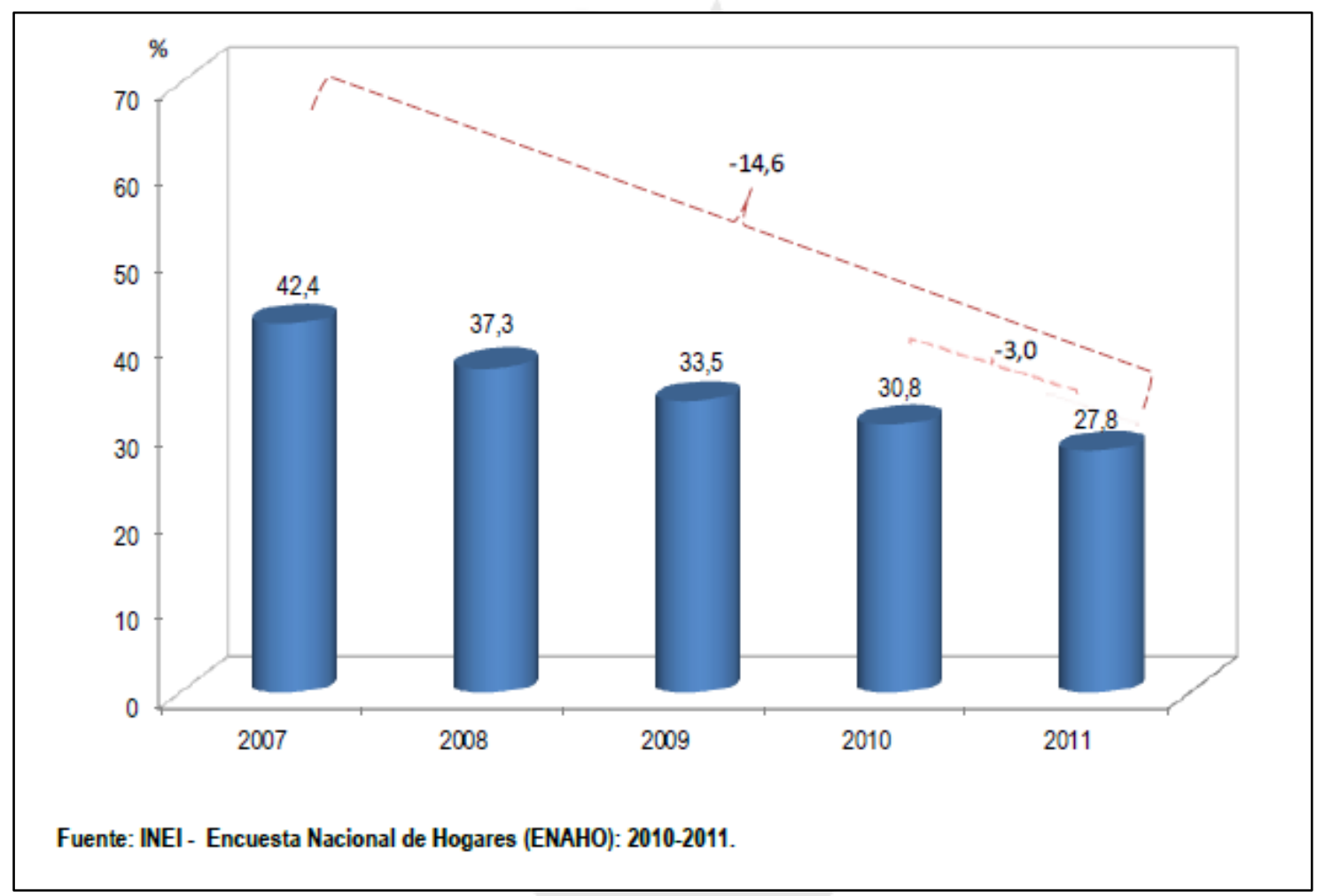

Fuente: INEI - Encuesta Nacional de Hogares (ENAHO): 2007-2011 en INEI. "Informe Técnico. Evolución de la Pobreza 2007-2011”. Lima: INEI. Recuperado de:

http://www.inei.gob.pe/DocumentosPublicos/Pobreza InformeTecnico.pdf

Pero esta incidencia ha sido heterogénea, pues afectó a menos personas en el área urbana que en el área rural, siendo la relación entre ambas de aproximadamente 3 a 1 respectivamente. Por tanto, en los dos últimos años como a lo largo del periodo, la pobreza se redujo más en las zonas rurales que en las zonas urbanas del país. Sin embargo, tuvo un efecto mayor en el área rural. La pobreza incidió mucho más en la Sierra que en las otras 2 regiones, afectando más a la población de la Sierra rural. 
Figura 1.6

Perú: Variación de la Pobreza Total, según ámbitos geográficos, 2010-2011 (puntos porcentuales)

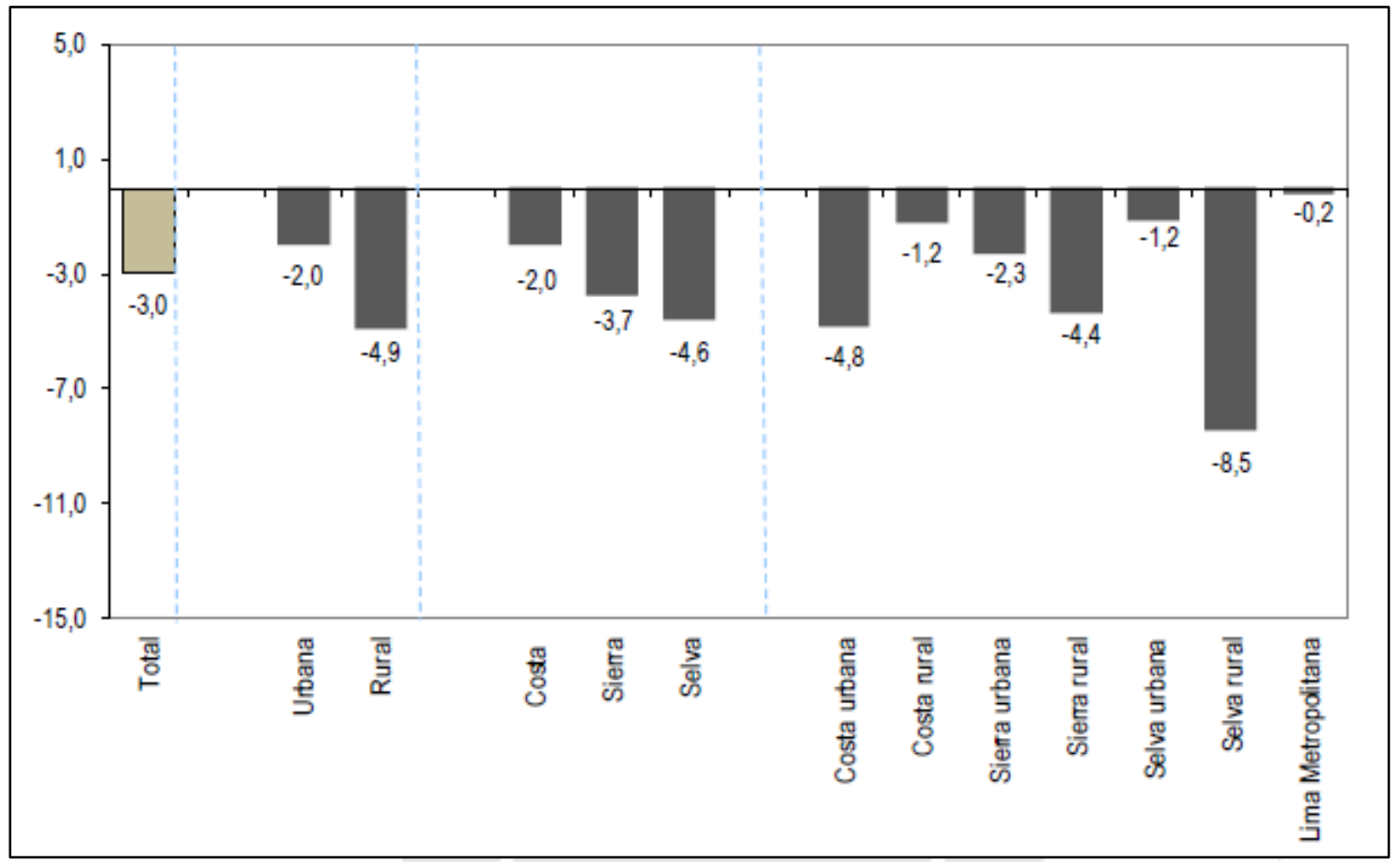

Fuente: INEI - Encuesta Nacional de Hogares (ENAHO): 2007-2011 en INEI. “Informe Técnico. Evolución de la Pobreza 2007-2011". Lima: INEI. Recuperado de: http://www.inei.gob.pe/DocumentosPublicos/Pobreza InformeTecnico.pdf 
Tabla 1.3

Perú: Evolución de la Incidencia de la Pobreza Total, según ámbitos geográficos, 2007-2011 (En nuevos soles corrientes)

\begin{tabular}{|c|c|c|c|c|c|c|c|}
\hline \multirow{2}{*}{ Ámbitos geográficos } & \multicolumn{5}{|c|}{ Años } & \multicolumn{2}{|c|}{$\begin{array}{c}\text { Variación } \\
\text { (en puntos porcentuales) }\end{array}$} \\
\hline & 2007 & 2008 & 2009 & 2010 & 2011 & 2011-2010 & 2011-2007 \\
\hline Total & 42,4 & 37,3 & 33,5 & 30,8 & 27,8 & $-3,0$ & $-14,6$ \\
\hline \multicolumn{8}{|l|}{ Área de residencia } \\
\hline Urbana & 30,1 & 25,4 & 21,3 & 20,0 & 18,0 & $-2,0$ & $-12,1$ \\
\hline Rural & 74,0 & 68,8 & 66,7 & 61,0 & 56,1 & $-4,9$ & $-17,9$ \\
\hline \multicolumn{8}{|l|}{ Región natural } \\
\hline Costa & 29,3 & 25,3 & 20,7 & 19,8 & 17,8 & $-2,0$ & $-11,5$ \\
\hline Sierra & 58,1 & 53,0 & 48,9 & 45,2 & 41,5 & $-3,7$ & $-16,6$ \\
\hline Selva & 55,8 & 46,4 & 47,1 & 39,8 & 35,2 & $-4,6$ & $-20,6$ \\
\hline \multicolumn{8}{|l|}{ Dominios geográficos } \\
\hline Costa urbana & 31,7 & 27,4 & 23,7 & 23,0 & 18,2 & $-4,8$ & $-13,5$ \\
\hline Costa rural & 53,8 & 46,6 & 46,5 & 38,3 & 37,1 & $-1,2$ & $-16,7$ \\
\hline Sierra urbana & 31,8 & 26,7 & 23,2 & 21,0 & 18,7 & $-2,3$ & $-13,1$ \\
\hline Sierra rural & 79,2 & 74,9 & 71,0 & 66,7 & 62,3 & $-4,4$ & $-16,9$ \\
\hline Selva urbana & 44,0 & 32,7 & 32,7 & 27,2 & 26,0 & $-1,2$ & $-18,0$ \\
\hline Selva rural & 69,2 & 62,5 & 64,4 & 55,5 & 47,0 & $-8,5$ & $-22,2$ \\
\hline Lima Metropolitana & 25,1 & 21,7 & 16,1 & 15,8 & 15,6 & $-0,2$ & $-9,5$ \\
\hline
\end{tabular}

Fuente: INEI - Encuesta Nacional de Hogares (ENAHO): 2007-2011 en INEI. “Informe Técnico. Evolución de la Pobreza 2007-2011". Lima: INEI. Recuperado de:

http://www.inei.gob.pe/DocumentosPublicos/Pobreza_InformeTecnico.pdf

Al comparar la reducción de los niveles de pobreza, se puede ver que la Sierra rural está en el tercer lugar con mayor reducción de pobreza, con un 4.4\%, comparado a los demás zonas geográficos, lo que es consistente con lo anteriormente mencionado.

\section{Evolución de la pobreza extrema}

Para el 2011, las personas que pertenecían a la categoría de pobres extremos era de $6.3 \%$, una cifra que experimentó una reducción de casi 5\% en comparación con el 2007, es decir que, en promedio, ha venido disminuyendo $1 \%$ por año, porcentaje menor a la reducción anual aproximada de la pobreza total. Sólo en el último año, la variación de la pobreza extrema fue de $1.3 \%$, pero el año en el que se observa una mayor disminución es en el 2010, pues la incidencia de la pobreza extrema disminuyo en casi $2 \%$ respecto al año anterior. 
Figura 1.7

Perú: Evolución de la Incidencia de la Pobreza Extrema, 2010-2011

(porcentaje respecto del total de población)

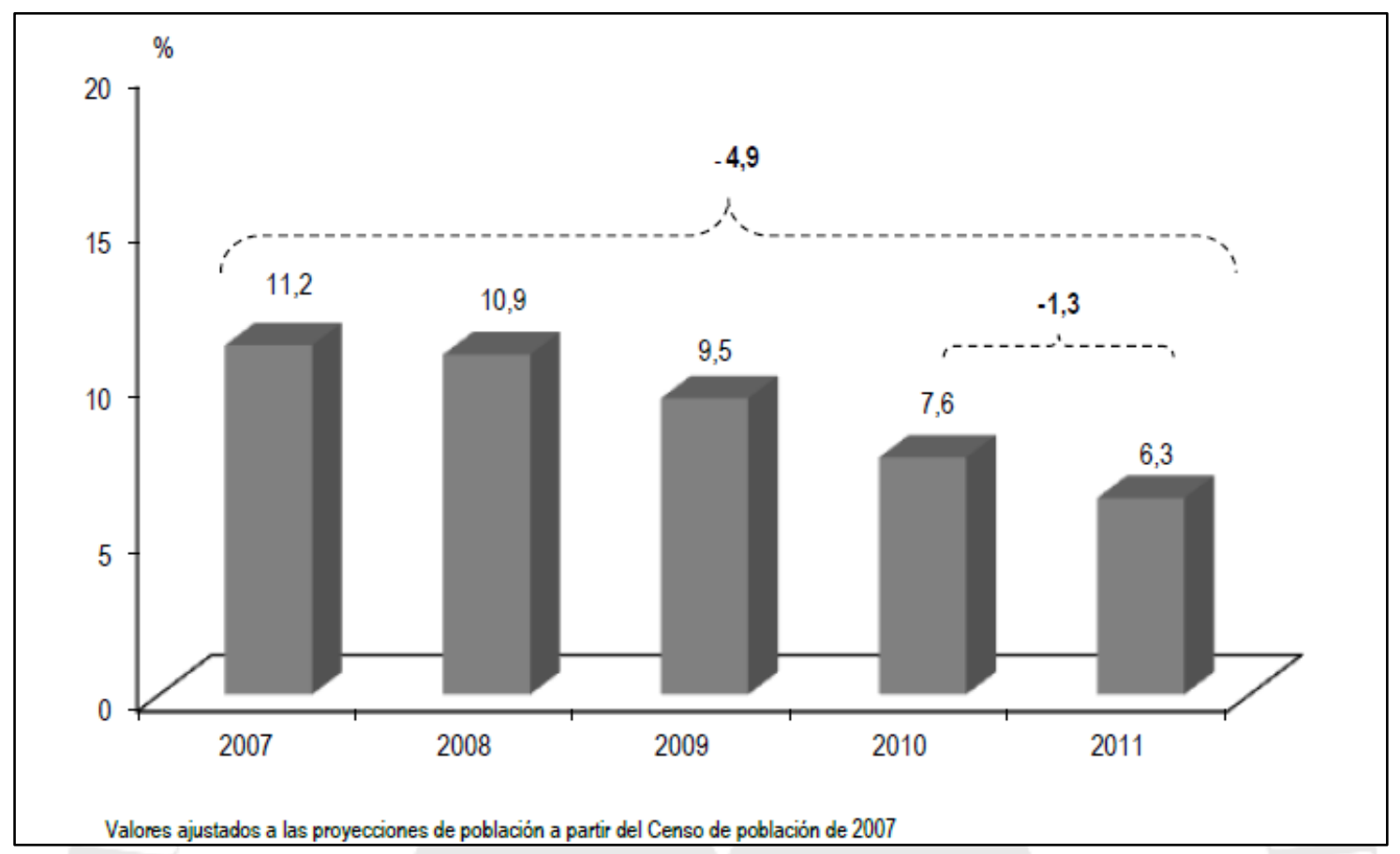

Fuente: INEI - Encuesta Nacional de Hogares (ENAHO): 2007-2011 en INEI. “Informe Técnico. Evolución de la Pobreza 2007-2011". Lima: INEI. Recuperado de:

http://www.inei.gob.pe/DocumentosPublicos/Pobreza InformeTecnico.pdf

La incidencia de la pobreza extrema, según el área de residencia de las personas, presenta resultados dispersos. Es así que, en tanto en el área rural, el 20.5\% de la población es pobre extrema, en la zona urbana, sólo el 1.4\% se encuentra en situación de extrema pobreza. Sin embargo, son las zonas rurales las que mayor reducción han tenido respecto al 2010: un $3.3 \%$. Se puede también observar que las regiones que mayor índice de pobreza extrema tienen son la Sierra y la Selva, con $13.8 \%$ y $9 \%$ respectivamente, siendo mayor esta incidencia en las zonas rurales de dichas regiones. 
Tabla 1.4

Perú: Evolución de la Pobreza Extrema, según ámbitos geográficos, 2007-2011 (porcentaje respecto del total de población)

\begin{tabular}{|c|c|c|c|c|c|c|c|}
\hline \multirow[t]{2}{*}{ Ámbitos geográficos } & \multicolumn{5}{|c|}{ Anual } & \multicolumn{2}{|c|}{$\begin{array}{c}\text { Variación } \\
\text { (en puntos porcentuales) }\end{array}$} \\
\hline & 2007 & 2008 & 2009 & 2010 & 2011 & 2011-2010 & 2011-2007 \\
\hline Total & 11,2 & 10,9 & 9,5 & 7,6 & 6,3 & $-1,3$ & $-4,9$ \\
\hline \multicolumn{8}{|l|}{ Área de residencia } \\
\hline Urbana & 2,9 & 2,7 & 2,0 & 1,9 & 1,4 & $-0,5$ & $-1,5$ \\
\hline Rural & 32,7 & 32,4 & 29,8 & 23,8 & 20,5 & $-3,3$ & $-12,2$ \\
\hline \multicolumn{8}{|l|}{ Región natural } \\
\hline Costa & 1,9 & 1,9 & 1,5 & 1,5 & 1,2 & $-0,3$ & $-0,7$ \\
\hline Sierra & 24,8 & 23,4 & 20,1 & 15,8 & 13,8 & $-2,0$ & $-11,0$ \\
\hline Selva & 14,6 & 15,5 & 15,8 & 12,5 & 9,0 & $-3,5$ & $-5,6$ \\
\hline \multicolumn{8}{|l|}{ Dominios geográficos } \\
\hline Costa urbana & 2,0 & 2,3 & 1,6 & 1,7 & 1,2 & $-0,5$ & $-0,8$ \\
\hline Costa rural & 11,0 & 8,1 & 7,8 & 6,7 & 8,3 & 1,6 & $-2,7$ \\
\hline Sierra urbana & 5,8 & 5,6 & 3,8 & 2,5 & 2,0 & $-0,5$ & $-3,8$ \\
\hline Sierra rural & 40,2 & 38,2 & 34,0 & 27,6 & 24,6 & $-3,0$ & $-15,6$ \\
\hline Selva urbana & 8,2 & 5,2 & 5,2 & 5,3 & 4,5 & $-0,8$ & $-3,7$ \\
\hline Selva rural & 21,9 & 27,6 & 28,6 & 21,4 & 14,7 & $-6,7$ & $-7,2$ \\
\hline Lima Metropolitana & 0,9 & 1,0 & 0,7 & 0,8 & 0,5 & $-0,3$ & $-0,4$ \\
\hline
\end{tabular}

Fuente: INEI - Encuesta Nacional de Hogares (ENAHO): 2007-2011 en INEI. “Informe Técnico. Evolución de la Pobreza 2007-2011". Lima: INEI. Recuperado de:

http://www.inei.gob.pe/DocumentosPublicos/Pobreza_InformeTecnico.pdf

Se puede observar en la figura 1.8, que a pesar de tener la mayor incidencia, son la Sierra y, en especial el área rural, las que mayores reducciones de pobreza extrema han tenido, siendo esta disminución de $11 \%$ y $12.2 \%$ respectivamente. 
Figura 1.8

Perú: Variación de la Pobreza Extrema, según ámbitos geográficos, 2010-2011 (puntos porcentuales)

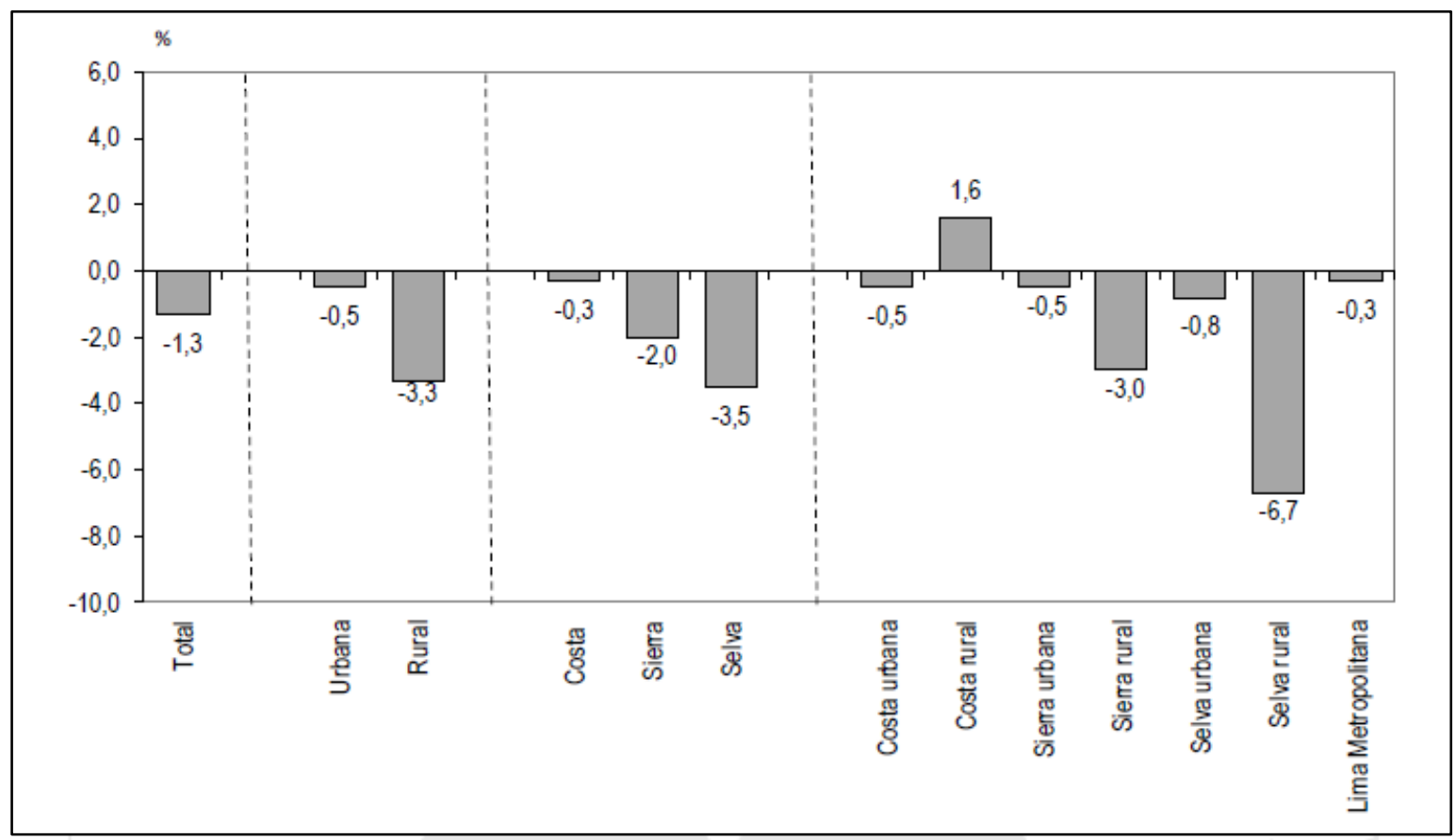

Fuente: INEI - Encuesta Nacional de Hogares (ENAHO): 2007-2011 en INEI. “Informe Técnico. Evolución de la Pobreza 2007-2011". Lima: INEI. Recuperado de:

http://www.inei.gob.pe/DocumentosPublicos/Pobreza_InformeTecnico.pdf

\subsubsection{Pobreza en Huánuco}

El departamento de Huánuco pertenece a la región natural de la Sierra y es en base a los resultados presentados por el INEI que se ha decidido analizar la evolución de la pobreza total y extrema en esta región, con énfasis en este departamento.

En la tabla 1.5 se puede apreciar la incidencia de la pobreza total por departamentos para los dos últimos años. Si bien esta incidencia ha disminuido, se observa que, para el 2010, sólo dos departamentos pertenecían al grupo 1, el de los de mayor incidencia de la pobreza. Sin embargo, en el 2011, este grupo creció e incluyo 3 nuevos departamentos que anteriormente se encontraban en el segundo grupo de incidencia de pobreza. 
Tabla 1.5

Perú: Incidencia de la Pobreza por grupos de Departamentos, 2010 y 2011 (porcentaje)

\begin{tabular}{|c|c|c|c|c|c|c|c|}
\hline \multirow{3}{*}{ Grupo } & \multicolumn{3}{|c|}{2010} & \multirow{3}{*}{ Grupo } & \multicolumn{3}{|c|}{2011} \\
\hline & \multirow{2}{*}{ Departamento } & \multicolumn{2}{|c|}{ Límites } & & \multirow{2}{*}{ Departamento } & \multicolumn{2}{|c|}{ Límites } \\
\hline & & Inferior & Superior & & & Inferior & Superior \\
\hline 1 & $\begin{array}{l}\text { Huancavelica } \\
\text { Apurímac }\end{array}$ & $62 \%$ & $63 \%$ & \multirow[b]{2}{*}{1} & \multirow{2}{*}{\begin{tabular}{|l} 
Apurímac \\
Cajamarca \\
Huancavelica \\
Huánuco \\
Ayacucho
\end{tabular}} & \multirow[b]{2}{*}{$53 \%$} & \multirow[b]{2}{*}{$57 \%$} \\
\hline \multirow[b]{2}{*}{2} & $\begin{array}{l}\text { Cajamarca } \\
\text { Huánuco } \\
\text { Amazonas }\end{array}$ & \multirow[b]{2}{*}{$43 \%$} & \multirow[b]{2}{*}{$55 \%$} & & & & \\
\hline & $\begin{array}{l}\text { Loreto } \\
\text { Puno } \\
\text { Ayacucho } \\
\text { Piura } \\
\text { Cusco }\end{array}$ & & & 2 & $\begin{array}{l}\text { Loreto } \\
\text { Amazonas } \\
\text { Pasco } \\
\text { Puno } \\
\text { Piura }\end{array}$ & $35 \%$ & $48 \%$ \\
\hline 3 & $\begin{array}{l}\text { Lambayeque } \\
\text { San Martín } \\
\text { Pasco }\end{array}$ & $36 \%$ & $38 \%$ & \multirow{2}{*}{3} & \multirow{2}{*}{$\begin{array}{l}\text { San Martín } \\
\text { Lambayeque } \\
\text { Cusco } \\
\text { La Libertad } \\
\text { Áncash } \\
\text { Junin }\end{array}$} & \multirow{2}{*}{$24 \%$} & \multirow{2}{*}{$31 \%$} \\
\hline \multirow[t]{2}{*}{4} & $\begin{array}{l}\text { La Libertad } \\
\text { Junín } \\
\text { Áncash }\end{array}$ & \multirow[t]{2}{*}{$22 \%$} & \multirow[t]{2}{*}{$31 \%$} & & & & \\
\hline & Ucayali & & & \multirow{2}{*}{4} & Tacna & \multirow{2}{*}{$16 \%$} & \multirow{2}{*}{$17 \%$} \\
\hline \multirow[b]{2}{*}{5} & Tumbes & \multirow[b]{2}{*}{$12 \%$} & \multirow[b]{2}{*}{$20 \%$} & & Lima 1/ & & \\
\hline & $\begin{array}{l}\text { Lima 1/ } \\
\text { Moquegua } \\
\text { Tacna } \\
\text { Arequipa } \\
\text { Ica }\end{array}$ & & & 5 & $\begin{array}{l}\text { Tumbes } \\
\text { Ucayali } \\
\text { Arequipa } \\
\text { Ica } \\
\text { Moquegua }\end{array}$ & $11 \%$ & $14 \%$ \\
\hline 6 & Madre de Dios & $3 \%$ & $7 \%$ & 6 & Madre de Dios & $2 \%$ & $6 \%$ \\
\hline
\end{tabular}

Fuente: INEI - Encuesta Nacional de Hogares, 2010 y 2011 en INEI. "Evolución de la Pobreza en el Perú al 2011”. Lima: INEI. Recuperado de: http://www.inei.gob.pe/DocumentosPublicos/Pobreza ExposicionJefe.pdf

Respecto a la incidencia de la pobreza extrema, se puede observar, en la tabla 1.6 que, en el grupo de mayor incidencia, se encuentran los departamentos de Cajamarca, Apurímac y Huánuco con un límite inferior y superior de $20.2 \%$ y $24.3 \%$, respectivamente.

Huánuco no solo pertenece al grupo con mayor incidencia de pobreza sino también al grupo con mayor porcentaje de pobreza extrema, a diferencia de departamentos como Huancavelica, donde la pobreza total es mayor que la pobreza extrema. Es por esta razón por la que es importante el estudio de este departamento. 
Tabla 1.6

Perú: Incidencia de la Pobreza Extrema por grupos de Departamentos, 2011

(En porcentaje)

\begin{tabular}{|c|l|c|c|}
\hline \multirow{2}{*}{ Grupo } & \multicolumn{1}{|c|}{ Departamentos } & Intervalo de confianza al \\
\cline { 3 - 4 } & & Inferior & Superior \\
\hline \hline GRUPO 01 & Cajamarca, Apurimac, Huánuco & 20,2 & 24,3 \\
\hline GRUPO 02 & Ayacucho, Huancavelica, Amazonas, Loreto, Pasco & 10,0 & 16,3 \\
\hline GRUPO 03 & Puno, Piura, La Libertad, Áncash,San Martín, Cusco, Junin & 4,3 & 9,6 \\
\hline GRUPO 04 & Ucayali, Lambayeque, Moquegua, Tacna, Arequipa, Lima 1/, Tumbes & 0,7 & 2,9 \\
\hline GRUPO 05 & Ica, Madre de Dios & 0,1 & 0,2 \\
\hline
\end{tabular}

Fuente: INEI - Encuesta Nacional de Hogares 2011 en INEI. "Evolución de la Pobreza en el Perú al 2011". Lima: INEI. Recuperado de: http://www.inei.gob.pe/DocumentosPublicos/Pobreza_ExposicionJefe.pdf

En el aspecto nutritivo, en la figura 1.9 se puede observar que el departamento que mayor disminución presentó fue Huánuco, que redujo este porcentaje en aproximadamente 10\% entre el 2007 al 2010, aun cuando en el año 2011 pertenecía al grupo de departamentos con mayor porcentaje de pobres extremos. Esta reducción de la desnutrición se debe en gran parte a la intervención del Programa a través de las transferencias monetarias, de los controles de salud permanentes y a la construcción de viviendas saludables impulsadas principalmente por las gestoras locales quienes también han sido promotoras de la limpieza y orden de hogares en situación de hacinamiento; las enfermedades diarreicas y parasitarias son las principales causas de la Desnutrición Crónica Infantil, pero con la promoción de mejores estilos de vida de parte del Programa y su adopción por la población beneficiaria, se propició la reducción de dichas enfermedades y consecuentemente la reducción también de la desnutrición. 
Figura 1.9

Perú: Desnutrición Crónica, según departamento, 2007 y 2009-2010

(por patrón de referencia NCHS)

\begin{tabular}{|ll|ll|l|l|l|}
\hline Huancavelica & $\mathbf{5 2 , 2}$ \\
Huánuco & $\mathbf{4 1 , 5}$ \\
Cajamarca & $\mathbf{3 7 , 3}$ \\
Ayacucho & $\mathbf{3 6 , 8}$
\end{tabular}

Fuente: INEI - "Indicadores de Resultados de los Programas Estratégicos. Encuesta Demográfica y de Salud Familiar - ENDES Continua". Lima: INEI. Recuperado de:

http://desa.inei.gob.pe/endes/Investigaciones/Expo Jefe 2010.pdf

La pobreza extrema está fuertemente relacionada con la desnutrición pues un menor ingreso monetario en las familias dificulta una adecuada alimentación, llevando a una menor ingesta calórica que la requerida para vivir; además, la falta de educación en salud y nutrición de las propias familias lleva a que los alimentos consumidos no necesariamente sean los que mayores nutrientes aporte.

Respecto a la educación, en base a la Encuesta Nacional de Hogares (2004-2010), se presentan los resultados obtenidos en el sector, en la tabla 1.7.

A nivel nacional la tasa neta de matrícula ha aumentado, más en inicial $(11.7 \%$ respecto al 2005) y secundario (7.4\% más en el 2010). Sin embargo, a nivel departamental, se puede observar que en algunos casos, este porcentaje disminuye: Amazonas en inicial (de 61.2\% en 2005 a 57.7\% en 2010); Apurímac, Huánuco, Ayacucho, Ica y Puno en primaria, siendo este último el que más disminuyó; Loreto, Pasco y Tumbes disminuyeron su tasa de matrícula del 2010 respecto al 2005 registrando los dos primeros un $4.8 \%$ menos. 
Para combatir la pobreza, el Estado a través de sus distintas instituciones realiza acciones tanto a nivel de la política económica: aspectos laborales, salariales, de estabilización monetaria, etc., así como de política social, dentro del cual se enmarcan los distintos programas de lucha contra la pobreza implementados a nivel nacional y que se enfocan en distintos aspectos como salud, educación, nutrición, vivienda, etc. es dentro de ésta última política que se enmarca los Programas de Transferencia Condicionada, que para el caso peruano se realiza a través del programa JUNTOS.

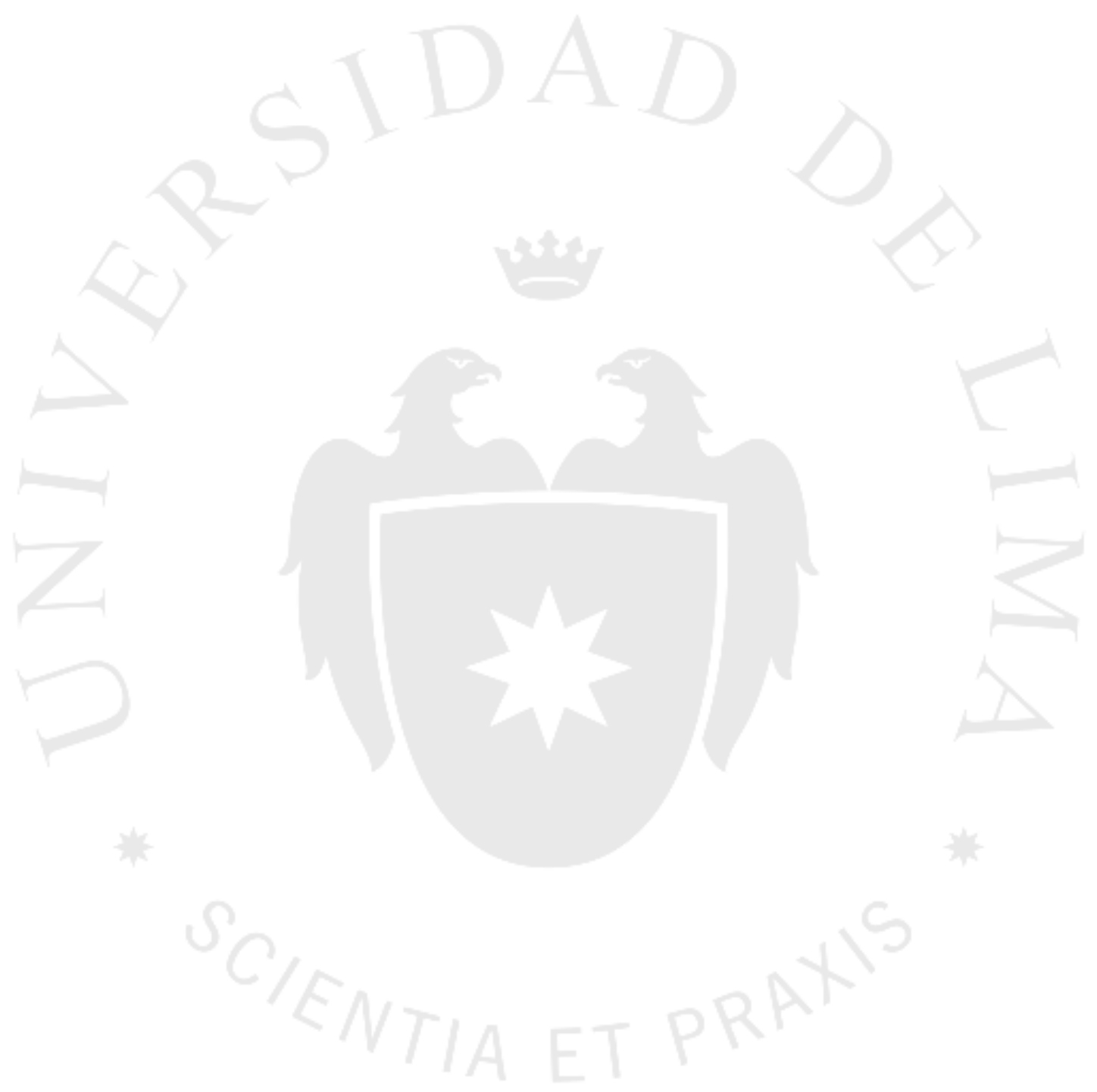


Tabla 1.7

Perú: Tasa neta de matrícula por año, 2005 - 2010

(porcentajes)

Número de matriculados en Inicial 3-5 años, Primaria o Secundaria que se encuentran en el grupo de edades que teóricamente corresponde al nivel de enseñanza, expresado como porcentaje de la población total de dicho grupo de edades.

\begin{tabular}{|c|c|c|c|c|c|c|}
\hline & \multicolumn{2}{|c|}{ Inicial } & \multicolumn{2}{|c|}{ Primaria } & \multicolumn{2}{|c|}{ Secundaria } \\
\hline & 2005 & 2010 & 2005 & 2010 & 2005 & 2010 \\
\hline PERÚ & 58.6 & 70.3 & 92.5 & 94.0 & 71.8 & 79.2 \\
\hline \multicolumn{7}{|l|}{ Área } \\
\hline Urbana & 67.1 & $\underline{74.3}$ & 92.7 & 93.7 & $\underline{80.4}$ & $\underline{84.5}$ \\
\hline Rural & 45.0 & $\underline{61.0}$ & $\underline{92.4}$ & $\underline{94.5}$ & $\underline{56.7}$ & 68.4 \\
\hline \multicolumn{7}{|l|}{ Región } \\
\hline Amazonas & 61.2 & 57.7 & 92.5 & 95.1 & 61.3 & 64.3 \\
\hline Ancash & 59.8 & 71.3 & 93.0 & 94.5 & 65.4 & 80.3 \\
\hline Apurímac & 55.6 & 67.2 & 94.1 & 92.1 & 74.6 & 82.6 \\
\hline Arequipa & 75.6 & 79.9 & 92.3 & 94.0 & 87.4 & 92.6 \\
\hline Ayacucho & 51.1 & 61.5 & 94.4 & 91.9 & 67.9 & 72.8 \\
\hline Cajamarca & 51.3 & 67.1 & 92.4 & 94.7 & 61.2 & 72.6 \\
\hline Callao & 63.7 & 77.3 & 86.3 & 96.8 & 73.4 & 86.1 \\
\hline Cusco & 54.6 & 69.2 & 94.7 & 95.6 & 63.6 & 82.9 \\
\hline Huancavelica & 33.0 & 72.5 & 91.4 & 97.9 & 59.8 & 75.5 \\
\hline Huánuco & 39.2 & 52.1 & 95.1 & 95.0 & 60.4 & 66.2 \\
\hline Ica & 82.4 & 80.1 & 96.4 & 94.8 & 82.1 & 84.0 \\
\hline Junín & 44.9 & 62.5 & 94.0 & 94.7 & 72.5 & 82.9 \\
\hline La Libertad & 47.6 & 69.4 & 89.5 & 95.3 & 65.9 & 72.9 \\
\hline Lambayeque & 67.2 & 66.5 & 95.5 & 96.3 & 73.1 & 80.3 \\
\hline Lima Metropolitana & 72.6 & 81.5 & 90.6 & 92.0 & 82.2 & 84.2 \\
\hline Lima Provincias & 73.2 & 79.7 & 91.1 & 95.0 & 77.1 & 81.6 \\
\hline Loreto & 57.0 & 59.1 & 86.9 & 91.0 & 59.6 & 58.2 \\
\hline Madre de Dios & 55.8 & 74.3 & 95.7 & 96.0 & 82.0 & 83.4 \\
\hline Moquegua & 78.3 & 77.0 & 96.2 & 97.1 & 82.2 & 87.6 \\
\hline Pasco & 54.7 & 64.8 & 90.8 & 94.8 & 83.2 & 78.4 \\
\hline Piura & 55.2 & 66.5 & 96.1 & 96.3 & 67.8 & 75.7 \\
\hline Puno & 51.0 & 50.7 & 92.6 & 90.0 & 74.8 & 83.3 \\
\hline San Martín & 41.0 & 68.6 & 95.7 & 96.7 & 66.3 & 71.8 \\
\hline Tacna & 77.3 & 71.6 & 96.8 & 96.6 & 87.6 & 91.6 \\
\hline Tumbes & 71.4 & 80.7 & 93.7 & 96.3 & 84.5 & 79.8 \\
\hline Ucayali & 57.2 & 68.6 & 90.9 & 92.5 & 70.8 & 74.0 \\
\hline
\end{tabular}

Fuente: INEI-Encuesta Nacional de Hogares 2004-2010. Lima: INEI. 


\subsection{Programas de Transferencia Condicionada}

Luego de la llamada "década perdida", se realizaron programas de ajuste estructural promovidos por el Fondo Monetario Nacional (FMI) y por el Banco Mundial (BM), los cuales implicaron que se disminuya el gasto público entre otros. En la dirección del "Consenso de Washington" y para enfrentar los costos sociales que implicaban estas medidas, se llevó a cabo cambios en los paradigmas respecto a políticas sociales: se pasó al selectivismo y a la "Lucha contra la pobreza". Se buscó eliminar la intermediación oficial con el fin que los subsidios lleguen de manera directa, a los más pobres bajo un enfoque de demanda. (Aramburú, 2010, pp.12) Para ello, se implementaron Programas de Transferencias Condicionadas (PTC) que, de acuerdo a Fiszbein y Schady (2009) son:

(...) programas que entregan dinero generalmente a hogares en situación de pobreza y pobreza extrema, con la condición de que realicen inversiones en el capital humano de sus hijos. Las condiciones de salud y nutrición generalmente requieren controles periódicos, controles de talla y vacunas para niños menores de 5 años; controles pre-natales para las madres y su asistencia a charlas de salud. Las condiciones de educación incluyen matrícula escolar, asistencia al 80\%-85\% y ocasionalmente la medición del rendimiento. (p.1)

Lo que se buscaba era aumentar la capacidad de gasto de los beneficiarios y evitar la burocratización en los Programas Sociales que evita que el beneficio llegue en su totalidad a la población objetivo. Estas transferencias, al requerir el cumplimiento de condiciones establecidas, promueven la corresponsabilidad de los participantes y evitan el asistencialismo. Uno de los principales problemas que enfrentan los PTC es la limitada oferta de servicios públicos que existe en paralelo a su funcionamiento, tanto en la calidad como en la cobertura de los mismos. Es así que se puede incentivar la demanda a través de las transferencias de dinero, más si no existe un equilibrio con la oferta, los resultados no serán los óptimos.

Las transferencias de dinero sujetas al cumplimiento de condiciones les permiten a los participantes salir de la pobreza, al menos en un corto plazo, mientras que en el largo plazo pueden romper el círculo de la pobreza a través del enfoque de capital humano, con una mayor inversión en salud y educación. 
De acuerdo a estudios realizados (Aramburú, 2010; Fiszbein y Schady, 2009; Trivelli, 2009), se puede haber llegado a un consenso sobre los objetivos primordiales de los Programas de Transferencias condicionadas (PTC):

* Incrementar el consumo de bienes básicos por parte de las familias en situación de pobreza y pobreza extrema, mediante la entrega directa de un monto determinado de dinero; $y$,

* Fomentar la inversión en capital humano con la finalidad de romper el círculo de la pobreza y la transmisión intergeneracional de la misma.

Para ello, el Estado les otorga a los participantes un beneficio, sea de manera efectiva a través de dinero, o por medio de víveres. Por esta transferencia, los beneficiarios deben cumplir con las responsabilidades establecidas por el Programa. Una consecuencia implícita de los objetivos de los PTC es el empoderamiento de la mujer en la sociedad, ello debido a que son ellas las que reciben las transferencias de dinero y son también las responsables del cumplimiento de las corresponsabilidades adquiridas en su participación. Con ello, se está logrando romper de cierta manera con las brechas de género que existen actualmente en los distintos países que aplican este tipo de programas.

La diferencia principal de los PTC con los programas sociales tradicionales con visión asistencialista radica en el hecho que los beneficiarios no son simplemente receptores de los beneficios, sino que, en adición, tienen responsabilidades y condiciones que cumplir para recibir y mantener la ayuda del Programa. De esta manera, se facilita el cumplimiento de los objetivos planteados por el Estado respecto a distintos ámbitos como salud, educación, nutrición, etc.

Teóricamente, estos programas deben suscitar la promoción de los derechos humanos y el cumplimiento de responsabilidades por parte de los beneficiarios; sin embargo, en la realidad, el contexto cultural influye en gran medida en la concepción que se genera dentro de los beneficiarios respecto al objetivo del programa. Es decir, que en un país, la implementación de un programa social del tipo de Transferencias Condicionadas puede percibirse como otro programa más de ayuda, pero relacionado al consumo individual de cada hogar, mientras que en otro país, la aplicación del mismo tipo de programa puede resultar en una salida de la pobreza, gradual y a largo plazo de muchos hogares participantes. 
Todo depende del planteamiento de las metas que quiera cumplir el Estado, de la manera en la que se implementan este tipo de programas y del control efectivo que se realice.

Los PTC, al igual que los otros programas sociales, requieren de mecanismos mínimos para su implementación y funcionamiento (Fiszbein y Schady, 2009, p.7):

1. Un sistema de focalización que permita la identificación de los beneficiarios y su inscripción en el programa;

2. Un mecanismo de pago de las transferencias; $y$,

3. Sistemas eficientes y eficaces de control.

Hay, según Fiszbein y Schady (2009, p. 8-11), dos argumentos para condicionar las transferencias monetarias: inversión en capital humano y las condicionalidades:

\section{Capital humano}

Se pueden condicionar las transferencias de dinero cuando la inversión privada en el capital humano de los niños es muy baja y esto puede darse de dos maneras:

Inversión privada por debajo del óptimo privado: Esta inversión puede estar aún por debajo del nivel óptimo privado si es que los hogares se aferran a la creencia errónea sobre el proceso de inversión en la salud y educación de los niños o en los resultados de dichas inversiones.

Inversión privada debajo del óptimo social: el óptimo privado de la inversión realizada en salud y educación puede estar por debajo del óptimo social, lo que puede darse si es que existen externalidades positivas derivadas de la salud y de la educación entre los hogares.

\section{Condicionalidades}

La aplicación de los PTC puede justificarse también cuando son necesarias ciertas condiciones desde el punto de vista de la economía política, es decir que la redistribución es políticamente posible sólo si se condiciona un buen comportamiento por parte de los beneficiarios. (Fiszbein y Schady, 2009, pp.11). 
Aun cuando la respuesta a lo anterior considera establecer una redistribución de amplia base que pueda incluir a la clase media, una alternativa que se plantea es la de apelar a motivos altruistas de la sociedad, si se interpreta que los PTC constituyen una forma de “contrato social” (Fiszbein y Schady, 2009, pp.10) en el que los beneficiarios están dispuestos a adoptar determinadas acciones para mejorar su nivel de vida y el de sus descendientes.

Cuando las condiciones se tratan como corresponsabilidades, se logra un mejor efecto en los beneficiarios pues se los trata más como personas capaces de solucionar sus propios problemas y recae en ellos la responsabilidad de alcanzar su potencial de desarrollo, y se ve al Estado no como un ente que brinda ayuda puramente asistencialista sino como un socio que colabora a su desarrollo.

El hecho de que las condiciones impuestas se centran en el desarrollo de capital humano enfocado principalmente en los niños, brinda a los PTC ser aceptados como un promotores de oportunidades; y en ese sentido, el uso de los recursos públicos, para su implementación, los convierte en programas de lucha contra la pobreza y no en programas meramente asistencialistas. (Fiszbein y Schady, 2009, pp. 10-11).

En casi su totalidad, los PTC entregan las transferencias a las mujeres, pues en base a la evidencia internacional se puede constatar que son ellas las que realizan una mejor administración de dinero, destinándolo a un uso productivo que resulte en un alto beneficio para sus familias.

Los PTC tienen su origen en América Latina, y en base a las experiencias exitosas que se obtuvieron en esta región, se crearon y desarrollaron programas para otros continentes como Asia y África e incluso Europa. La tabla 1.8 muestra una matriz referente al tamaño de los programas y al alcance de sus condiciones.

Sea que la focalización de sus objetivos sea respecto a la extrema pobreza y a la exclusión social como en Chile y Turquía, a la reducción de la brecha educativa como en Bangladesh y Cambodia, o para combatir la epidemia del VIH/SIDA en el África, los PTC han demostrado ser exitosos gracias a la versatilidad de aplicación que tienen, siendo ésta la razón por la cual son bastante populares. (Fiszbein y Schady, 2009, pp. xi). 
Tabla 1.8

Perú: Matriz de tamaño de Programa y alcance de las condiciones

\begin{tabular}{|c|c|c|}
\hline \multirow[b]{2}{*}{ Program size/Target } & \multicolumn{2}{|c|}{ Conditions } \\
\hline & Education and health & Education only \\
\hline \multirow[t]{5}{*}{ Nationwide } & Bolsa Família (Brazil) & Bolsa Escola (Brazil) \\
\hline & Oportunidades (Mexico) & Jaring Pengamanan Sosial (Indonesia) \\
\hline & Bono de Desarrollo Humano (Ecuador) & \\
\hline & Familias en Acción (Colombia) & \\
\hline & $\begin{array}{l}\text { Program of Advancement through Health and } \\
\text { Education (Jamaica) }\end{array}$ & \\
\hline \multirow{4}{*}{$\begin{array}{l}\text { Niche (regional } \\
\text { or narrow target } \\
\text { population) }\end{array}$} & Chile Solidario & $\begin{array}{l}\text { Female Secondary School Assistance Program } \\
\text { (Banoladesh) }\end{array}$ \\
\hline & & Japan Fund for Poverty Reduction (Cambodia) \\
\hline & & Education Sector Support Project (Cambodia) \\
\hline & & Basic Education Development Project (Yemen) \\
\hline \multirow[t]{5}{*}{ Small scale/pilot } & Programa de Asignación Familiar (Honduras) & Subsidio Condicionado a la Asistencia Escolar- \\
\hline & Cash Transfer for Orphans and Vulnerable & Bogotá (C \\
\hline & Children (Kenya) & Punjab Education Sector Reform Program \\
\hline & Atención a Crisis (Nicaragua) & stan) \\
\hline & Red de Protección Social (Nicaragua) & \\
\hline
\end{tabular}

Fuente: Fiszbein, A., Schady, N. (2009). Conditional Cash Transfers. Reducing Present and Future Poverty. Recuperado del sitio de Internet del Banco Mundial: http://siteresources.worldbank.org/INTCCT/Resources/5757608-1234228266004/PRRCCT web noembargo.pdf. (p.5)

Aramburu (2010) agrupa los resultados de los PTC, en base a evidencia internacional en 4 categorías; sin embargo, para efectos del presente trabajo, se agrupan estos resultados en 3 grupos, con la pertinente limitación que presenta cada uno (p. 13):

- Consumo: el beneficio monetario evidencia un aumento en el consumo de familias pobres, más no se puede afirmar que los alimentos adquiridos con dicho dinero contengan la carga nutricional que se exige de acuerdo a cada programa y población, así como tampoco se puede evidenciar el destino de un uso productivo de las transferencias.

- Educación y salud: se puede observar un incremento en la asistencia de los menores a la escuela y a los controles de salud y nutrición. Ello principalmente debido a la condicionalidad de las transferencias a las que están sujetos los beneficiarios. A pesar de ello, el impacto de los PTC es limitado en cuanto no exista la correspondiente oferta de servicios de calidad en los sectores educativos y de salud; otra vez se manifiesta el problema de un desequilibrio entre la demanda creada por los PTC y la oferta que realiza el Estado en los países en los que se implementan.

- Filtración y subcobertura: los beneficiarios de estos programas pertenecen en efecto a los grupos de pobreza y pobreza extrema, pero, se manifiestan casos de países en los que no 
todas las poblaciones identificadas como pobres son participantes, además de que se pueden estar excluyendo a otros grupos vulnerables de la sociedad.

La tabla 1.9 ofrece una muestra del impacto que tuvieron los PTC en los indicadores de pobreza en algunos países de América Latina. Donde A significa la línea de base, es decir, antes de que los hogares en el grupo de tratamiento de los PTC recibieran las transferencias. B significa que el programa no tuvo un impacto significativo sobre la medición de la pobreza; el asterisco y el doble asterisco significan el nivel de significancia del impacto, que se ubica al nivel del 10\% y del 5\% respectivamente. Así se puede observar que la aplicación de cada uno de estos PTC contribuyeron a reducir la pobreza de la población beneficiaria y tuvo un impacto significativo, a excepción de Honduras, donde no tuvo tal impacto.

Tabla 1.9

Impacto de los Programas de Transferencia Condicionada sobre los indicadores de pobreza

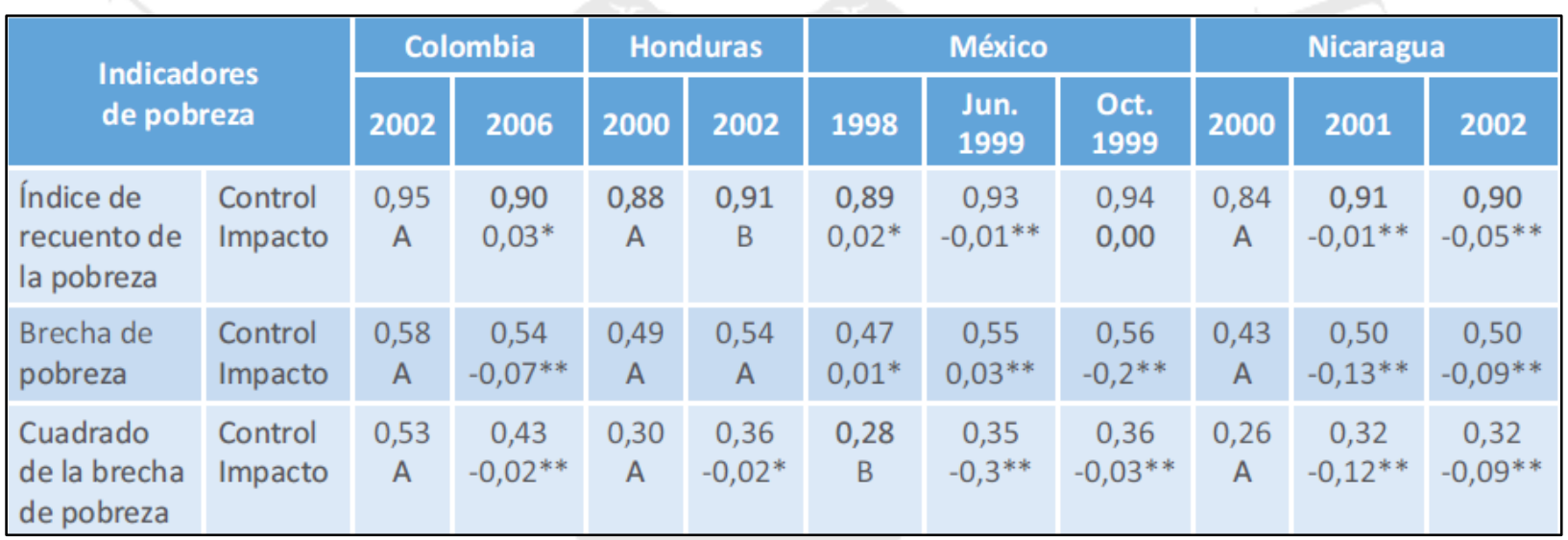

Fuente: Aramburú, C. (2010). Informe Compilatorio: El Programa JUNTOS, resultados y retos. Recuperado del sitio de Internet del Programa JUNTOS: http://www.juntos.gob.pe/modulos/mod infojuntos_V1/docs/11.pdf pp. 14

En América Latina, los PTC que mayor éxito evidenciaron han sido “Oportunidades" en México y el Programa "Bolsa Escola” en Brasil. Para el año 2008, eran aproximadamente 25 los países que desarrollaban PTC, incluyendo al Perú con la aplicación del Programa JUNTOS.

Sin embargo, aun cuando el impacto de los PTC sea altamente significativos, estos no aliviarán la pobreza definitivamente si se aplican aisladamente y sin cooperación con otros programas que busquen el desarrollo integral de la población, en especial si la misma población beneficiaria entiende el PTC más como un soporte a su consumo y no como una 
oprtunidad de salir de la pobreza y mejorar su vida y la de sus generaciones futuras. (Aramburú, 2010, pp. 13)

\subsubsection{México: Programa "Oportunidades"}

En 1997, se creó en México el PTC Progresa, que luego se convertiría en Oportunidades y que recientemente ha cambiado de nombre a PROSPERA, con el objetivo de mitigar la pobreza actual y futura a través de la inversión en capital humano (educación y salud) como condición para recibir una transferencia monetaria mensual. La población objetivo de este programa son los hogares en condición de pobreza alimentaria, la cual ha tenido una disminución de aproximadamente el 16\% desde el inicio de Oportunidades. En el gráfico 1.10 se puede apreciar la evolución de los diferentes tipos de pobreza, desde 1992 a 2010, pudiendo observarse que ésta alcanzó su pico más alto en 1996.

Se ha convertido en el principal programa anti-pobreza en este país, y se centra en tres componentes esenciales: educación, salud y nutrición. Las transferencias monetarias, en educación, son progresivas, y abarcan desde primaria hasta secundaria; el dinero entregado es mayor para las niñas que para los niños, cuando estos empiezan el nivel secundario, y esto se debe a que las tasas de deserción escolar en mujeres son más elevadas. (Banco Mundial, 2003, p.1). En cuanto a salud, el programa provee este servicio, a través de las instituciones públicas de salud, para todos los miembros del hogar sin distinción alguna, y se centran en salud preventiva. Para el componente de nutrición, el programa asigna un monto fijo mensual, que busca ser destinado a la obtención de mejores alimentos y suplementos nutricionales, tanto para niños entre los cuatro meses y los cuatro años, así como para mujeres gestantes y en etapa de lactancia. (Banco Mundial, 2003, pp. 1-2). 
Figura 1.10

México: Evolución de la pobreza, 1992-2010

(\% de individuos)

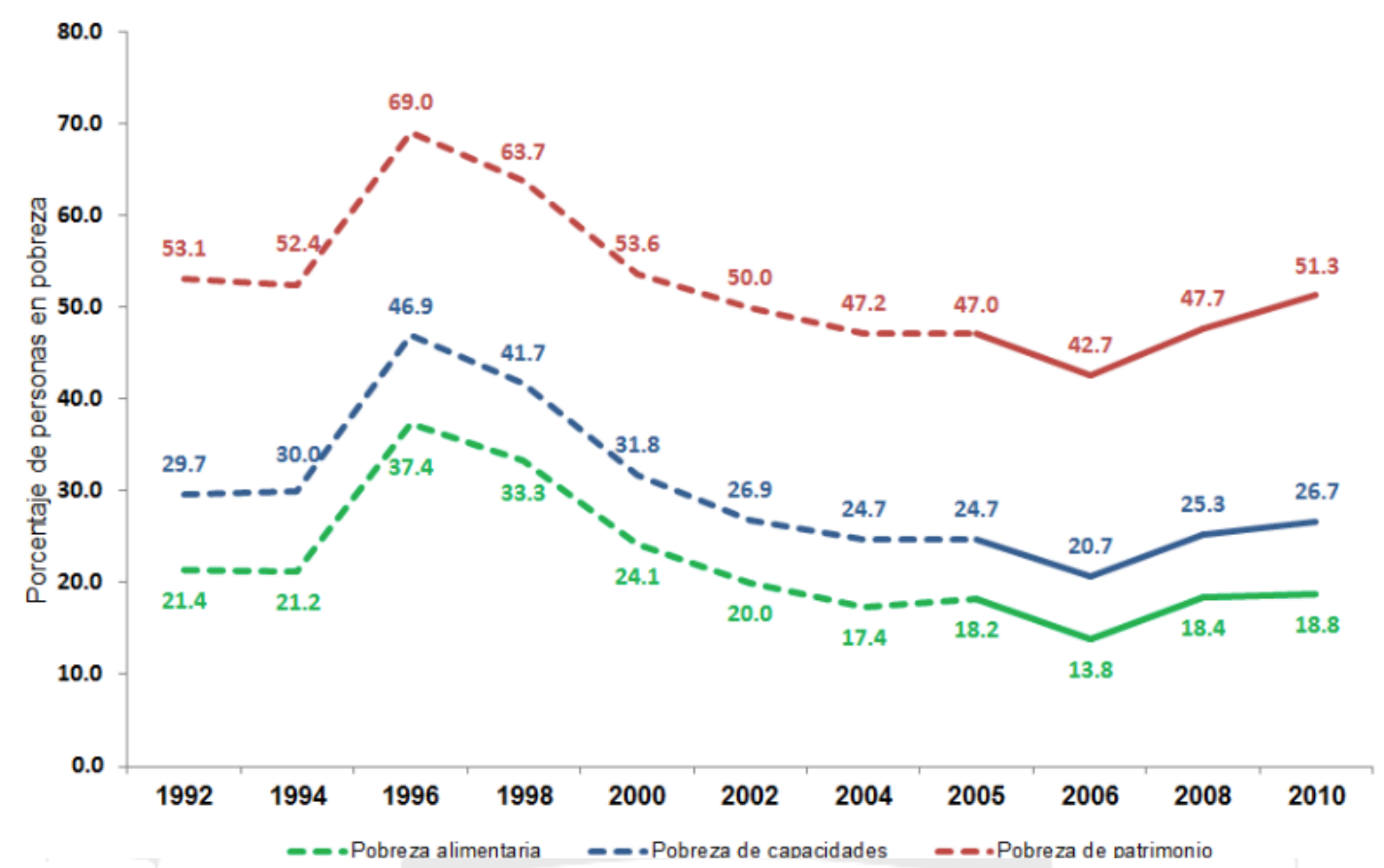

Fuente: Parker, S. (2014). Los Programas de Transferencia Condicionadas: Impactos del programa Oportunidades después de 15 años. Recuperado del sitio de Internet del Gobierno Mexicano: https://www.gob.mx/cms/uploads/attachment/file/31414/SEDESOL_SusanParker.pdf pp. 5

Actualmente son aproximadamente 6 millones de hogares los que reciben los beneficios del Programa (Parker, 2014, pp. 3), lo que equivale a 32 millones de personas, que representan el $27 \%$ de la población total. La figura 1.11 muestra la evolución de la cobertura del programa desde sus inicios hasta el año 2010. 
Figura 1.11

México: Crecimiento de la cobertura del programa Oportunidades, 1997-2010

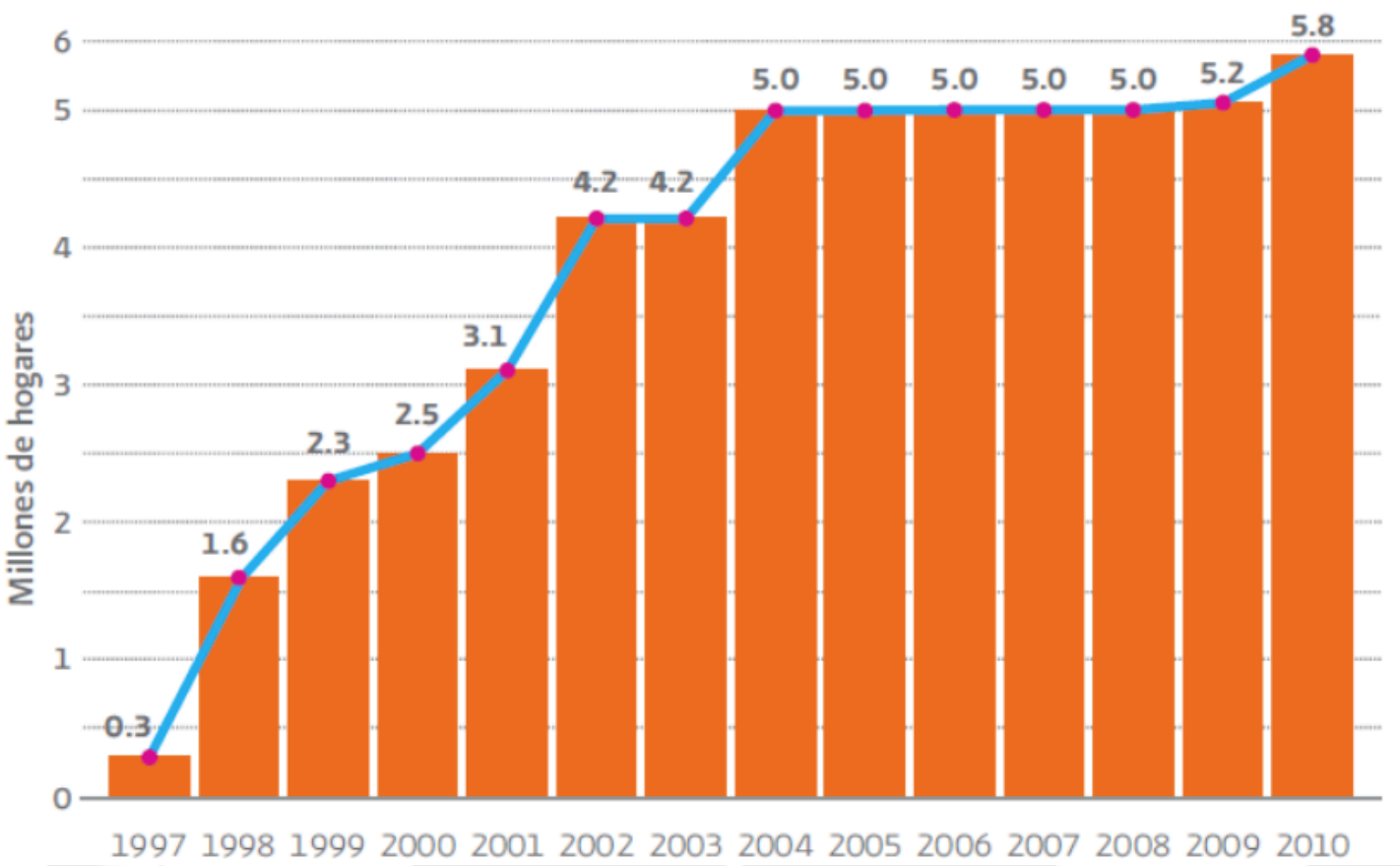

Fuente: Parker, S. (2014). Los Programas de Transferencia Condicionadas: Impactos del programa Oportunidades después de 15 años. Recuperado del sitio de Internet del Gobierno Mexicano: https://www.gob.mx/cms/uploads/attachment/file/31414/SEDESOL_SusanParker.pdf pp. 4

Para focalizar su cobertura, se hace primero geográficamente para finalmente llegar a hacerlo comunitariamente y para seleccionar a los hogares beneficiarios utilizan como herramienta un cuestionario de información socioeconómica. ${ }^{1}$ Un aspecto importante y crucial del programa, es el criterio para la salida de los hogares del programa: se emplea para esto un Esquema Diferenciado de Apoyos (EDA), según el cual los hogares reciben el apoyo monetario hasta el sexto año de su ingreso, luego de los cuales son recertificados y trasladados al EDA, donde siguen recibiendo apoyo seis años más para finalmente salir definitivamente del programa; cabe resaltar que una vez en el EDA, ya no se les brinda apoyo alimentario ni escolar para niños en el nivel primario. ${ }^{2}$

Finalmente, la evidencia sugiere que los efectos del programa han sido beneficiosos para las familias receptoras, mostrándose avances tanto en los componentes del mismo: incremento en matrícula del nivel secundario, menor ratio de repetición en el nivel

CEPAL. Programas de Transferencia Condicionada: Bases de datos. Ver: http://dds.cepal.org/bdptc/programa/?id=22 Chile: CEPAL.

Ibíd. 
primario, mayor peso de nacimiento de los niños durante el programa, reducción de la mortalidad infantil en niños menores de 5 años en un 17\%, mejor estatura infantil, etc.; así como efectos colaterales: mayor porcentaje de mujeres jóvenes trabajando fuera de casa, incremento de proporción en jóvenes con primeros trabajos no agrícolas, inversión agrícola de parte de los hogares beneficiarios, etc.

El programa Prospera, después de 17 años, sigue siendo el más exitoso en América Latina y ha servido de inspiración y modelo para la implementación de otros programas del mismo tipo en diferentes países, gracias a su impacto positivo, demostrando que la implementación de los PTC son efectivos no solo para reducir la pobreza actual sino también la pobreza futura a través de la inversión en capital humano (salud y educación).

\subsubsection{Brasil: Programa "Bolsa Familia"}

Se creó en 2003 como resultado de una fusión de cuatro programas sectoriales de transferencia condicionada: Bolsa-Escola, Bolsa-Alimentação, Auxílio-Gás y CartãoAlimentação. (Draibe 2006 p. 139) Si bien no fue el primer programa de este tipo, sí se convierte en el principal programa de la estrategia nacional de disminución de la pobreza, y es que prácticamente monopolizó las políticas dirigidas a la población en situación de pobreza. (Draibe 2006 p. 139). Al igual que los demás PTC, Bolsa Familia subsidia la demanda y significa también inversión en capital humano, centrándose en las familias en extrema pobreza; además, al igual que otros programas de su tipo, establece condicionalidades a la transferencia monetaria en aspectos educativos, de salud y alimentación, que ofrece el gobierno. (Draibe 2006 p. 139). Dos años después de crearse, se fusiona con el Programa de Erradicación de Trabajo Infantil (PETI), con lo cual se adicionan corresponsabilidades, pero específicas para familias cuyos miembros presentan situación de trabajo infantil. Y, desde el año 2012 se incluye un beneficio adicional: superación de la pobreza extrema, el cual busca cubrir la brecha existente entre el ingreso per cápita familiar y el valor de la línea de pobreza extrema ${ }^{3}$. Se puede observar que en el período comprendido entre 1990 y 2003 hubo una reducción de la pobreza extrema de aproximadamente 5 puntos; mientras que entre ese mismo año y el 2009, ésta se redujo en más de la mitad, ubicándose

3 CEPAL. Programas de Transferencia Condicionada: Bases de datos. Ver: http://dds.cepal.org/bdptc/programa/?id=6 Chile: CEPAL. 
por debajo de la línea objetivo del milenio para el 2015. En la figura 1.12 se puede apreciar dicha evolución.

Figura 1.12

Brasil: Evolución de la pobreza extrema, 1990-2009

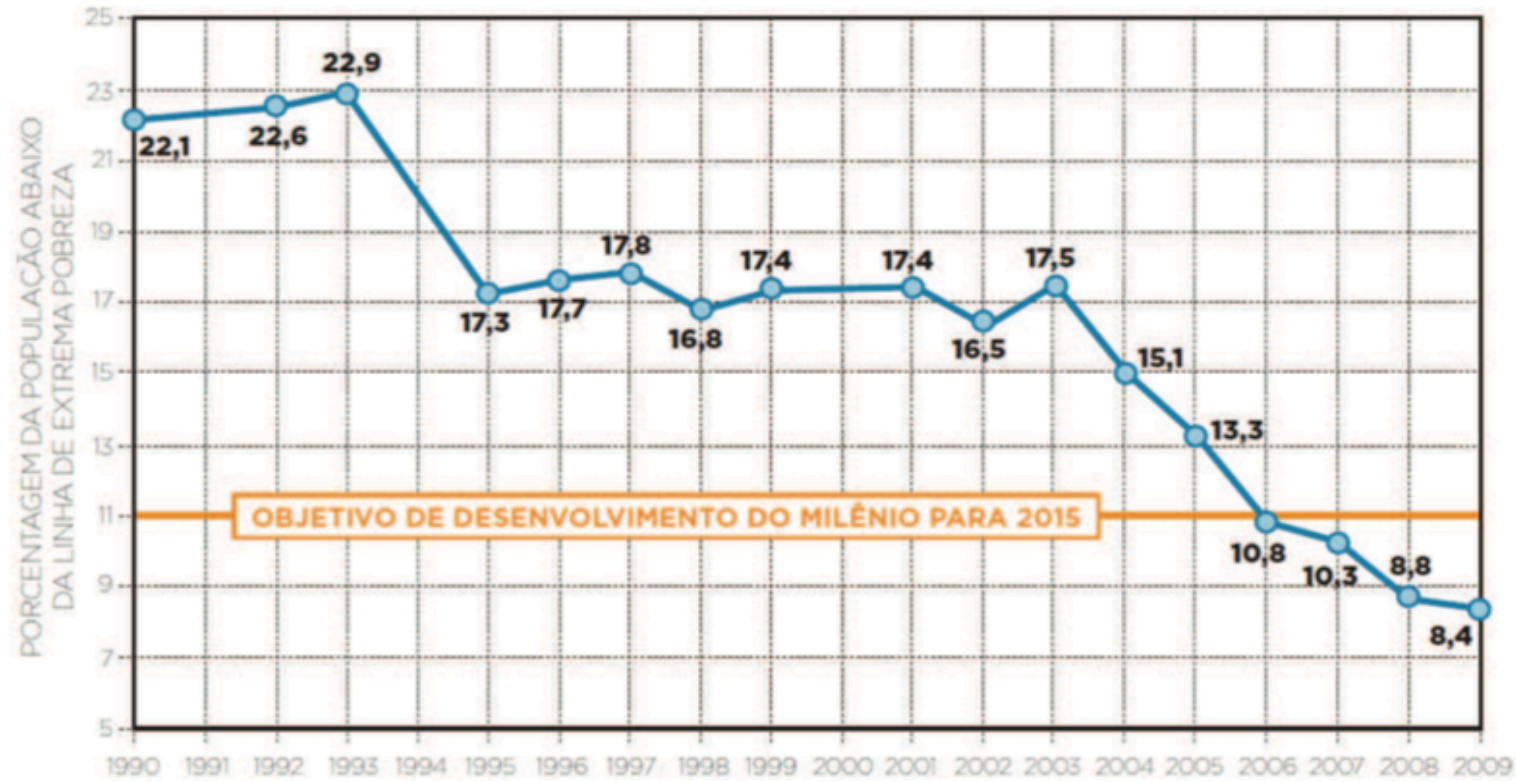

Fuente: Programa Bolsa Familia y Brasil sin Miseria. Recuperado de https://es.slideshare.net/FAOoftheUN/ministra-tereza-campello pp. 2

A diferencia de Oportunidades (México), su población objetivo no son los hogares en situación de pobreza alimentaria, sino las familias tanto en pobreza como pobreza extrema. Su focalización es geográfica, más no comunitaria y utilizan el Padrón Único para Programas Sociales del Gobierno Federal para la selección de los beneficiarios; el alcance del programa, así como en México, es a nivel nacional.

Actualmente el programa tiene una cobertura de 14 millones de hogares beneficiando a 57 millones de personas, que son aproximadamente el $29 \%$ de la población total, lo que significa un aumento del $20 \%$ en la cobertura de personas desde el inicio del 
programa. Dentro del programa, las familias pueden recibir hasta 8 bonos distintos, que pueden ser monetarios o no, y tienen criterios específicos: ${ }^{4}$

a) Bono básico: transferencia mensual fija entregada a las madres de familias en extrema pobreza (cuyos ingresos sean menores a R\$70) con condicionalidad al 85\% de asistencia escolar, cumplimiento de vacunas, controles de crecimiento y desarrollo, controles prenatales y acompañamiento a las madres en etapa de lactancia.

b) Bono variable: los beneficiarios son los hijos menores de 15 años de los hogares cuyos ingresos mensuales per cápita sean menores a $\mathrm{R} \$ 140$. La transferencia es mensual y se realiza de acuerdo al número de hijos de cada hogar, con un máximo de cinco hijos por hogar, para lo cual deben cumplir con las mismas corresponsabilidades del bono anterior.

c) Bono variable adolescente: para familias con hijos entre 16 y 17 años con la misma situación de pobreza. La transferencia es mensual y está sujeta a un ratio de asistencia escolar de $75 \%$, pudiendo entregarse dos bonos por familia como máximo pues este bono se calcula en función de los hijos adolescentes por hogar.

d) Bono variable embarazadas: está dirigido a las mujeres gestantes entre los 14 y 44 años de hogares en pobreza extrema. Se les entregan $\mathrm{R} \$ 32$ mensuales por nueve meses, los cuales se pagan completos sin importar el mes en el que se identificó a las beneficiarias; la única condicionalidad es la asistencia a los controles pre natales, pudiéndose suspender el beneficio si no existe tal asistencia. Este bono no excluye la posibilidad de recibir el bono variable adolescente, en el caso de las adolescentes gestantes.

e) Bono variable niños lactantes: para los niños entre cero y seis meses de familias en extrema pobreza. Durante seis meses se entrega $\mathrm{R} \$ 32$ mensuales condicionados a los controles de vacunas y de nutrición. El número máximo de beneficiarios es cinco por familia.

f) Bono para la superación de la extrema pobreza: para las familias con un ingreso mensual per cápita menor a $\mathrm{R} \$ 70$ aun después de recibir los otros beneficios; se entrega mensual y no tiene corresponsabilidades ni un número de beneficiarios máximo. 
g) Programa de Atención Integral a la familia (PAIF): se trata de un seguimiento para asegurar el cumplimiento de las corresponsabilidades de los hogares beneficiarios.

h) Brasil cariñoso: para familias en situación de pobreza extrema que tengan niños entre los cero y los seis años. Se les entrega dinero y suplementos nutricionales, y se puede recibir solo un beneficio por familia.

En una presentación de Tereza Campello, Ministra de Desarrollo Social y Combate al Hambre de Brasil, realizada durante el Sexto Seminario de Transferencias Condicionadas de Ingresos, realizado en Santiago de Chile el 29 y 30 de septiembre 2011 (pp. 7), se observa que los resultados mostraron incrementos en la asistencia escolar, tasas de progresión más altas, y además el ingreso al mercado laboral por parte de los adolescentes se posterga. Adicionalmente la desnutrición infantil entre 2003 y 2008 se redujo 8\%, hay menos partos prematuros y un aumento en el porcentaje de menores con vacunas al día y el porcentaje de niños nutridos fue superior en los beneficiarios que en los que no reciben el programa. Existen efectos positivos externos a las condicionalidades que exige el programa como mejores condiciones de vida y nutrición de las familias dentro del programa, aproximadamente un $60 \%$ de las familias beneficiarias han salido de la pobreza extrema y también las familias beneficiarias han disminuido sus niveles de pobreza experimentando un aumento de su ingreso.

Por otro lado, la pérdida de las condiciones para ser elegidos beneficiarios constituyen la salida del programa; los hogares son rectificados cada dos años. Además, pueden vincularse a programas de capacitación y empleo y pueden acceder a programas municipales. ${ }^{5}$ Sin embargo, no existe una articulación adecuada a otro programa o un mecanismo de graduación de las familias, tal como en el caso de México, lo que contribuiría a asegurar la salida definitiva de la pobreza de las familias beneficiarias.

5 CEPAL. Programas de Transferencia Condicionada: Bases de datos. Ver: http://dds.cepal.org/bdptc/programa/?id=6 Chile: CEPAL. 


\subsubsection{Colombia: Programa "Familias en Acción"}

Creado en el año 2000 como programa transitorio dentro de la Red de Apoyo Social (RAS) para dar respuesta a la crisis de finales de los años noventa, y su finalidad inicial era la de mantener el capital humano de los hogares más vulnerables. En el 2002 atendió a 320 mil familias y en la actualidad ${ }^{6}$ beneficia a más de 2.8 millones de familias, además de haber ampliado su cobertura a más municipios e incluir dentro de sus beneficiarios a población en situación de desplazamiento, áreas urbanas y pueblos indígenas (Unidad Temporal de Econometría - SEI, junio 2012, p. 6).

Al igual que la mayoría de PTC, Familias en acción cuenta con tres componentes principales: educación, salud y nutrición. A las familias beneficiarias se les entrega dos tipos de subsidios, condicionados al cumplimiento de compromisos establecidos. El primero es el subsidio educativo entregado a las familias que tengan menores entre los 7 y 17 años de edad, se entrega cada dos meses y es por cada niño matriculado en el sistema educativo básico y que asista al menos al $80 \%$ de las clases durante el año; este subsidio es diferenciado, siendo US\$ 6 para primaria y US\$ 12 para secundaria (bachillerato), y se ha escalonado así tomando en cuenta el mayor riesgo de deserción escolar que existe para secundaria (Banco Mundial [BM], s.f., pp. 1). Con esto, el programa espera que en el corto plazo se reduzcan las tasas de inasistencia y de deserción, en el largo plazo se espera impactar a través de un aumento en los años de escolaridad dentro de las zonas en las que impacta el programa, y finalmente se espera regresar a niños en edad escolar que hayan desertado de la escuela (BM, s.f., pp. 1).

El segundo subsidio es el de nutrición, el cual es entregado por familia, que tenga niños menores de 7 años, sin importar el número de hijos que existan en la familia; el monto es de US\$ 20 aproximadamente y está condicionado a la participación de las familias beneficiarias en los controles de Crecimiento y Desarrollo; sus objetivos son incrementar el número de menores de 7 años atendidos en el sistema de salud, mejorar el consumo de las familias en alimentos nutritivos, y en el largo plazo se pretende disminuir las tasas de desnutrición infantil, mejorar la salud infantil y el desempeño escolar.

Un factor importante en el éxito de este programa, es la credibilidad del Sistema de Selección de Beneficiarios para Programas Sociales (SISBEN) entre los beneficiarios, 
además de que es aceptado por todos los sectores de la sociedad como el único sistema que puede realizar la selección de familias pobres de manera transparente (Policy Brief 2, 2006, pp. 4). Este sistema se maneja a través de puntajes, entre 0 a 100 , donde más cerca de 0 significa mayor pobreza y más cercano a 100, menos pobreza. Para seleccionar a los beneficiarios, primero se debe elegir a los municipios elegibles, los cuales deben cumplir requisitos tales como tener menos de 100 mil habitantes, contar con una entidad financiera y tener la base del SISBEN con fecha de corte al 31 de diciembre de 1999; además se les aplica una evaluación ex-ante, que tiene como finalidad determinar si un municipio tiene capacidad suficiente en oferta de servicios de educación y salud para afrontar la demanda actual de la población más la nueva demanda creada por el programa (BM, s.f., pp. 3-4). En la tabla 1.10 se presenta a detalle los niveles de acuerdo a su puntaje. Los niveles 1 y 2 concentran la pobreza total del país, pero solo el nivel 1 abarca la extrema pobreza, y es en este nivel en el que se enfoca el programa.

Tabla 1.10

Niveles del SISBEN

\begin{tabular}{|c|c|c|}
\hline Nivel de Pobreza & Zona Urbana & Zona Rural \\
\hline SISBEN 1 & $0-36$ & $0-18$ \\
\hline SISBEN 2 & $37-47$ & $19-30$ \\
\hline SISBEN 3 & $48-58$ & $31-45$ \\
\hline SISBEN 4 & $59-69$ & $46-61$ \\
\hline SISBEN 5 & $70-86$ & $62-81$ \\
\hline SISBEN 6 & $87-100$ & $82-100$ \\
\hline
\end{tabular}

Fuente: http://siteresources.worldbank.org/SAFETYNETSANDTRANSFERS/Resources/2819451131468287118/1876750-1140107387177/ColombiaCCT.pdf

El programa ha tenido durante su duración, un impacto positivo, especialmente en las zonas rurales. En educación, según el Departamento Nacional de Planeación de Colombia (2007), el impacto más significativo se ha dado en el incremento de la asistencia escolar en secundaria en las zonas rurales así como la reducción de años repetidos en el mismo nivel, tanto en el área urbano (0.9 años) como rural (1 año). (p.7). En el aspecto nutricional y de salud, se ha reducido la desnutrición crónica en los menores de 7 años, con mayor impacto en las zonas rurales; en la tabla 1.11 se observa los porcentajes de la desnutrición, tanto crónica como global. 
Tabla 1.11

Impacto positivo en el estado nutricional de niños(as) menores de 7 años, 2007

\begin{tabular}{|c|c|c|c|}
\hline Grupo de edad & Zona & $\begin{array}{l}\text { \% desnutrición } \\
\text { crónica }\end{array}$ & $\begin{array}{c}\% \text { desnutrición } \\
\text { global }\end{array}$ \\
\hline \multirow{2}{*}{$0-84$ meses } & Rural & -9 & -2.5 \\
\hline & Urbano & 2.5 & 0.9 \\
\hline \multirow[t]{2}{*}{0 - 35 meses } & Rural & -5.2 & -6 \\
\hline & Urbano & 10.1 & -4.1 \\
\hline
\end{tabular}

Fuente: DEPARTAMENTO NACIONAL DE PLANEACIÓN. (2007). Seminario Internacional Programa de Transferencias Condicionadas: La experiencia de diversos países. "El caso de Colombia: Programa Familias en Acción". Recuperado del sitio de Internet de la CEPAL:

http://www.cepal.org/dds/noticias/paginas/1/30291/Colombia_JFArias_DNP.ppt.pdf pp. 7

El programa ha sido exitoso además en mejorar el cumplimiento de los controles CRED (Control de Crecimiento y Desarrollo) de niños entre los 36 y 83 meses en el área rural $(20.1 \%)$ y urbana (44.1\%). Se ha impactado también en el aumento del consumo de alimentos en las zonas rurales (US\$ 16.8) y urbanas (US\$ 12.1). Pero uno de los impactos más significativos es quizás el que ha tenido en la reducción de la pobreza extrema: 17.1 puntos en la zona urbana y 12.6 puntos en la zona rural (Departamento Nacional de Planeación 2007 p.8); en la figura 1.13 se observa la evolución de la pobreza extrema en Colombia para el período 2002 a 2014. Las cabeceras se refieren a la población parte de cada municipio donde se ejerce la función administrativa del mismo, podría equivaler a la capital de cada municipio. Finalmente, se puede decir que el mayor impacto del programa Familias en Acción se ha dado en el ámbito rural más que en el urbano, y en el nivel de educación secundario. En esta reducción de la pobreza tanto urbana como rural en Colombia ha tenido mucho impacto el mejoramiento de la educación básica y la caída de la desnutrición, dos componentes esenciales que en el largo plazo conllevan a obtener mayores oportunidades en la generación de ingresos de las familias beneficiarias. 
Figura 1.13

Incidencia de la pobreza extrema por dominio, 2002 - 2014

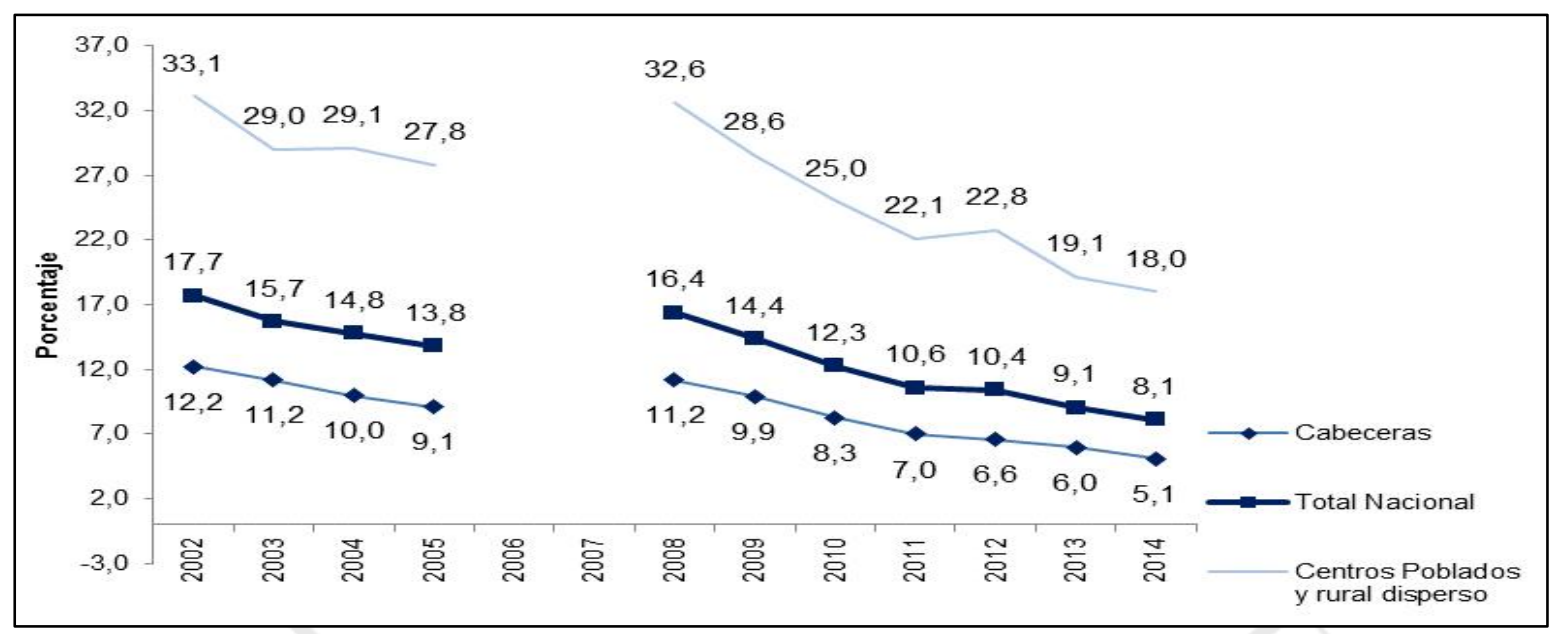

Fuente: Departamento Administrativo Nacional de Estadística (DANE). (2015). Boletín Técnico sobre Pobreza monetaria y multidimensional en Colombia 2014. Recuperado del sitio de Internet del DANE: http://www.dane.gov.co/files/investigaciones/condiciones_vida/pobreza/bol_pobreza_14_pdf

En conclusión, siendo la pobreza un fenómeno constante en el mundo, se debe entender que no existe una definición única sobre lo que representa, ni un método absoluto para su medición, ni tampoco una solución para acabar con la pobreza que sea mejor que otra o alguna que sea única, sino que cada una es aplicada de acuerdo a la realidad de las distintas sociedades. Pero lo cierto, es que para combatir la pobreza es necesario proveer a las personas con las oportunidades necesarias para que tengan la libertad de elegir las capacidades que éstas deseen desarrollar en su futuro. En este sentido, si bien el fin principal de los PTC no es el de la reducción de la pobreza, este termina siendo un efecto indirecto, a través del impacto que tienen estos programas en la formación y aumento del capital humano; los datos de evolución de la pobreza presentados en los tres programas (Brasil, México y Colombia) sugieren que el mayor impacto se registra en la pobreza extrema; el uso que le dan las familias al dinero que reciben se destina mayormente a comprar alimentos más nutritivos, a los cuales antes no podían acceder, en otros casos la evidencia sugiere que destinan una parte del dinero a la compra de materiales para la educación de sus hijos; además, en los programas mencionados, se recibe un subsidio por nutrición y educación, lo que crea un incentivo para permanecer en la escuela y para mejorar la nutrición de los menores, lo cual se corresponde y genera en el largo plazo ciudadanos con mejores condiciones y oportunidades, rompiendo poco a poco con la transmisión intergeneracional de la pobreza. 


\section{CAPITULO 2 \\ PROGRAMA NACIONAL DE APOYO DIRECTO A LOS MAS POBRES "JUNTOS"}

El Perú, hasta la década del 90, la mitad del país estaba en situación de pobreza, pero, esto cambió hacia la última década, gracias al crecimiento económico sostenido que experimentó el país.

La población empezó a mejorar en muchos aspectos tanto económicos, mayor sueldo o el establecimiento de micro y pequeñas empresas; como sociales, mayor acceso a educación y salud. Sin embargo, todavía quedaba una parte de la población a la que el crecimiento económico del país parecía no llegarles de ningún modo, a pesar de los distintos Programas Sociales que funcionaban a nivel nacional.

Es, en este contexto, que se diseña el Programa de Apoyo Directo a los más Pobres "JUNTOS" (JUNTOS), cuyo objetivo y diseño era distinto a los programas tradicionales que implementaba el Estado desde décadas pasadas y que parecían no aliviar la situación de la población más pobre y en estado de exclusión social, a pesar del tiempo que llevaban en funcionamiento.

\subsection{EI Programa JUNTOS}

El programa JUNTOS se enmarca dentro de los PTC que, a diferencia de otros programas sociales llevados a cabo por diferentes países, son programas que no se enfocan en ayuda asistencialista o en un solo aspecto, sino que engloban los aspectos más importantes del desarrollo de las personas y les brindan ayuda, sea monetaria o en especias, para así fomentar la creación de capital humano y terminar con la pobreza y su transmisión intergeneracional.

\subsubsection{Objetivo del Programa}

El Programa nacional de apoyo directo a los más pobres "JUNTOS" es un PTC perteneciente a la política social y de lucha contra la pobreza llevada a cabo por el gobierno peruano. Se creó el 7 de abril de 2005, mediante Decreto Supremo Nº32-2005-PCM, el cual definió sus objetivos, su estructura de operación y las fuentes de su financiamiento; así mismo, este programa fue adscrito a la Presidencia del Consejo de Ministros (PCM). 
Por Resolución Suprema del 1 de enero de 2012, se transfirió el programa JUNTOS al Ministerio de Desarrollo e Inclusión Social (MIDIS), lo que va acorde con la nueva política del gobierno de fortalecer y articular mejor la intervención del Estado, impulsando el desarrollo y la inclusión social, para que los recursos se inviertan de manera eficiente y eficaz mejorando el impacto de estos en la reducción de la pobreza. (http://www.juntos.gob.pe/index.php/quienes-somos/antecedentes).

El programa se encarga de realizar de manera directa, la entrega de los incentivos monetarios a familias que se encuentran en situación de pobreza y pobreza extrema, rural o urbana, y que tengan madres gestantes y niños y adolescentes hasta 14 años de edad. Estos incentivos están condicionados al cumplimiento de compromisos, por parte de los hogares beneficiarios; dichos compromisos se orientan a mejorar el acceso de los hogares a servicios de educación, identidad, salud y nutrición.

\section{La finalidad del Programa es la de}

(...) contribuir a la reducción de la pobreza y a romper la transmisión intergeneracional de la pobreza extrema y como propósito generar Capital Humano en hogares en pobreza en corresponsabilidad Estado - Hogar, mediante la entrega de incentivos para el acceso y uso de servicios de salud - nutrición y educación; bajo un enfoque de restitución de esos los derechos básicos, con la participación organizada y la vigilancia de los actores sociales de la comunidad." (http://www.juntos.gob.pe/index.php/quienes-somos/antecedentes).

El objetivo principal del programa JUNTOS es terminar con el fenómeno de la transmisión intergeneracional pobreza, es decir, que el hecho de nacer en un hogar pobre no determine que la persona necesariamente siga en la misma condición de pobreza que sus padres, abuelos y generaciones anteriores. Para ello, se busca dar mejor acceso a los servicios de salud-nutrición y educación, para que todas las personas tengan las mismas oportunidades de desarrollar sus capacidades al máximo, independientemente de su condición económica. ${ }^{7}$

El programa JUNTOS se diferencia de los anteriores programas sociales para la lucha contra la pobreza en dos aspectos fundamentales e inherentes a su creación y diseño: (http://www.juntos.gob.pe/index.php/quienes-somos/antecedentes).

$7 \quad$ La falta de oportunidades para el desarrollo de capacidades corresponde al concepto de pobreza concebido por Amartya Sen, Cfr. Capítulo 1. 
- selección de los beneficiarios: a diferencia de otros programas, la selección se realiza a nivel de los hogares (focalización individual utilizando el índice SISFOH), en lugar de hacerlo por zona geográfica. Con ello, se busca asegurar que los recursos del programa se destinen a las familias en situación de extrema pobreza.

- alcance multisectorial: por su intervención paralela en los sectores de educación y salud. Al trabajar en ambas dimensiones del capital humano, se puede tener un mayor rendimiento social que cuando se enfrenta cada uno por separado.

Las transferencias monetarias realizadas por el programa generan en los hogares receptores demanda por servicios de salud y educación, lo que implica para el Programa una mayor oferta de dichos servicios sociales, lo que representa un reto para JUNTOS debido a que éste no es el fin para el que fue creado, pero influye en los resultados que este programa pueda obtener en la reducción de la pobreza.

\subsubsection{Diseño del Programa}

El objetivo primordial de JUNTOS, es la generación de capital humano para romper con la transmisión intergeneracional de la pobreza, y todo ello se puede ver reflejado en la misión y visión de dicho programa: (http://www.juntos.gob.pe/index.php/quienessomos/vision-y-mision).

\section{Misión}

El Programa tiene por misión contribuir al desarrollo humano y al desarrollo de capacidades especialmente de las generaciones futuras, orientado su accionar a romper la transferencia intergeneracional de la pobreza, mediante incentivos económicos que promuevan y apoyen el acceso a servicios de calidad en educación, salud, nutrición e identidad bajo un enfoque de restitución de esos derechos básicos, con la participación organizada y la vigilancia de los actores sociales de la comunidad. 


\section{Visión}

En el ámbito de acción del Programa, se han restituido los derechos básicos de los hogares, cuyos miembros acceden con pleno ejercicio de su ciudadanía de manera regular a servicios básicos de calidad en educación, salud y nutrición habiendo mejorado la calidad de vida y el desarrollo de capital humano reduciendo con ello la transferencia intergeneracional de la pobreza.

El programa JUNTOS fue diseñado para dirigir su accionar a familias que se encuentren en el grupo de pobres extremos, es decir, que su ingreso mensual no alcance para cubrir el costo de la canasta mínima de alimentos; y, que además, estén compuestas por niños menores de 14 años o madres gestantes. El dinero asignado por el programa es de S/. 200 bimestrales durante cuatro años, y se entrega a la madre responsable de cada hogar, pues es algo habitual en los PTC en el resto de países, además de que, por comprobadas experiencias internacionales, son las mujeres las mejores administradoras del dinero. ${ }^{8}$

Las transferencias monetarias van disminuyendo gradualmente, a medida que las familias participantes van avanzando y dejando atrás su condición de pobreza o pobreza extrema hasta la graduación de los mismos una vez superada esta condición. Sin embargo, ello crea incentivos perversos, pues una vez superada la pobreza, no se recibirá el dinero, que en muchos casos, se considera un flujo de ingresos permanentes al que la familia beneficiaria se ha acostumbrado, por lo que podrían llegar a evitar salir de la pobreza y mejorar su condición de vida para seguir en el Programa y continuar recibiendo el dinero asignado. Es, por ese motivo, que es de vital importancia que JUNTOS se articule con otros Programas Sociales durante el tiempo de participación de los hogares seleccionados, pues lo que se persigue en esencia es la creación de capital humano y no el asistencialismo puro.

Si bien el dinero que reciben los beneficiarios es de libre disponibilidad, éste no es otorgado de manera incondicional pues los participantes deben firmar un "Acuerdo de Compromiso" (Instituto de Estudios Peruanos [IEP] 2009 p. 22) en el que se detalla los compromisos en materia de salud y nutrición, educación e identidad a que se comprometen las madres que deseen que sus hogares participen del Programa. Ante un incumplimiento de dichas condiciones, el incentivo monetario es suspendido de manera temporal, siendo tres el

8 Para más información sobre este tema consultar: SPIEGEL, Peter. "Muhammad Yunus, el banquero de los pobres" Santander. Sal Terrae, 2007 
máximo de suspensiones que un hogar puede recibir, pues ante una cuarta reincidencia el hogar participante es retirado del programa de manera definitiva. Estas condiciones son:

Tabla 2.1

Condiciones del programa JUNTOS

\begin{tabular}{|c|c|c|}
\hline SECTOR & TEMAS & COMPROMISOS \\
\hline EDUCACION & Educación & $\begin{array}{l}\text { Para niños entre } 6 \text { y } 14 \text { años que no han completado la primaria: } \\
\text { asistencia del } 85 \% \text { promedio de los días en que se realizan } \\
\text { actividades en el establecimiento educacional }\end{array}$ \\
\hline \multirow[t]{2}{*}{ SALUD } & Salud & $\begin{array}{l}\text { Vacunación completa, desparasitación y suplementos vitamínicos } \\
\text { para niños hasta } 5 \text { años; controles pre y post natales y asistencia a } \\
\text { charlas educativas para madres gestantes. }\end{array}$ \\
\hline & \multirow[b]{2}{*}{ Nutrición } & Controles de crecimiento y desarrollo para niños hasta 5 años \\
\hline \multirow[t]{2}{*}{ MIMDES } & & $\begin{array}{l}\text { Participación en el Programa de complementación alimentaria para } \\
\text { grupos en mayor riesgo (PACFO) de todas aquellas unidades } \\
\text { beneficiarias que tienen niños entre } 6 \text { meses y } 3 \text { años (recepción de } \\
\text { papilla y participación en capacitación) }\end{array}$ \\
\hline & Identidad & $\begin{array}{l}\text { Participación en el programa "Mi Nombre" del MINDES de todas } \\
\text { aquellas familias que tienen niños y niñas sin partida de nacimiento } \\
\text { o mayores de } 18 \text { años sin DNI }\end{array}$ \\
\hline
\end{tabular}

Fuente: Huber L., Zárate P., Durand A., Madalengoitia O. y Morel J. (2009). Programa JUNTOS. Certezas y malentendidos en torno a las transferencias condicionadas Estudio de caso de seis distritos rurales del Perú. Recuperado del sitio de Internet del Instituto de Estudios Peruanos: http://repositorio.iep.org.pe/handle/IEP/187 p. 22.

Como se puede observar en la tabla 2.1, la condicionalidad en educación es la tasa de asistencia a la escuela, y no la tasa de matrícula. Ello debido a que el hecho de que las madres matriculen a sus hijos en el colegio no significa necesariamente que estos asistan a clases, sino que pueden estar realizando otras actividades como trabajo, sea dentro o fuera del hogar; al exigirse una tasa de asistencia escolar del 85\% de los menores del hogar beneficiario se busca asegurar el componente educativo del capital humano.

En el tema respectivo a la salud, se exige la vacunación de los niños y los suplementos vitamínicos para el cuidado de la salud de los menores de los hogares beneficiados. Otra condición en salud es que las madres participantes asistan con regularidad a sus controles pre y post natales para asegurar un embarazo seguro y evitar complicaciones tanto durante ese periodo como después del nacimiento. Así mismo, se exige la asistencia a 
charlas educativas para las madres embarazadas, con lo que se busca contribuir a que tengan toda la información necesaria durante esta etapa y puedan tomar los cuidados necesarios. Un punto importante a mencionar es que si bien se les exige a las madres en estado de gestación la asistencia obligatoria a los controles durante esta etapa así como el suplemento de vitaminas y ácido fólico, no se les exige el parto institucional, con lo cual no se puede asegurar que los nacimientos se den bajo las condiciones adecuadas, y en caso de presentarse alguna complicación, ésta no puede ser atendida de manera inmediata por el personal del centro de salud, debido muchas veces a la distancia que existe entre este centro y los poblados alejados, con lo cual se pueden presentar problemas graves con los recién nacidos o la madre que en ocasiones puede llevar a la muerte de uno o ambos.

Respecto al tema nutricional, los dos compromisos exigidos no son excluyentes, es decir, que el cumplimiento de uno no exime el cumplimiento del otro, ambos se complementan para un mejor resultado en la nutrición de los niños de los hogares beneficiarios. Por un lado, está la participación en un programa de complementación alimentaria que brinda alimentos blandos para los menores de 3 años y, a la vez, capacita a las madres para que éstas tengan conocimiento de los alimentos que sus hijos deberán consumir al menos durante los 3 primeros años de vida, para tener un adecuado crecimiento y una buena salud; mientras que los controles de crecimiento y desarrollo permiten detectar el estado de nutrición en el que se encuentra la población menor de 5 años, es decir, si se encuentra de acuerdo al rango de peso y talla correspondiente a su edad cronológica, a la vez que permite detectar problemas de nutrición entre los beneficiarios del programa, para así tomar las medidas de acción correspondiente en cuanto a la nutrición infantil.

En cuanto al tema de la Identidad, un derecho fundamental de todo ciudadano es el de tener un nombre y apellido y estar debidamente registrado. Pero especialmente en zonas rurales, muchos de los niños nacidos no tienen partida de nacimiento y, por lo tanto, tampoco DNI de menores de edad. Ello puede deberse a la lejanía respecto a la entidad registral o el desconocimiento de los padres. Es por ello, que el Estado peruano ofrece el servicio de emisión de DNI de menores de manera gratuita para cumplir con su objetivo de plena identificación de la población nacional, además de acceder al servicio de salud estatal para lo cual es exigible presentar el DNI del menor. Además, el beneficiario que reciba el dinero deberá contar con DNI vigente para poder realizar el cobro respectivo. 
Para la elección de los beneficiarios, el programa realiza un proceso de selección estándar que consta de tres pasos, y que busca así realizar una eficiente asignación del presupuesto del programa para que efectivamente se destine a las familias que realmente se encuentren en situación de extrema pobreza. Estas etapas son (IEP 2009 p. 22-23):

\section{Focalización geográfica}

Esta primera etapa sirve para identificar los distritos sobre los cuales tendrá intervención el Programa JUNTOS, para lo que se hace uso del Índice ponderado geográfico a nivel distrital, que está compuesto por: (http://www.juntos.gob.pe/index.php/usuarios/cobertura-geografica)

- Índice de pobreza

- Tasa de desnutrición crónica infantil en menores de 5 años

- Índice de número de niños menores a 3 años.

Otro indicador menos conocido pero igualmente utilizado para la identificación geográfica es el grado de afectación de la violencia política en la región. (IEP 2009 p. 3). En esta etapa, lo que se busca es identificar las áreas con mayor población en situación de pobreza y pobreza extrema, para luego pasar a la identificación de los hogares más pobres dentro de los pobres, lo que se realiza en la siguiente etapa.

Para los distritos seleccionados se identifican aquellos centros poblados que cuenten con establecimientos de salud e instituciones educativas.

2. Focalización de Hogares (censo)

En esta etapa, se busca identificar los hogares que recibirán la ayuda de JUNTOS, para lo cual, el INEI aplica un cuestionario sobre la situación socioeconómica de los hogares. Es, en base a estos resultados, que se escoge a los hogares, de los distritos previamente seleccionados en la primera etapa, que recibirán las transferencias monetarias del programa. Así se asegura que el dinero se transfiera a las familias en real situación de extrema pobreza y que necesitan verdaderamente del dinero para mejorar sus condiciones de vida. 


\section{Validación Comunal}

En esta última etapa del proceso, se busca la legitimación social del Programa (IEP 2009 p. 3) a la vez que se corrigen los errores que puedan haberse suscitado en la focalización hecha en las dos etapas anteriores. Se realiza una asamblea en las comunidades seleccionadas y se presenta la lista de las potenciales familias beneficiarias, teniendo la posibilidad de retirar a aquellas que según percepción comunal no merezcan recibir el dinero del programa pues su condición económica no lo amerita. Sin embargo, esta elección final por parte de los pobladores es subjetiva, pues depende de la comunidad $\mathrm{y}$, en algunos casos, pueden ser influenciados o forzados a incluir familias que no ameritan pertenecer al programa y retirar hogares que sí necesiten el beneficio monetario. También existen los conflictos entre beneficiarios, que pueden llevar a una exclusión del programa por razones ajenas al cumplimiento de las condicionalidades oficiales.

Luego de la validación por parte de la comunidad, la lista de beneficiarios finales, que firman el Acuerdo de Compromiso, se envía al Banco de La Nación para que éste pueda abrir cuentas de ahorro a nombre de los beneficiarios y realizar el respectivo abono bimestral. Las fechas y los lugares de pago se publican mediante la radio, las autoridades de cada distrito y los promotores del programa, tanto en castellano como en el idioma nativo de la comunidad. Es por ello, que una de las condiciones a cumplir es que también, las personas mayores de 18 años dentro de los hogares beneficiarios también cuenten con DNI, especialmente las madres que son las encargadas de recibir el dinero.

Con la finalidad de controlar que los beneficiarios cumplan con las condicionalidades antes mencionadas, el Programa, a través de sus promotores, se realiza un monitoreo trimestral en las comunidades en las que opera, verificando que en efecto accedan a los servicios de salud y educación.

\subsubsection{Identificación y Selección de beneficiarios}

Un problema crítico que tienen siempre los diversos programas sociales, sin importar su tipo, es la identificación y selección de beneficiarios (Ministerio de Economía y Finanzas [MEF] 2010 p.3); esto es porque que no hay una única manera de establecer la elegibilidad de una persona, familia u hogar para su ingreso a un programa social. Es en este 
punto donde se puede citar a la multidimensionalidad de la pobreza, pues algunos programas pueden establecer como criterio que el ingreso promedio per cápita de una persona, hogar o familia esté por debajo de la línea de pobreza o pobreza extrema para ser elegidos como beneficiarios de un programa, otro criterio puede establecer que sea ya no pobreza monetaria sino alimentaria, otro podría ser la pobreza de capacidades, no tener una vivienda adecuada o no poder acceder a servicios públicos adecuados, incluso se podría identificar a los potenciales beneficiarios ya no desde el punto de vista individual sino geográfico, es decir toda una comunidad, distrito o provincia; las posibilidades son muchas, y he ahí cuando se presenta un punto crítico.

Debido a esto, se producen fallas en la focalización de los beneficiarios de los diversos programas sociales, lo cual se ve reflejado finalmente en las altas tasas de filtración y de subcobertura de cada programa. Esto genera que los efectos sean menores a los esperados, así como generar desconfianza en el funcionamiento de los mismos.

El programa JUNTOS es el único que usa herramientas explícitas para focalizar y afiliar a sus beneficiarios (MEF, 2010, pp. 3). Ya se mencionaron que la selección de los beneficiarios va desde la focalización general, es decir la geográfica, hasta la validación por parte de las comunidades. Pero para llegar al punto de selección se debe realizar el procedimiento de determinar la elegibilidad, y es aquí donde se involucra el Sistema de Focalización de Hogares (SISFHO), el que antes de aplicar el algoritmo de asignación de puntaje, se debe en principio cruzar información con fuentes relevantes para así poder identificar criterios específicos que puedan determinar si un individuo es elegible o no para un programa social en particular (MEF, 2010, pp.6). Para esto se cuenta con el Padrón General de Hogares (PGH), una base de datos donde se encuentra información socioeconómica de los hogares, la que se alimenta de dos fuentes: registros administrativos de los receptores de ingreso del sector formal de la economía (Planillas público y privadas) y el Censo de Hogares en sectores pobres; la información sobre los gastos en servicios básicos, complementan esta información y permiten mejorar la elegibilidad de los potenciales beneficiarios (MEF, 2010, pp.6). La figura 2.1 muestra lo mencionado con más claridad. 
Figura 2.1

Padrón General de Hogares (PGH) del SISFHO

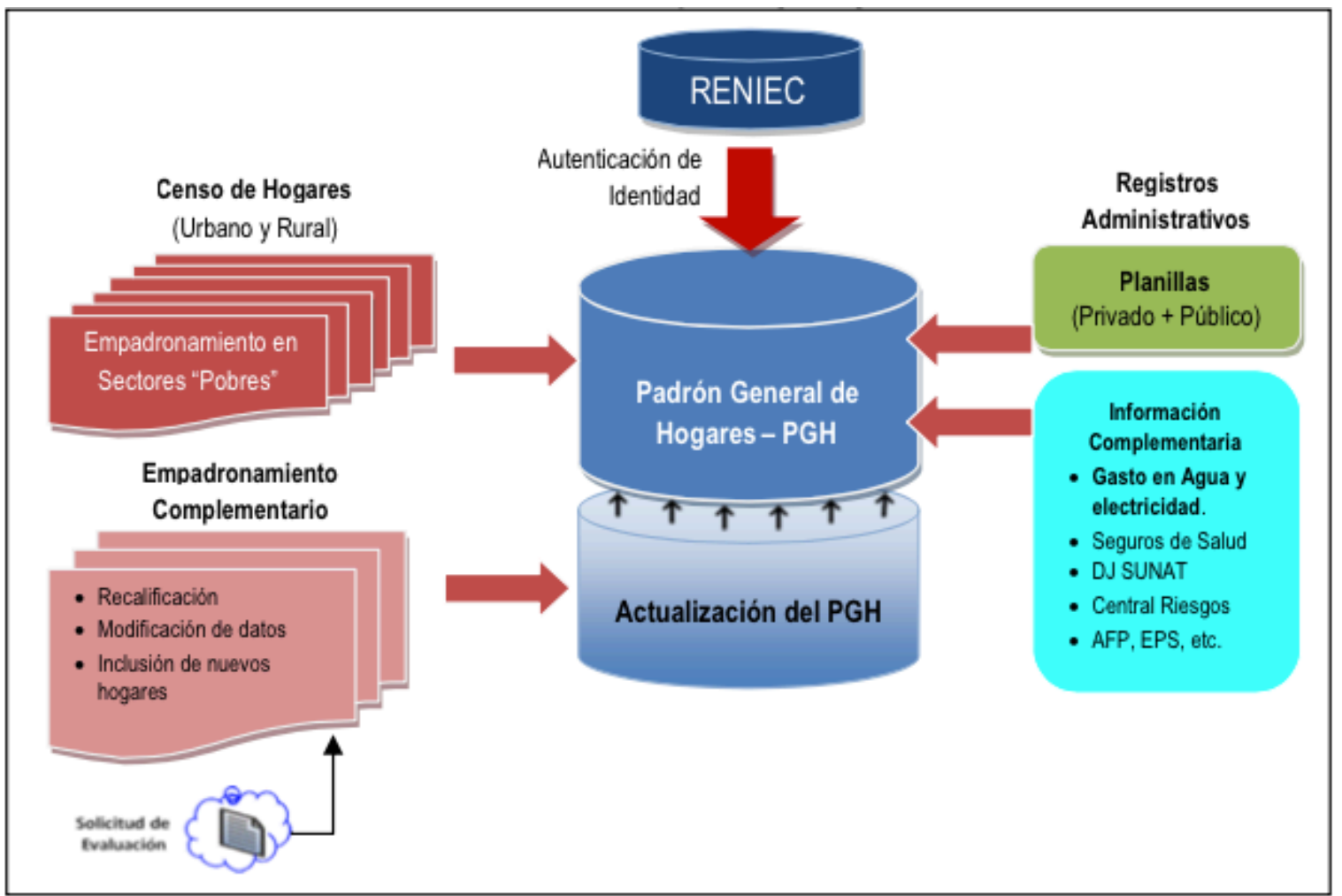

Fuente: Ministerio de Economía y Finanzas (MEF). (2010). Metodología de cálculo del Índice de Focalización de Hogares. pp. 6.

Es así que, para determinar si un hogar o persona es "elegible" o "no elegible" como beneficiario de un determinado programa social, se realiza a través de tres pasos (MEF 2010 p.7):

1. Se evalúa el nivel de ingreso tomando como fuente las planillas de ingreso. El punto de referencia para esto es un salario de S/. 1500, lo que sirve para calificar a un hogar como "pobre" o "no pobre".

2. Si no existe información sobre el ingreso o no se supera el umbral impuesto, se procede a utilizar los indicadores de calidad de vida que se encuentran en la Ficha Socioeconómica Única (FSU) y también de acuerdo al Índice de Focalización de Hogares (IFH).

3. Finalmente, se evalúa el gasto realizado en servicios básicos, como luz y/o agua. 
La figura 2.2 muestra la metodología usada en la elegibilidad de hogares.

Figura 2.2

Metodología para identificar a potenciales beneficiarios

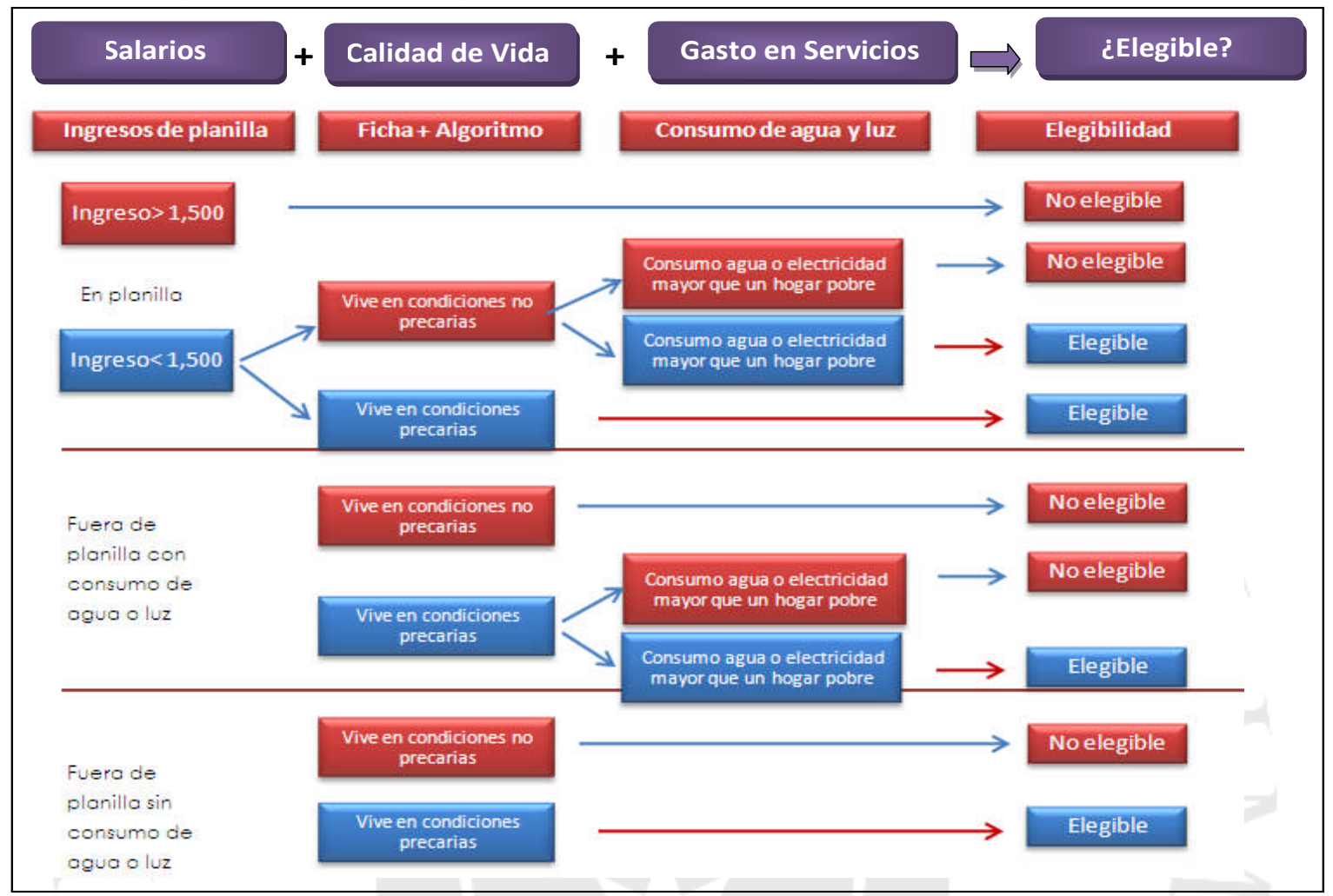

Fuente: Ministerio de Economía y Finanzas (MEF). (2010). Metodología de cálculo del Índice de Focalización de Hogares. pp. 8.

Entonces, la metodología del SISFHO para determinar la elegibilidad de potenciales beneficiarios es multidimensional, pues utiliza criterios de medición de pobreza monetaria, pero también contiene otras características "estructurales" de la pobreza que se pueden encontrar en el IFH y que da como resultado una mejor focalización de los hogares. (MEF, 2010, pp.20).

En la figura 2.3 se observa que para construirlo se empieza por seleccionar las variables asociadas al nivel de pobreza, luego se escoge el método estadístico a utilizarse para su construcción, y finalmente se seleccionan umbrales para calificar a los hogares según su nivel de pobreza. 
Figura 2.3

Procedimiento para la medición del Índice de Focalización de Hogares

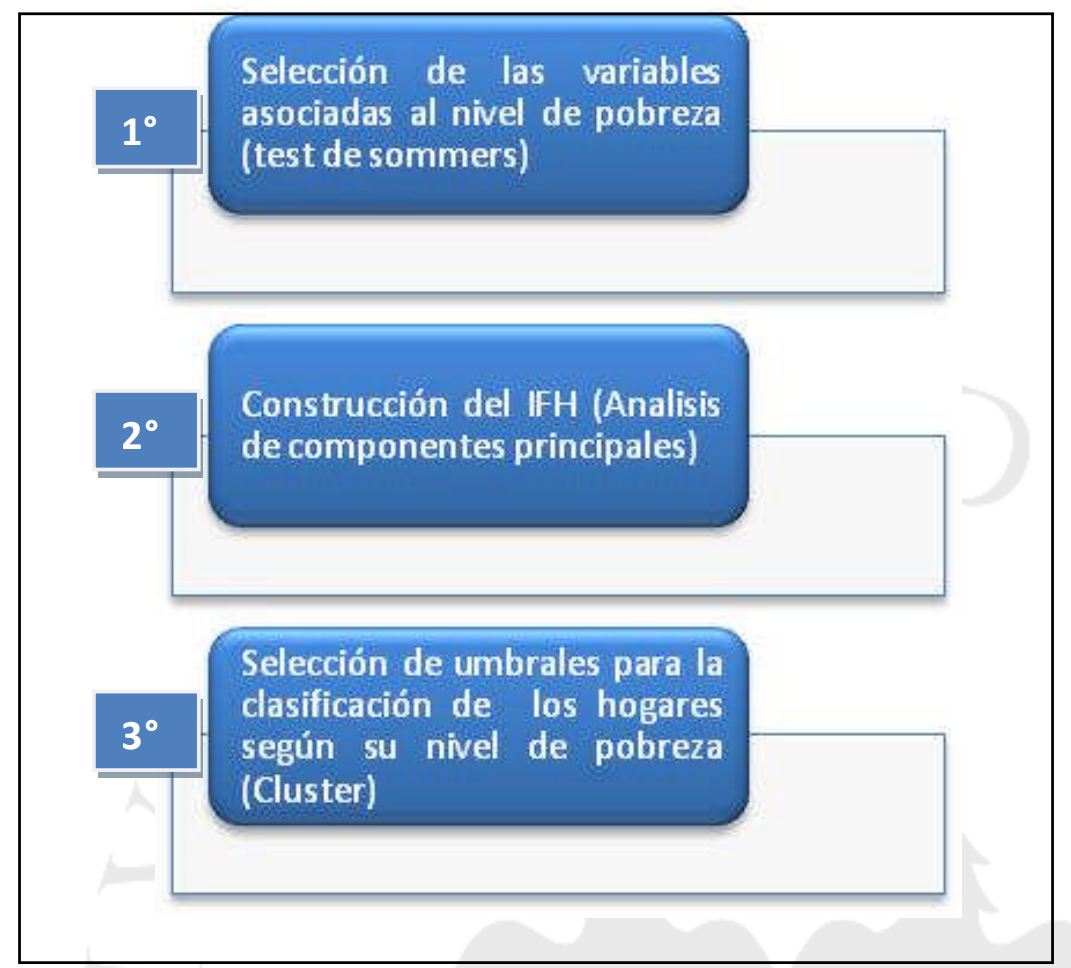

Fuente: Ministerio de Economía y Finanzas (MEF). (2010). Metodología de cálculo del Índice de Focalización de Hogares. pp. 10.

El conjunto de variables que se evalúan para la selección tienen su origen en la ENAHO 2009, y se refiere a las características del hogar, sus activos, educación, condiciones laborales de los miembros, hacinamiento, carga familiar, etc. (MEF, 2010, pp.11) Para la construcción del $\mathrm{IFH}^{9}$ se utiliza la técnica estadística del Análisis de Componentes Principales (ACP) ya que de acuerdo al MEF (2010) "permite captar la máxima cantidad de información de las variables originales y respeta las unidades de medida impuestas" (p.11); y de todos los componentes generados por el ACP se trabaja con aquellos que reproduzcan la mayor variabilidad de la matriz de datos, y es entonces que el primer componente se convierte en el IFH. Finalmente se deben de elegir umbrales de corte para el IFH y así determinar la variable de elegibilidad; así, los hogares que obtienen un IFH menor al del umbral se califican como "elegibles" y aquellos que superan el umbral, como "no elegibles".

Pero como no todos los instrumentos son perfectos, hay siempre errores, los cuales pueden ser de inclusión ("filtraciones) y de exclusión ("subcobertura") lo que es un reflejo de 
las características socioeconómicas de los hogares. Por ejemplo, pueden existir hogares que según la medición de pobreza monetaria no son calificados como pobres pero que tienen un bajo IFH, es decir, que aun no siendo pobres tienen una precaria calidad de vida. (MEF, 2010, pp.19)

\subsection{Cobertura y Presupuesto del Programa}

\section{Cobertura}

El Programa JUNTOS inició en cuatro regiones del país, las que presentaban el índice de pobreza más alto y cuyos hogares eran elegibles dadas sus condiciones de vida y situación de extrema pobreza. Las regiones con las que se inició el programa fueron Huancavelica, que en el año 2005 era el departamento más pobre del Perú con una incidencia de pobreza de 90.3\%; Huánuco, Ayacucho y Apurímac que se encontraban en un rango de incidencia de pobreza de $70 \%$ a $78 \%$ aproximadamente, y cuyos hogares fueron detectados en situaciones de extrema pobreza. (INEI, 2010, pp. 38). Hacia el 2011, JUNTOS estaba presente en 14 regiones del país, 9 más que las 4 iniciales, las que se fueron incorporando gradualmente al programa debido a la situación de pobreza que presentaban y atravesando la metodología de evaluación previamente descrita. Cabe resaltar que si bien se atiende a 14 regiones, no es una cobertura al 100\% pues luego de la selección geográfica, se realiza la selección de los hogares y la validación comunal, con lo que existen distritos que no son elegibles pues su situación socioeconómica y calidad de vida no lo amerita, en tanto otros distritos cuentan con hogares que si ameritan su participación en el Programa. La siguiente tabla muestra la cobertura de JUNTOS por departamento. 
Tabla 2.2

Cobertura del programa JUNTOS por regiones y distritos, 2005 - 2011

(regiones y distritos)

\begin{tabular}{|c|c|c|l|}
\hline $\mathbf{A n ̃ o}$ & $\mathbf{N}^{\circ}$ Regiones & Distritos & \multicolumn{1}{|c|}{ Regiones } \\
\hline $\mathbf{2 0 0 5}$ & 4 & 70 & Apurímac, Ayacucho, Huancavelica, Huánuco \\
\hline $\mathbf{2 0 0 6}$ & 9 & 320 & $\begin{array}{l}\text { Ancash, Apurímac, Ayacucho, Cajamarca, } \\
\text { Huancavelica, Huánuco, Junín, La Libertad, Puno }\end{array}$ \\
\hline $\mathbf{2 0 1 0}$ & 14 & 638 & $\begin{array}{l}\text { Amazonas, Ancash, Apurímac, Ayacucho, } \\
\text { Cajamarca, Cusco, Huancavelica, Huánuco, Junín, } \\
\text { La Libertad, Loreto, Pasco, Piura, Puno }\end{array}$ \\
\hline $\mathbf{2 0 1 1}$ & 14 & 646 & $\begin{array}{l}\text { Amazonas, Ancash, Apurímac, Ayacucho, } \\
\text { Cajamarca, Cusco, Huancavelica, Huánuco, Junín, } \\
\text { La Libertad, Loreto, Pasco, Piura, Puno }\end{array}$ \\
\hline
\end{tabular}

Fuente: Programa Nacional de Apoyo Directo a los más Pobres JUNTOS / Usuarios / Cobertura Geográfica. Recuperado de http://www.juntos.gob.pe

Elaboración: Propia

A finales del año 2011, el programa JUNTOS incorporaba a 492,871 hogares que se encontraban en situación de pobreza y pobreza extrema; hasta dicho periodo se realizó la transferencia monetaria a 474,064 hogares que cumplieron sus corresponsabilidades y entre los que se encuentran 995,592 niños y 9,415 madres gestantes. (http://www.juntos.gob.pe/index.php/usuarios/quienes). 
Figura 2.4

Cobertura del programa JUNTOS, 2005-2011

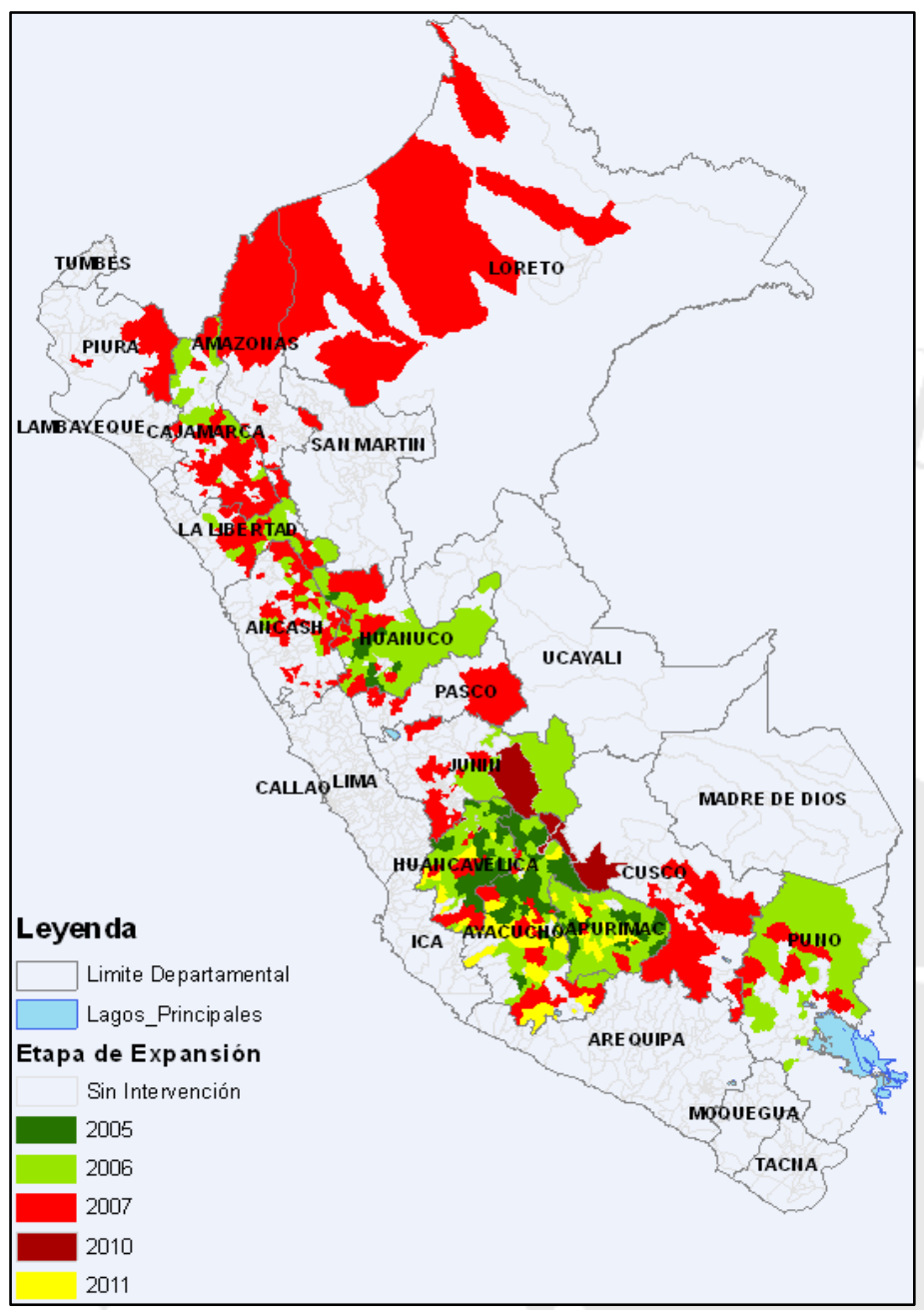

Fuente: Programa Nacional de Apoyo Directo a los más Pobres JUNTOS. Usuarios / Cobertura Geográfica. Recuperado de http://www.juntos.gob.pe

La figura 2.4 muestra la cobertura por regiones que tiene el programa JUNTOS desde sus inicios en el 2005 hacia el último año, 2011.

Se puede apreciar que si bien el programa se inició con cuatro regiones, éstas no fueron cubiertas en su totalidad al inicio, sino que la cobertura de muchos distritos se realizó de manera gradual a través de los siete años que viene funcionando. De las tres regiones naturales del Perú, la que más cobertura del programa recibe es la Sierra, seguida por la Selva y con menos presencia en la Costa.

Se muestra en la Tabla 2.3, el número de hogares beneficiarios del programa, así como el número de personas y el monto per cápita que le correspondería a cada una. Las 
transferencias monetarias se realizan bimensualmente y el monto entregado es de S/. 200, por lo que se asume un monto de S/.100 mensuales entregados a cada hogar.

Tabla 2.3

Cobertura de hogares y personas del programa JUNTOS, 2007 - 2011

(número de hogares, personas y Nuevos Soles)

\begin{tabular}{|l|c|c|c|c|c|}
\hline & $\mathbf{2 0 0 7}$ & $\mathbf{2 0 0 8}$ & $\mathbf{2 0 0 9}$ & $\mathbf{2 0 1 0}$ & $\mathbf{2 0 1 1}$ \\
\hline Cobertura hogares & 353,067 & 420,491 & 409,610 & 471,511 & 502,822 \\
\hline Cobertura personas & $1,941,869$ & $2,312,701$ & $2,252,855$ & $2,593,311$ & $2,765,521$ \\
\hline Transferencias monetarias S/. & $\mathrm{S} / .100 .00$ & $\mathrm{~S} / .100 .00$ & $\mathrm{~S} / .100 .00$ & $\mathrm{~S} / .100 .00$ & $\mathrm{~S} / .100 .00$ \\
\hline Transferencias monetarias per cápita S/ & $\mathrm{S} / .20 .41$ & $\mathrm{~S} / .20 .83$ & $\mathrm{~S} / .21 .28$ & $\mathrm{~S} / .21 .28$ & $\mathrm{~S} / .21 .28$ \\
\hline
\end{tabular}

Fuente: CEPAL. PTC. Base de Datos de Protección Social no contributiva en América Latina y el Caribe / Perú. Recuperado de http://dds.cepal.org

Aquí se puede apreciar que la cobertura de hogares desde el 2007 al 2010 fue ascendente, a excepción del año 2009 donde se redujo el número de hogares beneficiarios del programa, lo que puede deberse a factores como la graduación de los beneficiarios una vez superada su condición de pobreza, o debido a una mejor focalización del programa, sea en la selección geográfica, en la selección de hogares o en la validación comunal.

De las 14 regiones en las que el programa JUNTOS interviene, cinco se encontraban en el grupo 1 de incidencia de la pobreza en el 2011, con un porcentaje entre 53\% y 57\%; cinco pertenecen al grupo 2, con un promedio de 42\%; y, cuatro regiones pertenecen al grupo 3, con un máximo de $31 \%$ de incidencia de la pobreza (INEI, 2012, pp. 15) como se puede observar en la tabla 2.4 . 
Tabla 2.4

Incidencia de la pobreza por grupo de departamentos, 2005 y 2011

(porcentaje)

\begin{tabular}{|c|c|c|c|c|c|c|}
\hline Grupo & Departamentos & \multicolumn{2}{|c|}{2005} & Departamentos & \multicolumn{2}{|c|}{2011} \\
\hline 1 & Huancavelica & \multicolumn{2}{|c|}{$90.3 \%$} & $\begin{array}{l}\text { Huánuco, Huancavelica, } \\
\text { Apurímac, Ayacucho, } \\
\text { Cajamarca }\end{array}$ & $53 \%$ & $57 \%$ \\
\hline 2 & $\begin{array}{l}\text { Cajamarca, Amazonas, } \\
\text { Loreto, Huánuco, Pasco, } \\
\text { Ayacucho, Apurímac, } \\
\text { Puno }\end{array}$ & $60 \%$ & $77.3 \%$ & $\begin{array}{l}\text { Loreto, Amazonas, } \\
\text { Pasco, Puno, Piura }\end{array}$ & $35 \%$ & $48 \%$ \\
\hline 3 & $\begin{array}{l}\text { Piura, Lambayeque, La } \\
\text { Libertad, San Martín, } \\
\text { Ancash, Ucayali, Junín, } \\
\text { Cusco }\end{array}$ & $40 \%$ & $58.6 \%$ & $\begin{array}{l}\text { San Martín, } \\
\text { Lambayeque, Cusco, La } \\
\text { Libertad, Ancash, Junín }\end{array}$ & $24 \%$ & $31 \%$ \\
\hline 4 & $\begin{array}{l}\text { Lima, Ica, Madre de } \\
\text { Dios, Arequipa, } \\
\text { Moquegua, Tacna }\end{array}$ & $20 \%$ & $32.9 \%$ & Tacna, Lima & $16 \%$ & $17 \%$ \\
\hline 5 & Tumbes & & & $\begin{array}{l}\text { Tumbes, Ucayali, } \\
\text { Arequipa, Ica, } \\
\text { Moquegua }\end{array}$ & $11 \%$ & $14 \%$ \\
\hline 6 & --- & & & Madre de Dios & $2 \%$ & $6 \%$ \\
\hline
\end{tabular}

Fuente: INEI. Evolución de la pobreza al 2010 y Evolución de la pobreza al 2011. Recuperado del sitio de Internet del Ministerio del Ambiente: http://sinia.minam.gob.pe/documentos/informe-tecnico-evolucionpobreza-2010 y del sitio de Internet del INEI: https://www.inei.gob.pe/media/cifras de pobreza/presentaciondel-jefe.pdf

Al observar la tabla 2.4 y la figura 2.1 , se puede observar que uno de los departamentos en los que se inició el Programa, Huancavelica, fue el que mayor reducción de la incidencia de la pobreza presenta, reduciendo más del 30\% desde 2005 a 2011, mientras que Huánuco presenta una reducción menor, de aproximadamente $20 \%$, en el mismo período.

\section{Presupuesto}

Antes de analizar el presupuesto del programa JUNTOS, es preciso primero revisar el gasto social que realiza el Estado, como parte del PBI, y el gasto social destinado a los sectores de educación como salud, para observar si los objetivos nacionales están alineados con la asignación de recursos para realizar dichas acciones. 
Tabla 2.5

Gasto Social Total, en Educación y en Salud, 2007 - 2010

(Porcentaje del PBI)

\begin{tabular}{|c|c|c|c|c|c|c|c|}
\hline & & \multirow{2}{*}{\multicolumn{2}{|c|}{ Variables }} & \multicolumn{4}{|c|}{ Período } \\
\hline & & & & 2007 & 2008 & 2009 & 2010 \\
\hline \multirow{3}{*}{$\begin{array}{l}\text { País } \\
\text { Cobertura }\end{array}$} & \multirow{3}{*}{$\begin{array}{l}\text { Perú / Gobierno } \\
\text { General }\end{array}$} & \multirow{3}{*}{ Indicador } & Gasto social como $\%$ del PIB & 8.82 & 8.71 & 10.01 & 9.95 \\
\hline & & & $\begin{array}{l}\text { Gasto social en educación como \% } \\
\text { del PIB }\end{array}$ & 2.76 & 2.79 & 3.19 & 3.10 \\
\hline & & & $\begin{array}{l}\text { Gasto social en salud como \% del } \\
\text { PIB }\end{array}$ & 1.27 & 1.45 & 1.60 & 1.58 \\
\hline
\end{tabular}

Fuente: CEPAL. Gasto Social en América Latina y el Caribe / Estadísticas. Recuperado de http://dds.cepal.org/gasto/indicadores/

El porcentaje del PBI asignado para el gasto social fue creciente hasta el 2009, pero descendió al año siguiente, en especial el gasto en educación. Pero así mismo, es importante también conocer cuál es la estructura del Gasto Público Social (GPS), para saber a qué sector se le está dando la mayor importancia y si se corresponde con los objetivos para combatir la pobreza. 
Tabla 2.6

Gasto social en educación y salud, 2007 - 2010

(participación)

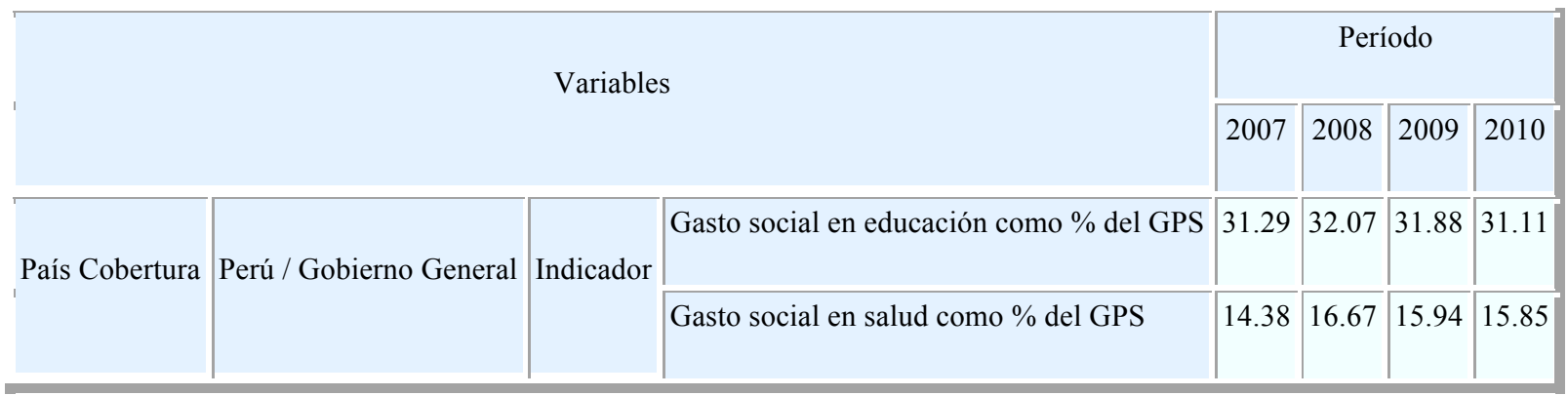

Fuente: CEPAL. Gasto Social en América Latina y el Caribe / Estadísticas. Recuperado de http://dds.cepal.org/gasto/indicadores/

El gasto realizado tanto en educación como en salud, como porcentaje del Gasto Público Social (GPS), ha venido disminuyendo a partir de 2008 y hasta el 2010, lo que se corresponde con las cifras del cuadro $\mathrm{N}^{\circ} 2.6$, para el periodo 2009 a 2010, cuando el gasto en educación y salud como porcentaje del PBI se redujo en $0.09 \%$ y $0.02 \%$, respectivamente.

A lo largo de los 4 años, el gasto en salud ha aumentado en términos del GPS, pasando de $14.38 \%$ a $15.85 \%$, mientras que en educación, el gasto disminuyó, aunque no de manera abrupta, de $31.29 \%$ a $31.11 \%$. Sin embargo, el gasto en ambos rubros, como porcentaje del PBI, aumentó durante el mismo período, de $2.76 \%$ a 3.10\% en Educación, y de $1.27 \%$ a $1.58 \%$ en Salud, siendo este sector el que mayor incremento registró $(0.31 \%)$ desde 2007 a 2010.

El presupuesto del programa JUNTOS ha variado de manera positiva durante el periodo 2007-2011 y, en especial, la ejecución del mismo, observándose que para el año 2009, se ejecutó casi en la totalidad el presupuesto asignado al Programa ese año. 
Tabla 2.7

Ejecución del presupuesto asignado al programa JUNTOS, 2007 - 2011

(nuevos Soles y porcentaje)

\begin{tabular}{|c|cc|cc|c|}
\hline \multirow{2}{*}{ AÑ } & \multicolumn{2}{|c|}{$\begin{array}{c}\text { PRESUPUESTO } \\
\text { INSTITUCIONAL } \\
\text { MODIFICADO }\end{array}$} & \multicolumn{2}{|c|}{$\begin{array}{c}\text { EJECUCION } \\
\text { PRESUPUESTAL }\end{array}$} & $\begin{array}{c}\text { \% EJECUCION DEL } \\
\text { PRESUPUESTO }\end{array}$ \\
\hline $\mathbf{2 0 1 1}$ & $\mathrm{S} /$. & $676,274,305.00$ & $\mathrm{~S} /$. & $640,111,558.96$ & $94.65 \%$ \\
\hline $\mathbf{2 0 1 0}$ & $\mathrm{S} /$. & $626,970,879.00$ & $\mathrm{~S} /$. & $612,864,073.22$ & $97.75 \%$ \\
\hline $\mathbf{2 0 0 9}$ & $\mathrm{S} /$. & $572,499,956.00$ & $\mathrm{~S} /$. & $571,741,273.00$ & $99.87 \%$ \\
\hline $\mathbf{2 0 0 8}$ & $\mathrm{S} /$. & $607,358,864.00$ & $\mathrm{~S} /$. & $534,630,755.00$ & $88.03 \%$ \\
\hline $\mathbf{2 0 0 7}$ & $\mathrm{S} /$. & $532,740,458.00$ & $\mathrm{~S} /$. & $497,369,771.00$ & $93.36 \%$ \\
\hline
\end{tabular}

Fuente: Programa Nacional de Apoyo Directo a los más Pobres JUNTOS. Usuarios / Cobertura Geográfica. Recuperado de http://www.juntos.gob.pe

Este presupuesto ${ }^{10}$ cuenta con distintos conceptos de gastos, pero es el rubro Otros Gastos, el más importante, pues está compuesto casi en su totalidad por las transferencias a los beneficiarios, representando en promedio un $90 \%$ del presupuesto total asignado al Programa anualmente; el otro rubro componente de Otros Gastos corresponde al concepto de Impuestos, multas y contribuciones, que se refiere al pago de arbitrios municipales.

Respecto a la ejecución del presupuesto, se observa que es el rubro de Otros Gastos, las transferencias monetarias a los beneficiarios, el que mayor porcentaje de avance presenta, llegando incluso en el año 2009 a ejecutarse en un 100\%, y, en los otros años, la ejecución de las transferencias sobrepasa el $90 \%$ del presupuesto asignado que, en todos los años, a excepción del 2010, es mayor que el porcentaje ejecutado del presupuesto total.

10 Existe una diferencia entre los montos del Presupuesto Total del año 2011 presentado en la Tabla $N^{\circ} 2.5$ y la Tabla $N^{\circ} 2.6$ que es propia de la fuente de origen de los mismos datos. En el Presupuesto Desagregado no se presenta el año 2007 pues el documento respectivo aparece en la fuente consultada más al parecer está dañado o ha sido retirado. 
Tabla 2.8

Porcentaje de ejecución del presupuesto total y de transferencias del programa JUNTOS, $2008-2011$

(nuevos soles y porcentaje)

\begin{tabular}{|c|c|c|c|c|}
\hline & CONCEPTO & PIM* & EJECUTADO & $\begin{array}{l}\text { \% } \\
\text { EJECUCIÓN }\end{array}$ \\
\hline \multirow[t]{3}{*}{2011} & Total & $\mathrm{S} / .639,877,130.00$ & S/. 627,175,358.00 & $98.01 \%$ \\
\hline & Otros Gastos & S/. 571,299,714.00 & S/. 566,022,394.00 & $99.08 \%$ \\
\hline & Porcentaje del Total & $89 \%$ & $90 \%$ & \\
\hline \multirow[t]{3}{*}{2010} & Total & S/. 626,970,879.00 & S/. 612,864,073.22 & $97.75 \%$ \\
\hline & Otros Gastos & S/. 566,708,870.00 & S/. 533,480,168.89 & $94.14 \%$ \\
\hline & Porcentaje del Total & $90 \%$ & $87 \%$ & \\
\hline \multirow[t]{3}{*}{2009} & Total & S/. 572,499,956.00 & S/. 571,741,273.00 & $99.87 \%$ \\
\hline & Otros Gastos & S/. 500,771,690.00 & S/. 500,754,385.00 & $100.00 \%$ \\
\hline & Porcentaje del Total & $87 \%$ & $88 \%$ & \\
\hline \multirow[t]{2}{*}{2008} & Total & S/. 607,358,864.00 & $\mathrm{S} / .534,630,755.00$ & $88.03 \%$ \\
\hline & Otros Gastos & S/. 532,903,750.00 & S/. 482,634,948.00 & $90.57 \%$ \\
\hline & \begin{tabular}{|l|} 
Porcentaje del Total \\
\end{tabular} & $88 \%$ & $90 \%$ & \\
\hline
\end{tabular}

Fuente: Programa Nacional de Apoyo Directo a los más Pobres JUNTOS. Usuarios / Cobertura Geográfica / Ejecución Presupuestal / Informes Trimestrales. Recuperado de http://www.juntos.gob.pe *PIM: Presupuesto Institucional Modificado

Aún no se puede asegurar una eficiencia en el gasto que realiza el programa respecto a las transferencias monetarias que asigna a los hogares, pues ésta depende de otros factores respecto a su operatividad pero, en general, se puede señalar que el presupuesto asignado para el objetivo final del programa, se ha ejecutado correctamente a lo largo del periodo de estudio. 


\subsection{Resultados del Programa}

Se presentarán los resultados obtenido por el programa JUNTOS durante el período de estudio de esta investigación, 2007 - 2011, tanto de fuentes primarias como de fuentes secundarias, es decir de la información recogida a partir de la institución responsable de los datos estadísticos nacionales, INEI, así como de estudios anteriores realizados por diversas instituciones respecto de los resultados y funcionamiento del programa JUNTOS.

Los resultados del mencionado Programa se presentarán en orden y de acuerdo a las condicionalidades que deben cumplir los beneficiarios, que se mencionaron anteriormente en este capítulo.

\subsubsection{Educación}

En educación se exige que los menores de 14 años pertenecientes a un hogar beneficiario, asistan al menos al $85 \%$ de las clases impartidas. Se exige la asistencia y no la matricula porque la segunda no garantiza necesariamente que los menores asistan a la escuela, sino que puedan realizar otras labores, como trabajar, fuera del hogar, o dentro del mismo, apoyando en las actividades productivas de la familia, como la agricultura o la ganadería.

Por tanto la matrícula escolar no provee resultados adecuados para medir el impacto que tiene el programa en este sector, mientras que la asistencia sí lo hace, pues garantiza que los menores se dediquen, al menos de manera parcial, a estudiar y no solamente a trabajar.

Sin embargo, los resultados del programa no permiten realizar una evaluación sobre el efecto que tiene JUNTOS en el aprendizaje escolar que puedan alcanzar los niños y niñas de los hogares beneficiarios. 


\section{Figura 2.5}

Inasistencia escolar en beneficiarios y no beneficiarios, en Huánuco, 2011 (porcentaje)

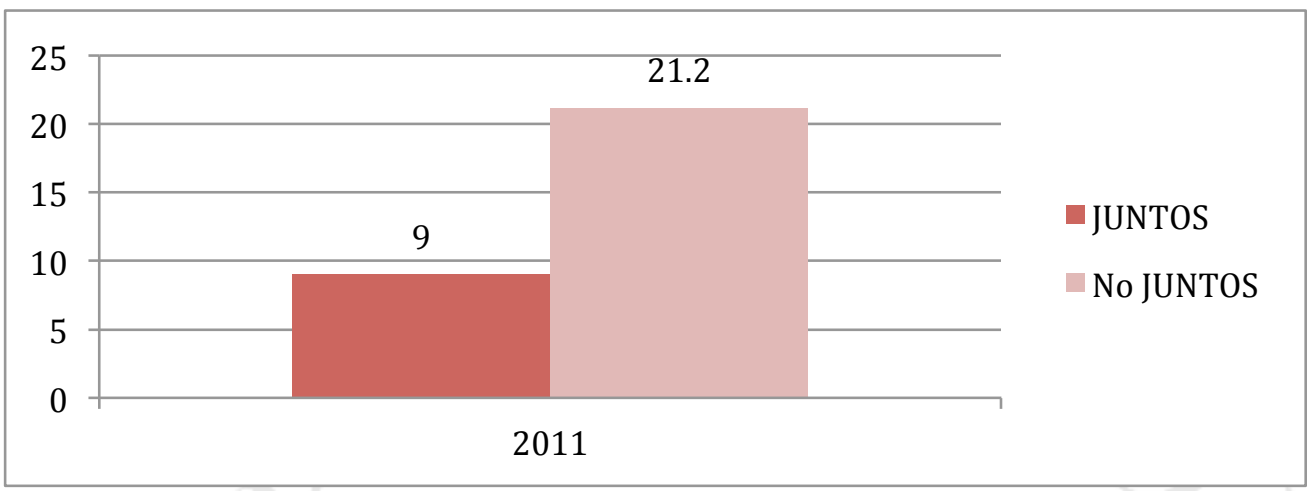

Fuente: Programa Nacional de Apoyo Directo a los más Pobres JUNTOS. (2011). Reporte Gerencial del programa JUNTOS Región Huánuco. Recuperado de http://www.juntos.gob.pe/images/noticias/2011/03/Huanuco8.pdf

En la figura 2.5, se observa que en el año 2011, la inasistencia escolar de los niños pertenecientes a hogares beneficiarios del programa fue menor a la tasa de inasistencia a clases que presentan los no beneficiarios de JUNTOS, siendo esta brecha entre ambas categorías bastante amplia.

Aun no se puede afirmar si esto se debe a un cambio de comportamiento debido al programa o no, pero dado que la asistencia como mínimo al $85 \%$ de las clases por parte de los niños beneficiarios es una condición exigida, esto podría explicar la diferencia observada. 
Figura 2.6

Incremento general en la tasa de matrícula y asistencia, 2007 - 2011

(porcentaje)

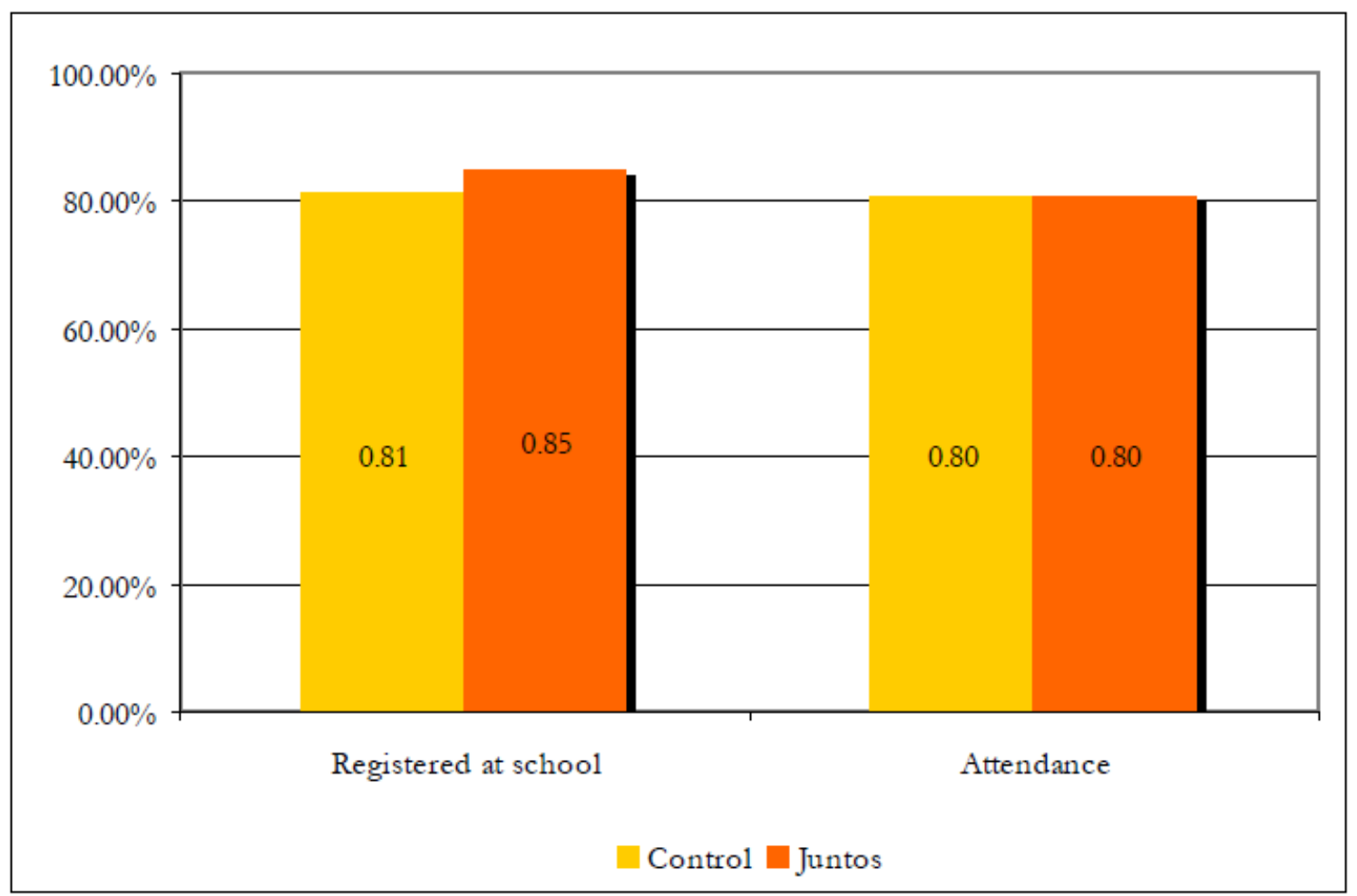

Fuente: Perova, E., Vakis, R. (2009). Welfare impacts of the Juntos Program in Peru: evidence from a nonexperimental evaluation. Recuperado del sitio de Internet del Programa JUNTOS:

http://www.juntos.gob.pe/modulos/mod_legal/archivos/Evaluacion_Cuasi-Experimental1.pdf pp. 21

Estudios de Perova y Vakis (2009), muestran que el porcentaje de niños matriculados en la escuela es mayor cuando estos pertenecen al programa que cuando no pertenecen (grupo de control); sin embargo, no se registró diferencia en la asistencia escolar. (p. 21).

\subsubsection{Nutrición}

Evidencia teórica como empírica (Sánchez y Jaramillo 2012) sugiere que las inversiones realizadas en los primeros años de vida de una persona tiene un efecto de largo plazo en la acumulación de capital humano, que conlleva a un efecto en el desempeño del mismo individuo una vez insertado en el mercado laboral. (p. 1). Así mismo, se conoce que una adecuada nutrición durante los 3 primeros años de vida de una persona, tiene efectos positivos en su desempeño educativo; es por ello que uno de los efectos que busca generar el 
programa es el de reducir la desnutrición crónica infantil en niños menores de 5 años. El siguiente cuadro muestra la evolución de la desnutrición crónica, según el patrón NCHS (Centro Nacional de Estadísticas de Salud, por sus siglas en inglés), para los años 2007 a 2011.

Figura 2.7

Proporción de niños menores de 5 años con desnutrición crónica (NCHS) en el ámbito del programa Juntos, $2007-2011$ (porcentaje)

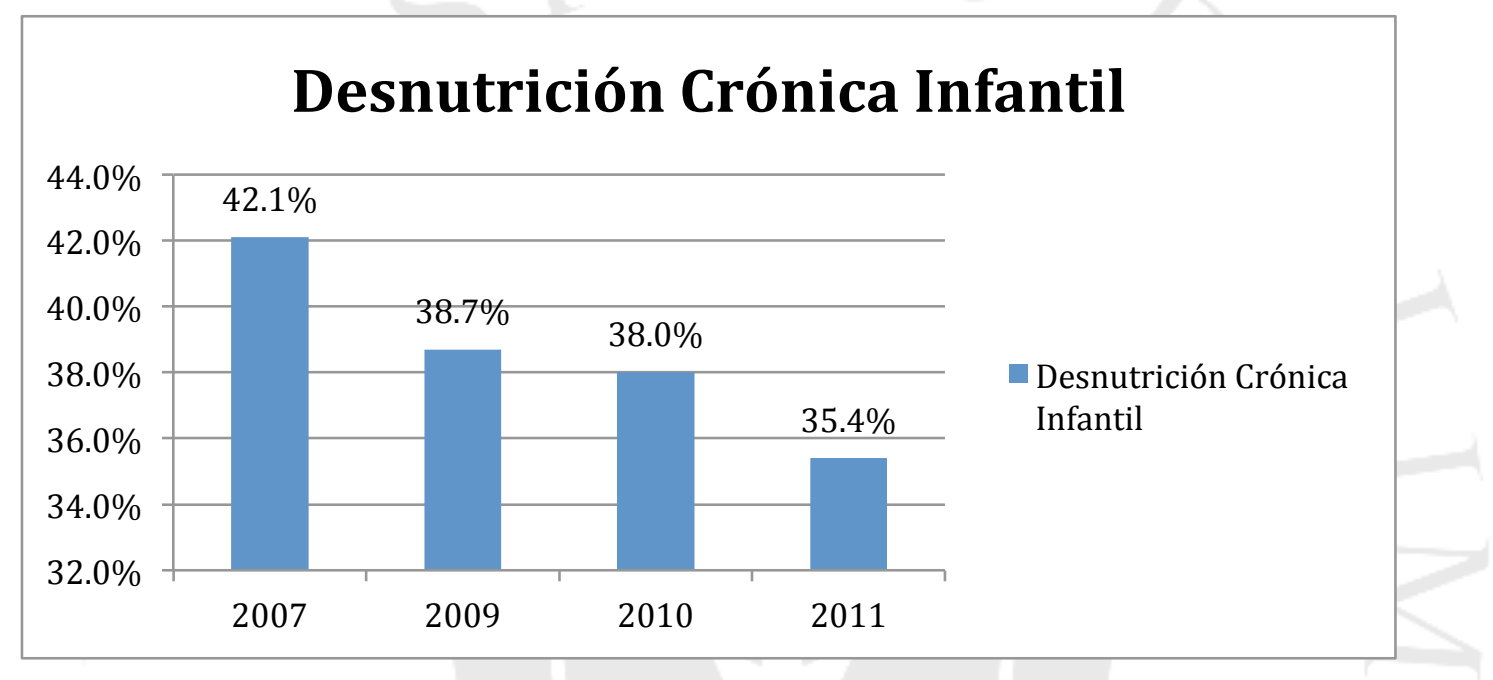

Fuente: INEI. (2012). Indicadores de Resultados de los Programas Estratégicos 2000 - 2011. Lima: Autor. pp 27.

Como se observa, la desnutrición infantil crónica hacia el 2007, afectaba al $42 \%$ de la población menor de 5 años perteneciente al programa. Para el último año, este porcentaje fue menor, experimentando una reducción de aproximadamente $7 \%$ en los 4 años.

La figura 2.8, se muestra la evolución de la desnutrición crónica infantil a nivel nacional; a nivel departamental, se eligió presentar sólo el departamento de Huánuco, que es ámbito de estudio de esta investigación y debido a ser uno de los departamentos donde se inició el Programa JUNTOS en el 2005 y por sus indicadores de educación, salud y nutrición. 
Figura 2.8

Proporción de menores de 5 años con desnutrición crónica según departamento (Patrón NCHS), Junio 2007 - 2011

(Porcentaje)

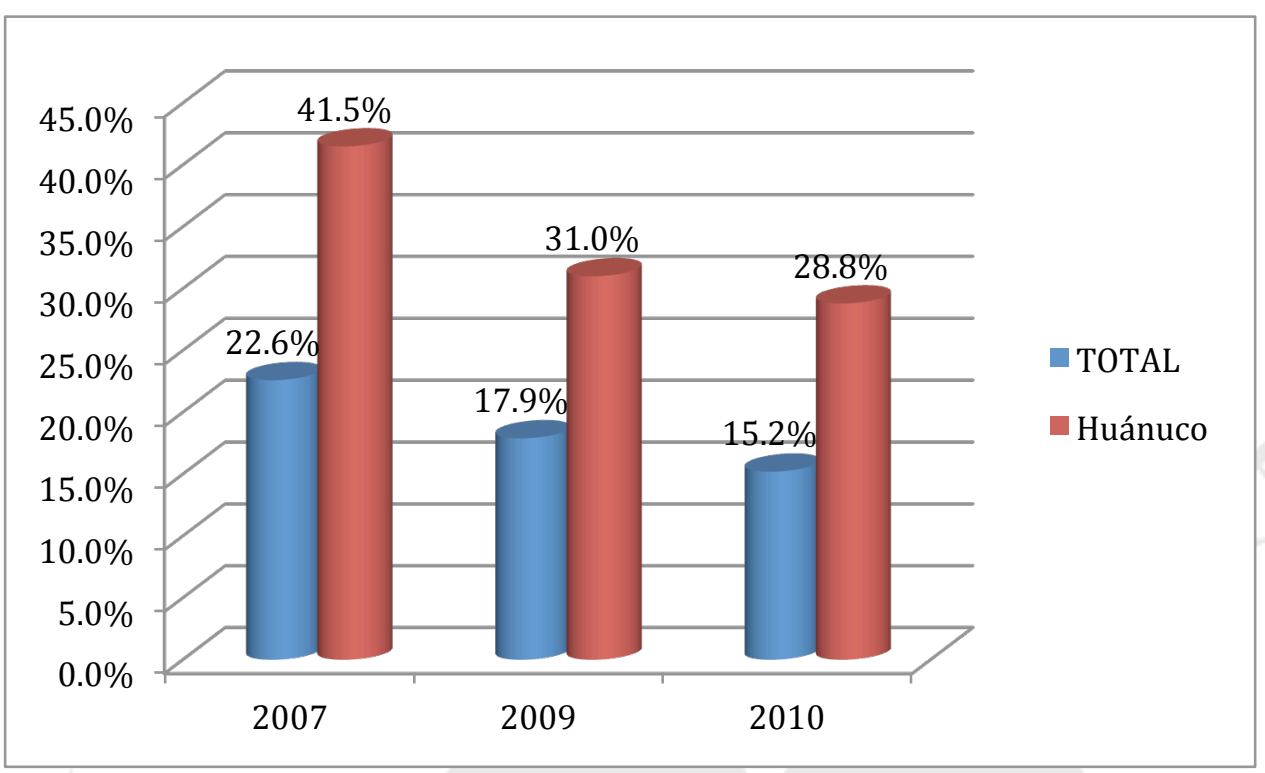

Fuente: INEI. (2012). Indicadores de Resultados de los Programas Estratégicos, 2000 - 2011. ENDES. Lima: Autor. pp 32.

A nivel nacional, la proporción de menores de 5 años en estado de desnutrición crónica se redujo en $7 \%$, en tanto que, para Huánuco, esta reducción fue de $12 \%$. Al comparar ambos resultados, se observa que la reducción de la desnutrición en la región Huánuco se dio en un mayor porcentaje que a nivel de todo el país. Una de las razones para la reducción de la desnutrición infantil en las regiones de cobertura del programa es el cambio en el consumo de alimentos que se genera en principio por la transferencia de dinero a los hogares beneficiarios. Se evidencia, según Perova y Vakis (2009), no sólo un mayor consumo alimentario sino también de alimentos con alto contenido nutricional que podría atribuirse al trabajo que realizan los promotores del programa. (p. 19-20). Es preciso recordar que una de las condiciones que requiere el programa es que los menores asistan periódicamente a controles de crecimiento y desarrollo, por lo que el cambio de comportamiento en consumo puede deberse también a esta condición dado que las familias beneficiarias pueden observar la evolución de la situación nutricional de sus hijos e hijas y cambiar sus patrones de consumo. 
Respecto al control de crecimiento y desarrollo completo de acuerdo a su edad, se observa que el resultado del programa en este indicador ha sido creciente, pasando de un $20 \%$ en el 2007 a un $60 \%$ en el último año. Esto puede deberse, principalmente debido a que los controles de crecimiento y desarrollo para los niños beneficiarios es de carácter obligatorio para continuar en el programa.

Figura 2.9

Proporción de menores de 3 años con controles de Crecimiento y Desarrollo (CRED) completo para su edad, en el ámbito del programa Juntos, 2007 - 2011

(Porcentaje)

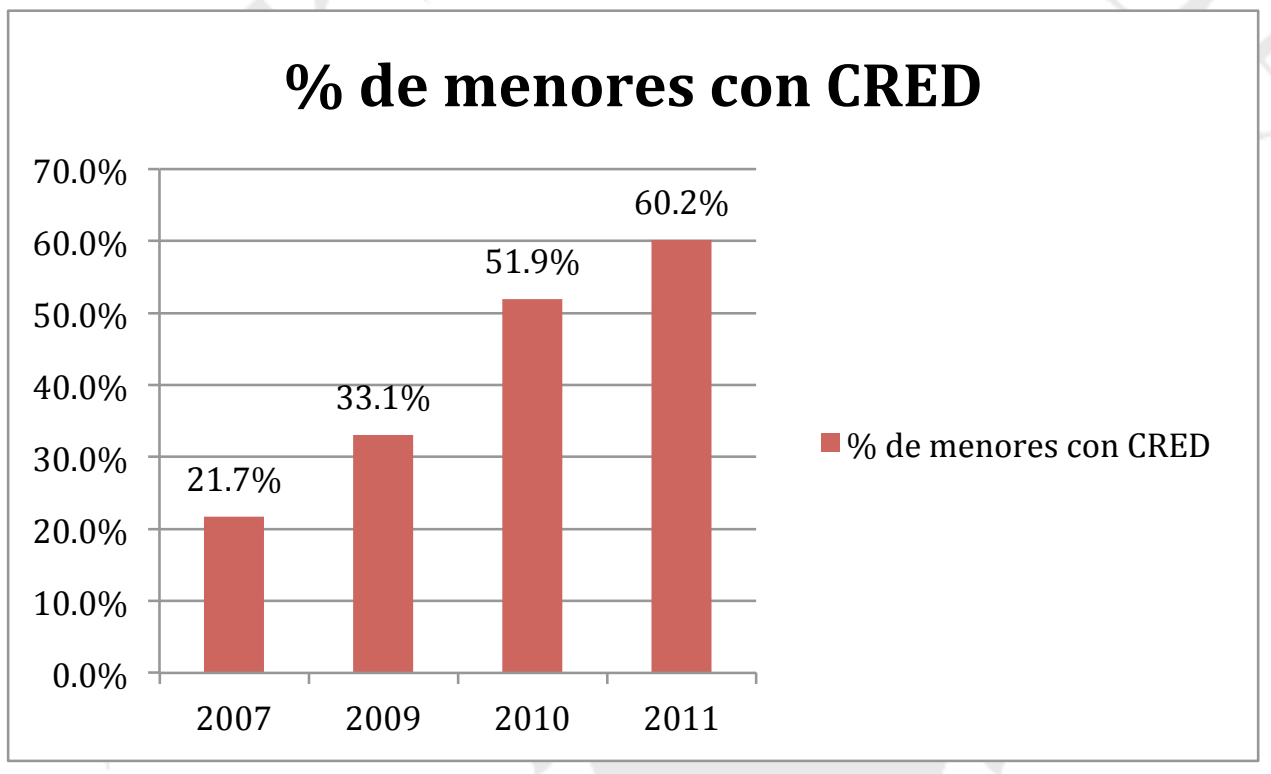

Fuente: INEI. (2012). Indicadores de Resultados de los Programas Estratégicos, 2000 - 2011. Lima: Autor. pp 66.

\subsubsection{Salud}

Uno de los principales indicadores en salud es la proporción de madres gestantes que reciben sus controles prenatales, asegurando un embarazo y nacimiento seguros y adecuados. Se puede apreciar, en el siguiente gráfico, que la proporción de madres gestantes que recibieron su primer control prenatal durante el primer trimestre de embarazo aumentó durante el periodo comprendido entre los años 2007 y 2011 en un 5\% aproximadamente, lo que en promedio significaría $1 \%$ por año. Cabe recordar que esta es una de las condicionalidades del programa que las madres deben cumplir para continuar recibiendo el beneficio económico. 
Figura 2.10

Proporción de mujeres gestantes que recibieron su primer control prenatal en el ler trimestre de gestación y proporción de mujeres gestantes que recibieron suplemento de hierro en el ámbito del Programa Juntos

$2007-2011$

(porcentaje)

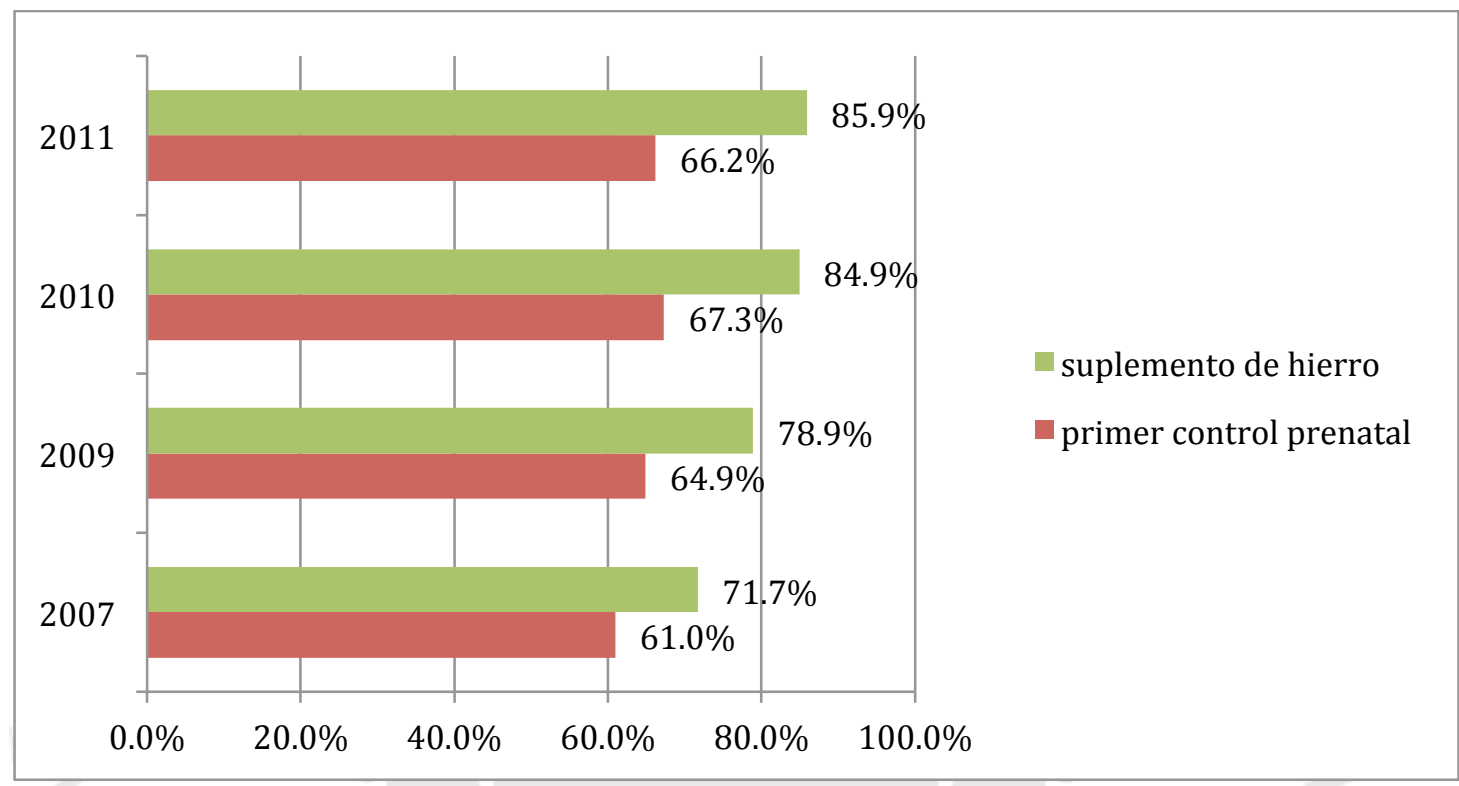

Fuente: INEI. (2012). Indicadores de Resultados de los Programas Estratégicos, 2000 - 2011. Lima: Autor. pp. 32.

Si bien el consumo de suplementos de hierro no es un requisito del Programa, se debe considerar debido a que contribuye a una mejor salud de la madre durante la etapa de embarazo, debido a la descalcificación que ocurre en este periodo; en el ámbito del programa se puede observar que el porcentaje de mujeres que consumieron suplementos de hierro durante su periodo de embarazo aumento en 14\% durante los 5 años, que en promedio, significa casi $3 \%$ por año, proporción mayor que el porcentaje que recibió su primer control prenatal, que si es condición indispensable del programa.

Otra de las condiciones que se exige en salud es la vacunación de los niños de los hogares beneficiarios. En la figura 2.11 se puede apreciar la evolución del porcentaje de niños menores de 3 años que cuentan con las vacunas completas de acuerdo a su edad dentro del accionar del programa, mientras que en el gráfico posterior se observa el mismo indicador pero a nivel nacional como a nivel del departamento de estudio de esta investigación. 
Figura 2.11

Proporción de menores de 3 años con vacunas básicas completas para su edad, en el ámbito del Programa Juntos, 2007 - 2011

(porcentaje)

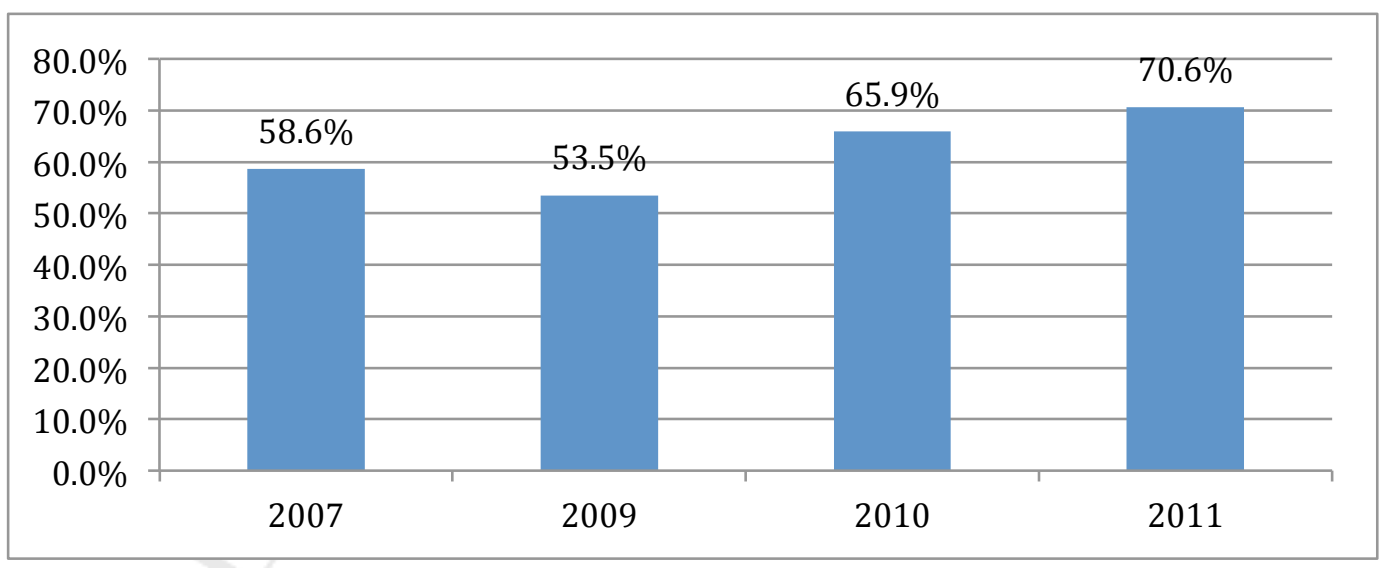

Fuente: INEI. (2012). Indicadores de Resultados de los Programas Estratégicos, 2000 - 2011. Lima: Autor. pp. 46.

Se puede observar que a lo largo de los cinco años, en las regiones que cubre JUNTOS, la proporción de menores de 3 años que se tienen sus vacunas completas ha aumentado en aproximadamente $12 \%$. En tanto que, a nivel nacional, se aprecia una tendencia primero descendente hacia 2009 y luego un ascenso a partir de ese año hacia el 2011, la misma situación que se presenta para el departamento de Huánuco. 


\section{Figura 2.12}

Proporción de menores de 3 años con vacunas básicas completas para su edad. Total nacional, región de Huánuco, 2007 - 2011

(porcentaje)

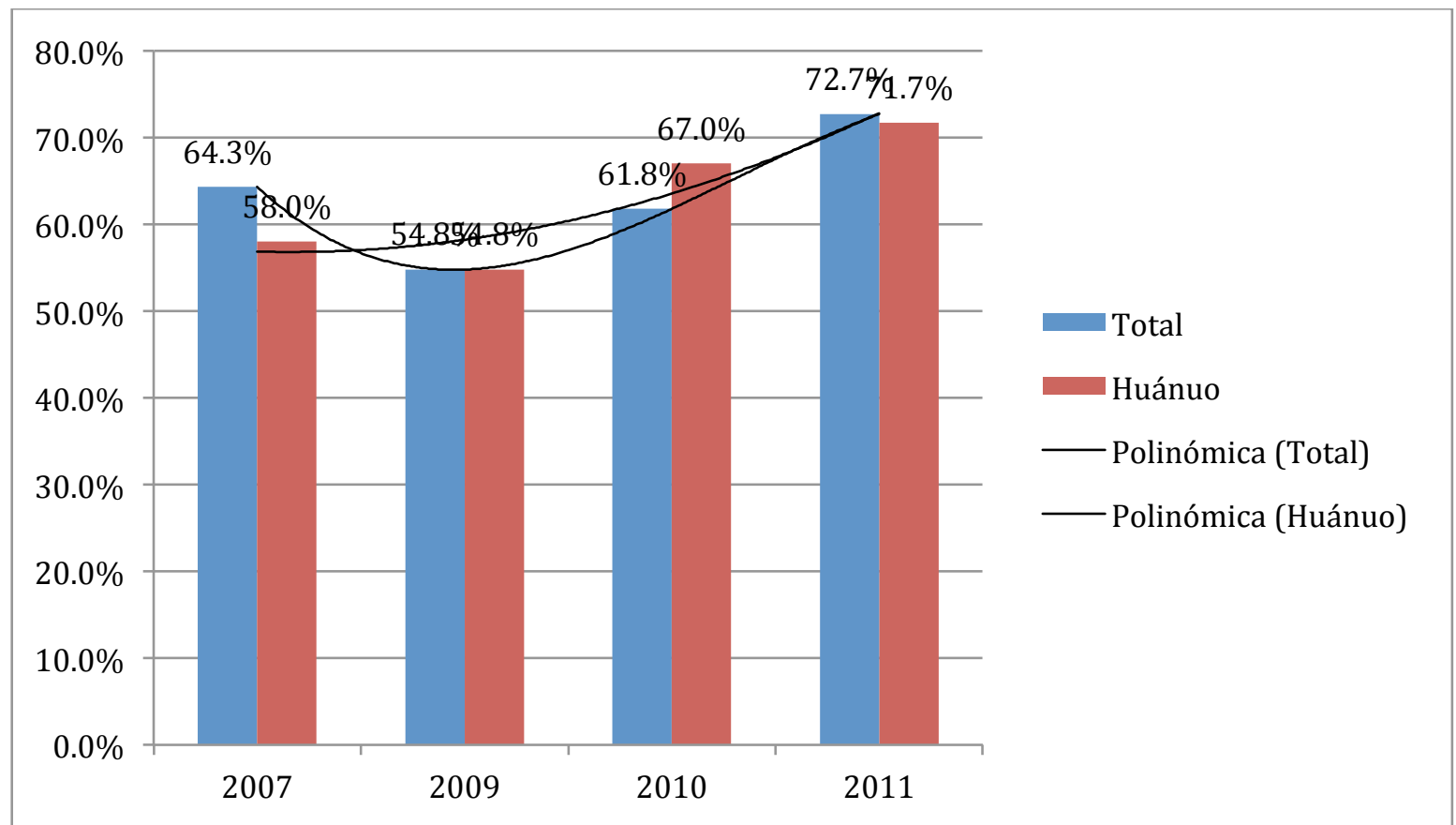

Fuente: INEI. (2012). Indicadores de Resultados de los Programas Estratégicos, 2000 - 2011. Lima: Autor. pp. 47. 


\section{CAPITULO 3 \\ ANÁLISIS DEL CONSUMO DE LOS BENEFICIARIOS Y DE LA SUBCOBERTURA DEL PROGRAMA JUNTOS EN HUÁNUCO}

El objetivo de este capítulo es contrastar las hipótesis para determinar si éstas son aceptadas o rechazadas. Se presentan los objetivos y las hipótesis, así como los aspectos metodológicos y los resultados hallados sobre el Programa JUNTOS en Huánuco.

\subsection{Objetivos}

\subsubsection{Objetivo General}

Estudiar el cambio en los patrones de consumo de las familias beneficiarias en Huánuco, en el período 2007-2011, como resultado de las transferencias realizadas por el programa JUNTOS, y las consecuencias generadas en la población como producto de una inadecuada cobertura de hogares por parte del Programa, utilizando para ello, indicadores cuantitativos y cualitativos.

\subsubsection{Objetivos Específicos}

- Investigar si la población de Huánuco identificada en el nivel de pobreza y pobreza extrema se encuentran dentro de los beneficiarios del programa JUNTOS.

- Estudiar el efecto de las transferencias del programa JUNTOS, en el gasto realizado por la población beneficiaria en las regiones de Huánuco, en el período 2007-2011, en base a indicadores cualitativos. 


\subsection{Hipótesis}

\subsubsection{Hipótesis General}

Las transferencias monetarias realizadas por el programa JUNTOS en el período 2007-2011, en Huánuco, afectan la economía regional, por la subcobertura del programa respecto de las familias beneficiarias y por los cambios en los patrones de consumo de las familias beneficiarias.

\subsubsection{Hipótesis Específicas}

- El programa JUNTOS no cubre a toda la población de Huánuco identificada como pobre o pobre extrema.

- Las transferencias monetarias realizadas por el Programa JUNTOS en Huánuco, en el 2007-2011, explicarían el mayor consumo de alimentos de las familias beneficiarias, aunque no necesariamente más nutritivo.

\subsection{Análisis de la subcobertura del programa JUNTOS en Huánuco}

Uno de los problemas que presentan los distintos Programas Sociales son respecto a los indicadores de focalización que pueden ser de dos tipos: infiltración y subcobertura. En esta investigación se trata de hallar el nivel de subcobertura que presenta el programa JUNTOS tanto al inicio como al final del periodo de estudio para analizar su evolución a lo largo de ese tiempo; se eligió analizar la subcobertura por considerarse, para el autor, el problema de focalización más grave pues se trata de aquella población que a pesar de ser elegible no es beneficiaria del mencionado Programa y por tanto se encuentra desatendida y en situación de mayor vulnerabilidad.

La metodología utilizada para esta fue la construcción de indicadores de subcobertura para los años 2007 y 2011, basados en dos módulos de la ENAHO de dichos años: el módulo de Características de Miembros del Hogar y el módulo Sumaria, y utilizando la herramienta informática STATA. Primero se unieron ambos módulos manteniendo las variables necesarias para construir el indicador. Luego se generaron dicotómicas de dos tipos: la primera para diferenciar a aquellos que reciben el programa JUNTOS y a aquellos que no, y la segunda para aquellos que tienen hasta 14 años de edad inclusive y aquellos mayores de tal 
edad; se creó esta segunda dicotómica pues se considera como una aproximación de la población objetivo definida por el Programa que son los hogares en situación de vulnerabilidad, exclusión o pobreza, que tengan entre sus miembros a niñas y niños hasta los 14 años de edad o mujeres en estado de gestación. (http://www.juntos.gob.pe/index.php/usuarios/quienes). ${ }^{11}$ Después se construyó una tabla de doble entrada que mostrara tanto a los hogares beneficiarios y no beneficiarios de JUNTOS como a los hogares no pobres, pobres y pobres extremos, pero sólo para el departamento de Huánuco y ajustado a la variable dicotómica de edad ya mencionada, y con estas tablas obtenidas con el STATA se realizó un cuadro resumen considerando a los potenciales beneficiarios como aquellos hogares en situación de pobreza y pobreza extrema con menores de hasta 14 años inclusive. Por último, a partir de estos cuadros se elaboraron los indicadores de subcobertura tanto para el 2007 como para el 2011.

En la tabla 3.1 se presentan los resultados obtenidos para el año 2007 en la región de Huánuco.

Tabla 3.1

Población objetivo del programa JUNTOS de acuerdo a su situación de pobreza

Huánuco, 2007

(En $\mathrm{n}^{\circ}$ de hogares)

\begin{tabular}{|r|cr|r|}
\hline pobreza & juntos & Total \\
\hline pobre extremo & 215 & 226 & 441 \\
pobreno extremo & 440 & 277 & 717 \\
no pobre & 352 & 41 & 393 \\
\hline Total & 1,007 & 544 & 1,551 \\
\hline
\end{tabular}

Fuente: Encuesta Nacional de Hogares - ENAHO 2007.

Elaboración: Propia

Al 3 de noviembre de 2012, los usuarios debían cumplir tales requisitos. En la actualidad (2016) el programa Juntos ha actualizado uno de estos requisitos: los niños, niñas, adolescentes y jóvenes hasta que culminen la secundaria o cumplan 19 años, lo que ocurra antes. 
En la tabla 3.1 se puede observar los hogares tanto beneficiarios como no beneficiarios ajustados a la población objetivo del Programa que son los menores de hasta 14 años, clasificados según sean pobres extremos, pobres no extremos y no pobres. Se considera a un hogar beneficiario cuando juntos $=1$ y no beneficiario cuando juntos $=0$. Para este año existen un total de 544 hogares adscritos al programa JUNTOS, de los cuales 226 son hogares en extrema pobreza, 277 se encuentran en situación de pobreza no extrema y existen 41 hogares que cuya situación no los califica como potenciales beneficiarios pero que sin embargo reciben las transferencias del Programa.

La tabla 3.2 muestra a los hogares que siendo parte de la población objetivo del Programa no se encuentran dentro del ámbito de cobertura del mismo, así como aquellos hogares que son parte de la población objetivo y pertenecen al Programa por lo que están adecuadamente focalizados.

Tabla 3.2

Hogares beneficiarios y no beneficiarios de acuerdo a su calificación para el programa JUNTOS, Huánuco, 2007

(En $\mathrm{N}^{\circ}$ de hogares)

\begin{tabular}{|l|r|r|r|}
\cline { 2 - 4 } \multicolumn{1}{c|}{} & Beneficiarios & No Beneficiarios & \multicolumn{2}{c|}{ Total } \\
\hline Califican & 503 & 655 & 1158 \\
\hline No Califican & 41 & 352 & 393 \\
\hline Total & 544 & 1007 & $\mathbf{1 5 5 1}$ \\
\hline
\end{tabular}

Fuente: Encuesta Nacional de Hogares - ENAHO 2007

Elaboración: Propia

Se puede observar que en el 2007, del total de los 1158 hogares que son potenciales beneficiarios, existen 655 hogares que califican para recibir las transferencias del Programa, pero que no son beneficiarios, mientras que 503 hogares pertenecen correctamente a la población objetivo de JUNTOS y sí son beneficiarios. A continuación se presenta el porcentaje de subcobertura del mencionado Programa para el año 2007. 
Tabla 3.3

Tasa de Subcobertura del programa JUNTOS

Huánuco, 2007

(En $\mathrm{n}^{\circ}$ de hogares y porcentaje)

\begin{tabular}{|l|r|}
\hline Hogares Objetivo & 1158 \\
\hline Hogares potenciales y no beneficiarios & 655 \\
\hline Tasa de subcobertura & $\mathbf{5 7 \%}$ \\
\hline
\end{tabular}

Fuente: Encuesta Nacional de Hogares - ENAHO 2007

Elaboración: Propia

Se encontró que para el año 2007, la tasa de subcobertura del programa JUNTOS en la región de Huánuco fue del 57\%, es decir que más del más de la mitad de la población objetivo no se encontraba adscrita al Programa. Esto puede deberse en parte a que solo habían pasado 2 años del inicio de la implementación de JUNTOS, por lo que aún faltaban incorporar a la mayoría de hogares. Sin embargo no puede dejar de ser observado el gran porcentaje de hogares que se encontraba fuera del Programa.

Para el año 2011, el número de hogares beneficiarios de JUNTOS aumento en el departamento de Huánuco.

Tabla 3.4

Población objetivo del programa JUNTOS de acuerdo a su situación de pobreza

Huánuco, 2011

(En $\mathrm{N}^{\circ}$ de hogares)

\begin{tabular}{|r|cr|r|}
\hline pobreza & \multicolumn{3}{|c|}{ juntos } \\
\hline pobre extremo & 117 & 1 & Total \\
\hline pobre no extremo & 218 & 324 & 393 \\
no pobre & 317 & 133 & 542 \\
\hline Total & 652 & 733 & 450 \\
\hline
\end{tabular}

Fuente: Encuesta Nacional de Hogares - ENAHO 2011

Elaboración: Propia 
Para el 2011, el número de hogares beneficiarios de JUNTOS en Huánuco aumentó en 189 hogares desde el 2007, lo que equivale a un 35\%; sin embargo, los hogares beneficiarios en situación de pobreza extrema fueron 276 , es decir 50 hogares más respecto al 2007, que equivalen a solo $22 \%$ de crecimiento en el periodo. En tanto, los hogares en situación de pobreza no extrema aumentaron en $17 \%$, porcentaje menor al de hogares en pobreza extrema. No obstante, lo más resaltante es el aumento de los hogares beneficiarios que no se encuentran en situación de pobreza cuyo aumento fue en $224 \%$. Pero también se puede observar que el número de hogares tanto en situación de pobreza como pobreza extrema y que no son beneficiarios del Programa se redujo en aproximadamente la mitad para ambos casos.

\section{Tabla 3.5}

Hogares beneficiarios y no beneficiarios de acuerdo a su calificación para el programa JUNTOS, Huánuco, 2011

$\left(\right.$ En $\mathrm{n}^{\circ}$ de hogares)

\begin{tabular}{|l|r|r|c|}
\cline { 2 - 5 } \multicolumn{1}{c|}{} & Beneficiarios & No Beneficiarios & Total \\
\hline Califican & 600 & 335 & 935 \\
\hline No Califican & 133 & 317 & 450 \\
\hline TOTAL & 733 & 652 & 1385 \\
\hline
\end{tabular}

Fuente: Encuesta Nacional de Hogares - ENAHO 2011

Elaboración: Propia

En este año, el número de hogares potencialmente beneficiarios pero no atendidos se redujo en $96 \%$ respecto al año 2007, es decir que existen 335 hogares que califican para ser beneficiarios de JUNTOS pero que no están dentro de dicho Programa. 


\section{Tabla 3.6}

Tasa de Subcobertura del programa JUNTOS, Huánuco, 2011

(En $\mathrm{n}^{\circ}$ de hogares y porcentaje)

Fuente: Encuesta Nacional de Hogares - ENAHO 2011

\begin{tabular}{|l|r|}
\hline Hogares Objetivo & 935 \\
\hline Hogares potenciales y no beneficiarios & 335 \\
\hline Tasa de subcobertura & $\mathbf{3 6 \%}$ \\
\hline
\end{tabular}

Elaboración: Propia

De la tabla 3.6 se observa que para el año 2011, la tasa de subcobertura en este departamento fue de $36 \%$, reduciéndose en $21 \%$ respecto al año 2007 , es decir que más de la tercera parte de los hogares que por sus características y situación de pobreza son objetivo del Programa aún continúan sin ser incorporados. Si bien el porcentaje de hogares no beneficiarios y potencialmente beneficiarios se ha reducido en 5 años, aún subsiste un importante número de hogares que deberían ser adscritos al Programa ya que por su situación lo ameritarían.

El sistema de focalización de JUNTOS se realiza bajo dos mecanismos: el primero es la focalización geográfica definida por el Ministerio de Economía y Finanzas (MEF) y el segundo es la focalización individual definida por el INEI (MEF s.f. p. 5). Y es en el nivel individual en el que se encontrarían los problemas que pueden explicar los niveles de subcobertura) (MEF s.f. p. 6):

Casos de omisión, mal registro y/o error material en los barridos censales o por los umbrales en la aplicación del algoritmo definido por el INEI para la preselección de $\operatorname{los}$

Debido a diferencias entre los

algoritmos utilizados por el INEI y el SISFOH, se habría generado un significativo grado de exclusión de familias potencialmente beneficiaria. (MEF p.6)

Sin embargo, también está el proceso de validación comunal, en el que se puede corregir los errores antes descritos, y que hasta la fecha son eficientes en la mayoría de los casos, pero que en ocasiones pueden incorporar hogares que por su condición de no pobres no merecen estar en el Programa y excluir a otros que por su situación de pobreza si ameritan pertenecer al Programa. 
También se puede presentar el caso de los líderes comunales del Programa que en ocasiones por problemas respecto a las relaciones entre las beneficiarias y éstos, puedan retirar a hogares beneficiarios que merecen seguir recibiendo las transferencias del Programa, como se aprecia en el caso de una beneficiaria entrevistada.

\section{Entrevistador: “ ¿Ud. recibe JUNTOS?”}

Entrevistada $\mathbf{N}^{\circ}$ 1: “...JUNTOS si recibí pero ya me han quitado de 9 meses ya no cobro ya (...) vecinos ahí no más medio envidiosos vengativos (...) pero ricos más reciben tiene carro tiene casa en Huánuco más reciben, tiene carro tienen camión bodega tienen y están cobrando, a mi si no quieren apoyar digo yo..."

Respecto a lo anterior, se entrevistó al Jefe del Programa JUNTOS de la región Huánuco y éste manifestó que los problemas de subcobertura y de filtración en el Programa son muy pocos, y que temas como los problemas de envidia o malos entendidos entre la comunidad de beneficiarios pueden darse pero no son frecuentes y que en los casos como el anterior y que han podido detectar, generalmente se les retiraba del Programa por el incumplimiento de algunas de las condicionalidades exigidas.

Entrevistador: “¿Cómo verifican realmente que la madre no esté cumpliendo las corresponsabilidades y no se trate de tema de enfrentamiento?"

Jefe de Programa JUNTOS en Huánuco: "La filosofia del programa está basada en que los gestores son fedatarios, entiendo que eso se puede dar, reconozco que seguramente habrá lugares que se puedan haber dado esas cosas porque hay lugares muy alejados que la misma accesibilidad no les permiten a los gestores llegar (...) este asunto de conflictos sociales se puede dar pero cuando ya hay una alerta, el gestor debe ir a verificar, esa verificación que hace va a sacar una conclusión, por ejemplo hemos estado en Chusqui y se presentan dos usuarias del programa y me informan: señor he salido del programa y no sé porque. Para salir del programa se tiene que cumplir tres requisitos: ausentarse más de 6 meses, porque ya no hay miembro objetivo y la tercera es tener información de que la usuaria ya tiene ingresos superiores a los S/. 300 puede ser que tenga una bodega o un comercio (...) me dijeron la señora no sabía por que la habian sacado yo se lo puedo asegurar que efectivamente ese puede ser un indicador en muchas personas pero si saben, incluso hay una cuarta salida: cuando ha sido suspendida tres veces..." 
Es cierto que esta subcobertura se ha reducido del 2007 al 2011 pero aún persiste una parte importante de potenciales beneficiarios que no son atendidos por JUNTOS, por lo que se puede decir que se acepta la hipótesis de que existe subcobertura del programa JUNTOS en Huánuco, situándose en el último año en un 36\% de hogares no atendidos.

\subsection{Análisis del gasto realizado por las familias beneficiarias del programa JUNTOS}

El programa JUNTOS otorga bimestralmente S/. 200, de libre disponibilidad por las familias receptoras, pero entregadas bajo la condición de que se cumplan ciertos requerimientos establecidos por el programa y plasmados en una Carta de compromiso firmada por las madres de los hogares beneficiarios. Estas condiciones son también llamadas corresponsabilidades, pues implican el cumplimiento de acuerdos por ambas partes: las madres beneficiarias y el Estado (http://www.juntos.gob.pe/index.php/comotrabajamos/procesos-operativos). Las madres tienen el compromiso de llevar a sus hijos menores hasta los 6 años a sus controles de crecimiento y desarrollo, y si están gestando de acudir a sus controles prenatales; y, en materia de educación, cumplir con la matrícula y asistencia de sus hijos a la escuela según el nivel que les corresponda. Al Estado, le corresponde la entrega de las transferencias en forma puntual y la verificación del cumplimiento de dichas condiciones.

Para la comprobación de esta hipótesis se realizaron entrevistas, a las madres beneficiarias, o que fueron beneficiarias o están suspendidas, del programa JUTNOS, en el departamento de Huánuco, en tres distritos pertenecientes a dos provincias del mismo: Churubamba, Ambo y San Rafael, sobre el uso que le dan al dinero recibido del Programa.

Se busca averiguar si el beneficio monetario que reciben los hogares beneficiarios se destinan en efecto a mejorar el bienestar de los niños de dichos hogares o si se gasta en rubros que no necesariamente contribuyen a una mejor situación para los menores. Adicionalmente se entrevistó a los responsables de los centros de Salud y al director de un colegio para respaldar lo expuesto por las madres entrevistadas. Las entrevistas realizadas se presentan en el anexo $\mathrm{N}^{\circ} 2$. 
La tabla 3.7 presenta las categorías de gasto que las personas entrevistadas aseguraron realizar con el dinero que reciben del Programa:

Tabla 3.7

Categorías de Gasto realizado con las transferencias recibidas del Programa

Huánuco, 2012

\begin{tabular}{|c|c|c|c|}
\hline $\begin{array}{c}\text { Categorías de } \\
\text { Gasto } \\
\end{array}$ & Tipo & Antes & Después \\
\hline \multirow{7}{*}{ Alimentos } & Menestras & lentejas, frijol, etc. & habas, arverjas, frijol, lentejas \\
\hline & Lácteos & Leche & leche, huevos, yogurt \\
\hline & Carnes & gallina, cuy, carnero & res, pollo, pescado, cerdo, \\
\hline & Verduras y granos & mote, trigo, maíz & No especifica \\
\hline & Tubérculos & Papa & Papa \\
\hline & Frutas & - & plátano, naranja \\
\hline & Otros & - & $\begin{array}{l}\text { aceite, arroz, azúcar, fideos, maca, soya, } \\
\text { quinua, café, quacker, etc. }\end{array}$ \\
\hline Vestimenta & & - & ropa, zapatos, pantalones, uniformes \\
\hline Otros & & - & pasajes, propinas, útiles escolares \\
\hline
\end{tabular}

Fuente: Entrevistas realizadas en Huánuco

Elaboración: propia

En todas las entrevistas realizadas a las beneficiarias, las respuestas en cuanto al uso, en mayor medida, que le daban al dinero que recibían del Programa, eran las mismas: alimentación y vestimenta. Solo algunas manifestaron que parte del dinero lo utilizaban en pasajes o propinas para sus hijos.

En el caso de los alimentos, las entrevistadas refirieron que con el dinero adicional que ahora tenían, podían adquirir más bienes, como alimentos que no cosechan en sus pequeñas chacras o carnes de animales que no crían. El grupo de alimentos que predomina en el consumo de los hogares beneficiarios es el de menestras, seguido por las carnes y los lácteos. Esto se debe principalmente, y de acuerdo a lo manifestado por las madres entrevistadas, a que ya antes de ingresar al Programa consumían alimentos tales como 
lentejas, frijoles, entre otros como papas, pues era lo que cosechaban en sus chacras ya que su actividad principal es la agricultura de autoconsumo, vendiendo solo una pequeña porción de lo producido con el objetivo de obtener ingresos adicionales para otros gastos tales como pasajes o gastos para poder enviar a sus hijos a la escuela. En cuanto al rubro de carnes, las personas entrevistadas afirmaron que anteriormente solo consumían lo que criaban como gallinas, carneros y cuyes, pero que este tipo de alimentos no era frecuente debido al tiempo que se requería para la crianza de un animal, es decir desde que nacen hasta que están aptos para el consumo, además no podían agotar todos sus animales pues debían continuar con la reproducción de estos y dejar algunos para la venta, con lo cual el consumo era muy poco frecuente; sin embargo, ahora con el dinero adicional que tienen, manifiestan poder acceder a otro tipo de carnes como res, pollo y en especial el pescado. Respecto a los lácteos, las entrevistadas, casi en su totalidad, dijeron que antes de recibir el dinero del Programa, a sus hijos les daban leche pero que no era muy frecuente debido a su falta de recursos, pero que ahora con el dinero recibido pueden comprar más leche para sus hijos, así como también huevos y en algunos casos sus hijos les piden yogurt, que ahora también pueden adquirir.

A continuación se presenta un extracto de una de las entrevistas realizadas a las beneficiarias, las cuales se encuentran completas en el anexo $\mathrm{N}^{\circ} 2$ :

Entrevistador: “ ¿y Ud. con el dinero del programa compraba algo más?”

Entrevistada $\mathbf{N}^{\circ}$ 1: "yo compraba con eso ropa de muchachos, su alimentos, útiles, ah pero para cuatro muchachos falta (...) nosotros comprábamos un poco aceite, un poco arroz, fideo, su ropa, zapatos, pantalón, comprábamos carne, gallinas criamos, carnero también criamos, eso siempre nosotros comemos, muchachos están acostumbrados quieren comer carne, chancho, gallina, huevo quieren comer, eso nomás quieren comer..."

Entrevistador: “ ¿y con el dinero del programa qué consumes, qué compras?”

Entrevistada $\mathbf{N}^{\circ}$ 2: "es para niño nada más da (...) compramos alimento niños, arroz, su leche, su carnecita..."

Como se puede apreciar en el primer extracto, algunas madres manifestaron que también compraban otros alimentos distintos al común denominador, como fideos, azúcar, arroz y aceite, aunque sin dejar de lado los alimentos que tradicionalmente consumían y a los cuales sus hijos estaban acostumbrados. 
Al preguntársele a una de las entrevistadas la razón por la que le daba alimentos como maca y quinua, ésta refiere que las profesoras del colegio le dicen que alimentos son más nutritivos para sus hijos.

Entrevistador: “¿y por qué le das esos alimentos a tus hijos, porque tú sabes que son nutritivos?"

Entrevistada $\mathbf{N}^{\circ}$ 18: "Porque las profesoras me dicen que tú le puedes dar esos alimentos a tus hijos"

Entrevistador: "Y antes de que tu estuvieras en el programa le dabas los mismos alimentos o que consumías antes"

Entrevistada No 18: "Antes que no me daban juntos no, probábamos siempre quacker leche así de vez en cuando nuestro café como siempre no, en la chacra nuestro machica nuestro cancha todo eso comíamos..."

El consumo alimentario de los hogares beneficiarios se ha ampliado en algunos de los rubros que ya se consumían antes de que ingresaran al Programa, mientras que en otros casos hay un nuevo consumo hacia otros alimentos que antes no se consumían, como fideos o arroz.

Es importante mencionar que dentro de los alimentos que compran las entrevistadas, no se incluyen golosinas ni comida chatarra, pues las madres saben que ese tipo de comida no es nutritivo y puede hacerles daño a sus hijos, ya sea que se los haya enseñado alguno de los promotores del Programa o en los centros de salud o que lo hayan visto en televisión.

Entrevistador: “ ¿y tú a tus hijos les das golosinas, chizitos eso?

Entrevistada $\mathbf{N}^{\circ}$ 13: "no eso no le doy, galletas si le doy porque yo he sufrido de gastritis por gaseosa, por eso no le doy, en vez de eso le doy agua de piña, le hago su jugo con betarraga su papaya, eso le hago, porque en televisión se ve que esas cosas tienen colorante intoxican por eso yo viendo eso no le doy, en la posta también nos capacita, antes no nos capacitaba..."

En el caso de la categoría de vestimenta, las entrevistadas afirman que lo que compran con parte del dinero del Programa que reciben, lo gastan en zapatos, polos, 
pantalones y en especial uniformes escolares para sus hijos. Esto, también refieren, que se lo recomiendan los promotores del mismo Programa, pues les informan que el dinero que reciben deben utilizarlo para sus hijos, para mejorar su alimentación, su educación y su bienestar, o para invertir en el desarrollo de sus hogares, mas no para gastos superficiales que no aporten nada al desarrollo de sus familias. Esto se puede evidenciar en las declaraciones de la misma entrevistada.

Entrevistador: “ ¿y los promotores te orientan, te dicen que puedes hacer con ese dinero?"

Entrevistada No 18: "él nos dice esa plata es para sus zapatos de tu hijo para educación de tu hijo cuando pide cuota para que das cuota para cuando pide falta otra cosa para su útiles para eso nos dice nos explica eso no es para que compres tu zapatos no es para que compres tu ropa eso son para tus hijos tu marido no tiene derecho porque pedirte ni 10 céntimos dice..."

Además de comprar ropa y calzado, también destinan parte del dinero a la adquisición de útiles escolares para sus hijos cuando estos lo requieran, aunque estos gastos, a diferencia del gasto en alimentos, no lo realizan cada mes, sino cuando se necesita o cuando se puede, dependiendo de los gastos prioritarios que han tenido en el mes, es decir que una vez pueden comprar más alimentos y ya no ropa ni zapatos, y con la siguiente transferencia que reciben pueden comprar ya sea un polo o un pantalón.

Entrevistador: "tú me dices que con el programa tu compras leche, cosas para ellos para el colegio, no necesariamente compras solo alimentos"

Entrevistada $\mathbf{N}^{\circ}$ 3: "no necesariamente porque tengo que hacer alcanzar como mamá yo ya sé que le falta entonces voy y compro lo que les falta no solamente ropa, por decir este mes no le compro ropa pero compro lo esencial para su comida ya el otro mes ya bueno si le falta tengo que hacer el esfuerzo de comprar"

Algunas madres manifestaron que en algunas ocasiones destinan una pequeña parte del dinero que reciben, a pasajes que necesitan para movilizarse ya sea para realizar sus compras o para llevar a sus hijos a sus controles de salud en los centros médicos que no siempre están cercanos a sus localidades o incluso para ir a trabajar pues saben que el dinero que les da el Programa no es suficiente para dos meses. 
También expresan que en ocasiones el dinero les sirve para darles propina a sus hijos cuando éstos van al colegio, para que puedan comprarse algo de comer, adicionalmente al refrigerio que le puedan mandar a la escuela.

Entrevistada $\mathbf{N}^{\circ}$ 6: “...y ahora también pasaje no más para trabajo porque eso también no nos va a aguantar dos meses (...) sus propinas para el colegio, ahora diario le doy un sol, porque si no, no hay nada más baratito para que coma el niño siempre antoja en el colegio..."

Sin embargo, el dinero que transfiere el programa JUNTOS a veces es utilizado por las madres beneficiarias para realizar pequeñas inversiones que les permitan desarrollarse y tener mejores ingresos y así no depender eternamente del Programa, pues muchas saben que las transferencias no las van a recibir siempre.

La tabla 3.8 muestra las inversiones más comunes que realizan las mujeres con parte del dinero que reciben del Programa.

\section{Tabla 3.8}

Categorías de Inversiones realizadas, 2012

\begin{tabular}{|l|l|}
\hline \multicolumn{1}{|c|}{ Categoría de inversión } & \multicolumn{1}{c|}{ Tipo } \\
\hline \multirow{2}{*}{ Crianza de animales } & cuyes \\
\cline { 2 - 2 } & carneros \\
\cline { 2 - 2 } & gallinas \\
\hline \multirow{2}{*}{ Mejoramiento de la chacra } & abono \\
\cline { 2 - 2 } & semillas \\
\hline
\end{tabular}

Fuente: entrevistas realizadas en Huánuco Elaboración: propia 
El tipo de inversión más común referido por las madres entrevistadas es el de la compra de cuyes para su crianza y reproducción y posteriormente la venta de los mismos, pues el costo de adquirir cada cuy es de aproximadamente S/. 10 y se reproducen con mayor rapidez que otros animales como las reses o los carneros; sin embargo, esto no significa que solo se compren los primeros animales, sino que la cantidad comprada puede ser mayor que los otros animales, como se ilustra en el extracto siguiente de una de las entrevistadas.

Entrevistada $\mathbf{N}^{\circ}$ 13: “...yo dos carneritos he comprado, ahora ya su carnerito ya ha dado cría también, eso cuando aumenta ya vendemos también (...) mantener sacar adelante a mi hijo tener un pequeño negocio para dejarle algún futuro a mi hijo porque yo también no voy a vivir todo el año, yo pienso yo digo como quisiera juntar esa plata dejarle algo a mi hijo siquiera cualquier cosita alguna bodeguita para que ellos también sepan mantenerse (...) hemos comprado cuyes, gallinas para criar, de machos cuatro no más he comprado..."

En ocasiones, estas actividades de emprendimiento por parte de las beneficiarias son realizadas de manera colectiva ya sea por iniciativa propia o nacidas a partir de las capacitaciones en los talleres de actividades productivas promovidos por el Programa.

Por lo tanto, el dinero que reciben las madres del programa JUNTOS, no lo destinan enteramente al consumo alimentario, sino que también utilizan parte de ese dinero para adquirir vestimenta, calzados, útiles, entre otros que consideran y son realmente necesarios para la salud y la educación de sus hijos, y en ocasiones, y cuando les es posible, ahorran parte de ese dinero para luego realizar pequeñas inversiones hacia actividades que les generen ingresos adicionales. Si bien el consumo alimentario no ha cambiado totalmente, pues por costumbre siempre han consumido lo mismo, éste si se ha ampliado a otro tipo de alimentos complementarios a su dieta tradicional como pastas y arroz, pero en esencia el aporte nutricional de los alimentos adquiridos con el dinero recibido del Programa no es menor sino que por el contrario ahora es mayor que antes, pues ya sea por conocimientos tradicionales o por enseñanza de las promotoras o educadoras de las escuelas, las madres saben que alimentos son mejores para sus hijos e hijas y cuáles no; por lo tanto no se acepta la esta primera hipótesis pues aunque el consumo alimentario haya aumentado, éste si es nutritivo. 
Por último, se puede aceptar la hipótesis general debido a las evidencias presentadas anteriormente:

- Las transferencias realizadas por el programa JUNTOS generan en las madres receptoras un mayor poder de compra, el cual se traduce principalmente en un mayor consumo de alimentos de distinto tipo, así como también se destina parte de ese dinero para la adquisición de vestimenta, calzado y útiles que consideran necesarios para el bienestar de sus hijos.

- Mientras que por otra parte, se ha comprobado que existe todavía un buen porcentaje de hogares que cumplen las condiciones para ser beneficiarios del Programa pero que hasta la fecha no han sido incorporados; si la tasa de subcobertura se ha reducido desde el 2007 hacia el 2011, esta sigue siendo alta pues representa aproximadamente la tercera parte de los hogares objetivos del programa JUNTOS. 


\section{CONCLUSIONES}

- A pesar de los positivos resultados obtenidos por los Programas de Transferencia Condicionada (PTC), éstos no están exentos de problemas relacionados a su focalización: subcobertura y filtración. El sistema de focalización individual (SISFHO) utilizado por el programa para la identificación de los usuarios, al 2011, no era el adecuado pues presentaba errores no solo en los barridos censos sino también en el algoritmo utilizado para la preselección de hogares beneficiarios, lo que habría causado que no se incluyan a los beneficiarios potenciales, que al mismo tiempo ocasiona en estos, una mayor sensación de exclusión por parte del sistema.

- El Programa JUNTOS constituye una herramienta efectiva en la lucha contra la pobreza debido a las condicionalidades que exige a los beneficiarios; sin embargo, en Huánuco a dos años de haberse iniciado no llegaba a más de la mitad de su población objetivo, y hacia el último año, aún no llega a más de un tercio de los potenciales beneficiarios a pesar de haber ampliado su cobertura hacia más distritos

- A siete años de su inicio en Huánuco, los indicadores de pobreza de la región aun no han disminuido según lo que se esperaría dada la cobertura geográfica y el tiempo de funcionamiento del programa en el mencionado departamento, debido a que todavía existe una parte de la población en situación de pobreza y que cumple con los criterios para participar pero a la que el Programa aun no llegaba.

- El programa JUNTOS, al igual que otros PTC, han generado en la población beneficiaria de Huánuco, un efecto positivo inmediato: aumentar y mejorar su consumo sea de alimentos u otros bienes; pero también genera un efecto secundario que puede darse en el mediano y largo plazo: la generación de ahorro e inversión en las familias para superar su situación de pobreza.

- Existe una baja articulación del Programa Juntos con otros programas generadores de proyectos, a los que los beneficiarios puedan acogerse y darle continuidad a su desarrollo. Al no generarse esta continuidad, pues no forma parte de los objetivos del 
programa, la población beneficiaria que supera su situación de pobreza corre el riesgo de volver a caer en ella una vez excluida del Programa Juntos.

- A pesar de que las condicionalidades oficiales del programa son informadas a la población beneficiaria, no existe transparencia sobre si además de ellas existen otras condiciones a las que la entrega del dinero está subordinada, como las que son transmitidas por los coordinadores del programa en las comunidades y que si bien están destinadas a fomentar el desarrollo y el mejor uso de las transferencias, no son obligatorias ni oficiales, pero que son asumidas por los beneficiarios como parte de sus corresponsabilidades, generando una sensación de confusión en los usuarios sobre el buen funcionamiento y eficiencia del programa. 


\section{RECOMENDACIONES}

A continuación detallaremos las recomendaciones:

- Para evitar los problemas de subcobertura que hasta ahora presenta JUNTOS en Huánuco, antes de ampliar la cobertura de hogares, se recomienda mejorar el sistema utilizado, sea en coordinación con la institución encargada de la focalización geográfica o que recaiga en ésta la tarea de focalizar los hogares que deben calificar para ser adscritos al programa, pues son estos los que cuentan con las herramientas y métodos adecuados para llevar una adecuada focalización que evite las limitaciones que hasta ahora experimenta el programa. Así mismo, se recomienda tener mayor control respecto a la validación comunal, hacer de este filtro más eficiente para evitar problemas en este nivel de la selección de beneficiarios.

- Para evitar el riesgo que los usuarios del Programa JUNTOS recaigan en situación de pobreza y puedan finalmente alcanzar su graduación del Programa, lo que está estipulado pero no se implementa, el programa debería:

- buscar la articulación, desde las etapas tempranas de intervención, con programas de distinto tipo: creación de proyectos microempresariales, sea con alianzas privadas o públicas, para las madres beneficiarias, sea de manera colectiva o de manera individual, sostenibles, que genere en ellas el impulso para su desarrollo y no una dependencia adictiva del programa, incorporando esto como parte de sus objetivos a largo plazo;

○ insertar a los beneficiarios al sistema financiero, más específicamente al de los microcréditos, públicos o privados y a una tasa preferente, para que en el mediano plazo, puedan utilizar parte del dinero recibido de las transferencias como garantía para la obtención de pequeños préstamos y creación de pequeños negocios propios; $\mathrm{y}$,

○ una articulación con programas educativos, para que los adolescentes de los hogares beneficiarios, que cursan el último año de escuela, puedan acceder a la educación superior, darle continuidad a su proceso educativo y así tener oportunidades de ampliar sus posibilidades de trabajo futuro con acceso a mejores salarios y servicios. Así mismo se recomienda una mejor calidad de la 
oferta educativa por parte del sector, en coordinación con el programa JUNTOS.

- Debido a que existen condicionalidades no oficiales que son impuestas a los beneficiarios, y dado que ayudan al desarrollo del hogar beneficiario, se recomienda internalizarlas al programa, pero no como condiciones para recibir las transferencias sino como actividades complementarias, creando un objetivo adicional al ya establecido por el programa: el desarrollo socioeconómico de los hogares beneficiarios.

- Para conocer el impacto que tiene el programa Juntos en su objetivo de eliminar la transmisión intergeneracional de la pobreza y mejorar la nutrición y la educación de la población beneficiaria, se recomienda realizar una Evaluación de impacto. ${ }^{12}$ Aun cuando el programa no cuenta con una línea de base, se pueden utilizar métodos no experimentales para esta conocer si el programa ha sido efectivo en los objetivos perseguidos. 


\section{REFERENCIAS}

Aramburú, C. (2010). Informe Compilatorio: El Programa JUNTOS, resultados y retos. Recuperado del sitio de Internet del programa JUNTOS: http://www.juntos.gob.pe/modulos/mod_infojuntos_V1/docs/11.pdf

Banco Mundial. (2003). Shanghai Poverty Conference: Case Study Summary. Estados Unidos: Banco Mundial. Recuperado del sitio de Internet del Banco Mundial: http://web.worldbank.org/archive/website00819C/WEB/PDF/CASE_62.PDF

Banco Mundial. (s.f.). Programa Familias en Acción. Colombia. Estados Unidos: Banco Mundial. Recuperado del sitio de Internet del Banco Mundial: http://siteresources.worldbank.org/SAFETYNETSANDTRANSFERS/Resources/281 945-1131468287118/1876750-1140107387177/ColombiaCCT.pdf

Boltvinik, J. (1990). Pobreza y necesidades básicas. Conceptos y métodos de medición. Caracas: Proyecto Regional para la Superación de la Pobreza, PNUD. Recuperado de https://periferiaactiva.files.wordpress.com/2015/03/pobreza necesidades basicas insa tisfechas-completo.pdf

CEPAL (s.f.). Programas de Transferencia Condicionada: Bases de datos. Chile: Autor. Recuperado del sitio de Internet de CEPAL: http://dds.cepal.org/bdptc/programa/?id=22

Draibe, S. (2006). Brasil: Bolsa-Escola y Bolsa-Familia. En E. Cohen y R. Franco. Transferencias con corresponsabilidad. Una mirada Latinoamericana. (pp. 137-178) México: SEDESOL.

DEPARTAMENTO NACIONAL DE PLANEACIÓN. (2007). El caso de Colombia: Programa Familias en Acción. Caso presentado en el Seminario Internacional Programa de Transferencias Condicionadas: La experiencia de diversos países. Recuperado de: http://dds.cepal.org/eventos/presentaciones/2007/1120/Colombia_JFArias_DNP.ppt.p $\underline{\mathrm{df}}$

Desnutrición crónica infantil disminuye 10.6\% en Huánuco. (2 de agosto 2011). Inforegión Agencia de Prensa Internacional. Recuperado de http://www.inforegion.pe/111017/desnutricion-cronica-infantil-disminuye-10-6-enhuanuco/

Fiszbein, A., Schady, N. (2009). Conditional Cash Transfers. Reducing Present and Future Poverty. Recuperado del sitio de Internet del Banco Mundial: http://siteresources.worldbank.org/INTCCT/Resources/57576081234228266004/PRR-CCT_web_noembargo.pdf

Flores, R. (1995). Pobreza en el Perú: Concepto, Situación y Metodología. Recuperado del sitio de internet del INEI: http://proyectos.inei.gob.pe/web/biblioineipub/bancopub/Est/Lib0070/1-4.htm 
Huber L., Zárate P., Durand A., Madalengoitia O. y Morel J. (2009). Programa JUNTOS. Certezas y malentendidos en torno a las transferencias condicionadas Estudio de caso de seis distritos rurales del Perú. Recuperado del sitio de Internet del Instituto de Estudios Peruanos: http://repositorio.iep.org.pe/handle/IEP/187

Ministerio de Economía y Finanzas (MEF). (2010). Metodología de cálculo del Índice de Focalización de Hogares. Lima: Autor. Recuperado de http://www.sisfoh.gob.pe/descargas/metodologia_2010.pdf

$\begin{array}{lllll}\text { Ministerio de } & \text { Economía } & \text { y } & \text { Finanzas } & \text { (MEF). }\end{array}$ Informe de recomendaciones de presupuesto evaluado.

Programa nacional de apoyo directo a los más pobres (JUNTOS). Lima: Autor. Recuperado del sitio de Internet del Ministerio de Economía y Finanzas: http://www.mef.gob.pe/contenidos/presu_publ/documentac/recomendaciones/JUNTO S.pdf

Programa de las Naciones Unidas para el Desarrollo. Proyecto Regional para la Superación de la Pobreza. (1990). La Pobreza en el Perú. Diagnóstico y Propuestas de Política. Bogotá: Autor.

Sen, A. (2000). Desarrollo y Libertad. Buenos Aires: Editorial Planeta.

Verdera, F. (2007). La pobreza en el Perú: un análisis de sus causas y de las políticas para enfrentarla. Lima: Instituto de Estudios Peruanos

Instituto Nacional de Estadística e Informática. (s.f.). Perú: Mapa de Necesidades Básicas Insatisfechas de los Hogares a nivel Distrital. Lima: Autor. En internet: http://proyectos.inei.gob.pe/web/biblioineipub/bancopub/Est/Lib0068/POB00002.htm

Instituto Nacional de Estadística e Informática. (s.f.). Informe Técnico. Evolución de la Pobreza 2007-2011. Lima: Autor. Recuperado de http://www.inei.gob.pe/DocumentosPublicos/Pobreza_InformeTecnico.pdf

Instituto Nacional de Estadística e Informática. (2012). Mejoras Metodológicas para la Medición de la Pobreza. Lima: Autor. Recuperado de https://www.inei.gob.pe/media/cifras_de pobreza/mejoras-metodologicas.pdf

Instituto Nacional de Estadística e Informática. (2013). Informe Técnico: Evolución de la Pobreza Monetaria 2007-2012. Lima: Autor. Recuperado de https://www.inei.gob.pe/media/cifras de pobreza/pobreza informetecnico2013 1.pdf

Instituto Nacional de Estadística e Informática. (2012). Evolución de la Pobreza al 2011. Lima: Autor. https://www.inei.gob.pe/media/cifras_de pobreza/presentacion-del-jefe.pdf

Instituto Nacional de Estadística e Informática. (2011). Evolución de la Pobreza al 2010. Lima: Autor. Recuperado de: http://sinia.minam.gob.pe/documentos/informe-tecnicoevolucion-pobreza-2010 
Parker, S. (2014). Los Programas de Transferencia Condicionadas: Impactos del programa Oportunidades después de 15 años. México. Recuperado del sitio de Internet de SEDESOL:

http://www.sedesol.gob.mx/work/models/SEDESOL/Resource/139/1/images/SEDES

OL SusanParker.pdf

Perova, E., Vakis, R. (2009). Welfare impacts of the Juntos Program in Peru: evidence from a non-experimental evaluation. (Banco Mundial). Recuperado del sitio web del programa Juntos: http://www.juntos.gob.pe/modulos/mod_legal/archivos/Evaluacion_CuasiExperimental1.pdf

Programa Bolsa Familia y Brasil sin Miseria. Recuperado de https://es.slideshare.net/FAOoftheUN/ministra-tereza-campello

Inter-Regional Inequality Facility Policy Brief 2. (2006). Familias en Acción Colombia. Recuperado de http://www.odi.org/sites/odi.org.uk/files/odi-assets/publicationsopinion-files/1690.pdf

Reyes, J. (1996). Presentación de Metodologías aplicadas en países: La experiencia peruana en la construcción del Mapa de NBI. Recuperado del sitio de Internet de CEPAL: http://repositorio.cepal.org/handle/11362/30739

Sánchez, A., Jaramillo, M. (2012). Impacto del programa Juntos sobre nutrición temprana. (DT. N²012-001 Serie de Documentos de Trabajo). Recuperado del sitio de Internet del Banco Central de Reserva del Perú: http://www.bcrp.gob.pe/docs/Publicaciones/Documentos-deTrabajo/2012/documento-de-trabajo-01-2012.pdf

Unión Temporal Econometría - SEI. (2012). Impactos de largo plazo del Programa Familias en Acción en municipios de menos de 100 mil habitantes en los aspectos claves del desarrollo del capital humano (Informe Final). Recuperado del sitio de internet: https://sinergiacp.dnp.gov.co/Sinergia/Archivos/92646308-df90-4107-a0748bf62ea9e862/Eval_Familias\%20Acci\%C3\%B3n\%20Largo\%20plazo.pdf 


\section{BIBLIOGRAFIA}

Spiegel, P. (Ed.). (2007). Muhammad Yunus, el banquero de los pobres. Santander: Sal Terrae.

Easterly, W. (Ed.). (2001). Es busca del crecimiento: Andanzas y tribulaciones de los economistas del desarrollo. Barcelona: Antoni Bosch 


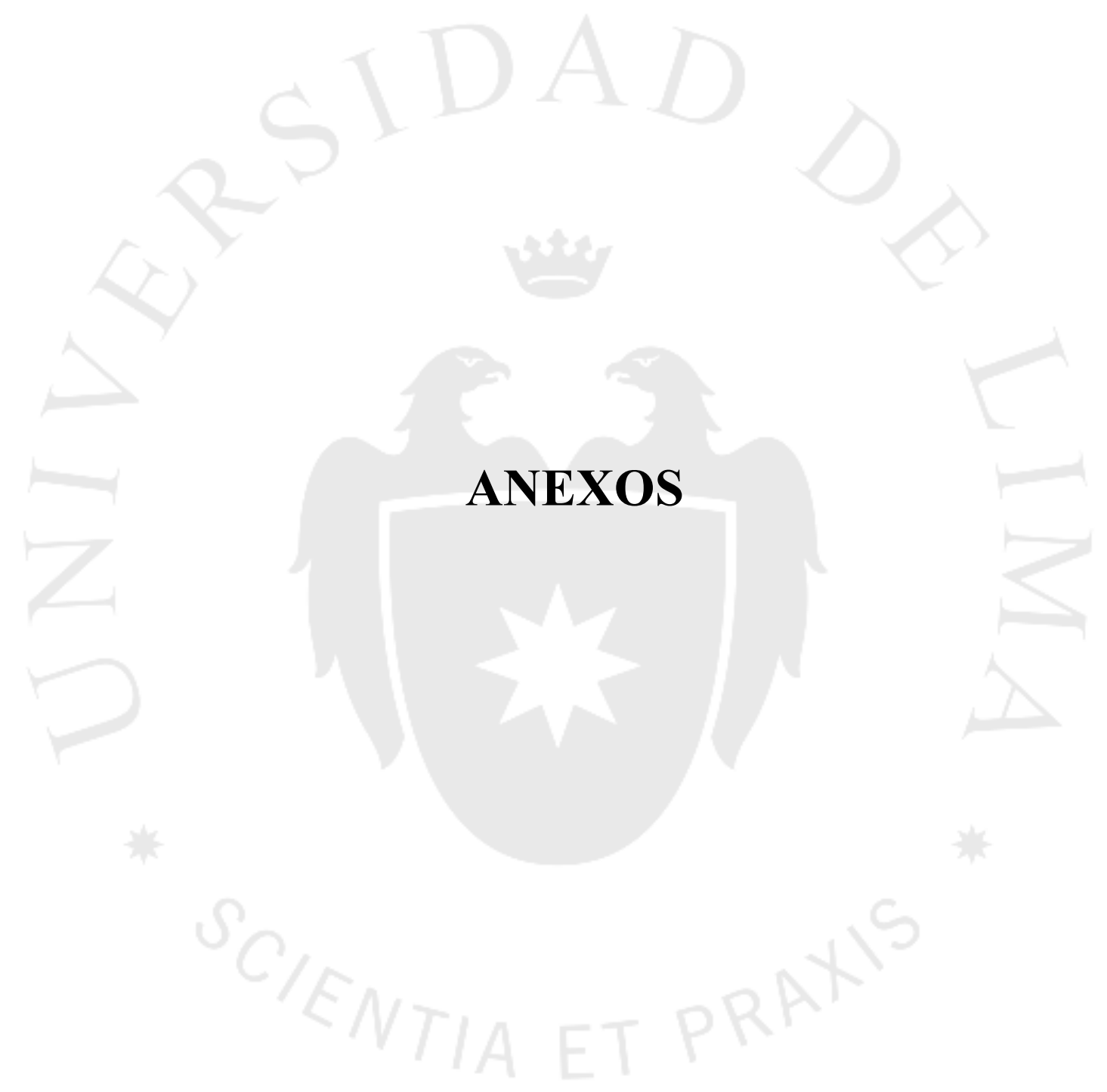




\section{ANEXO 1:Matriz de Coherencia Metodológica}

Matriz De Coherencia Metodológica $\mathrm{N}^{\circ} 1$

\begin{tabular}{|l|l|}
\hline OBJETIVOS & CONCLUSIONES \\
\hline ESPECIFICO 1 & $\begin{array}{l}\text { Investigar si el actual sistema de focalización del programa } \\
\text { JUNTOS es eficiente e identificar dónde se presentan los } \\
\text { errores de focalización más elevados, en la región de } \\
\text { Huánuco, caracterizando a las familias que forman parte de } \\
\text { estos errores, en base al análisis estadístico obtenido de las } \\
\text { fuentes oficiales. }\end{array}$ \\
\hline ESPECIFICO 2 & $\begin{array}{l}\text { Estudiar el efecto de las transferencias del programa } \\
\text { JUNTOS, en el gasto realizado por la población beneficiaria } \\
\text { en las regiones de Huánuco, en el período 2007-2011, en base } \\
\text { a indicadores cuantitativos y cualitativos. }\end{array}$ \\
\hline $\begin{array}{l}\text { Estudiar el cambio en los patrones de consumo de las familias } \\
\text { beneficiarias en Huánuco, en el período 2007-2011, como } \\
\text { resultado de las transferencias realizadas por el programa } \\
\text { JUNTOS, y las consecuencias generadas en la población } \\
\text { como producto de una inadecuada cobertura de hogares por } \\
\text { parte del Programa, utilizando para ello, indicadores } \\
\text { cuantitativos y cualitativos. }\end{array}$ \\
\hline GENERAL
\end{tabular}


Matriz De Coherencia Metodológica $\mathrm{N}^{\circ} 2$

\begin{tabular}{|c|c|}
\hline HIPO & CONCLUSIONES \\
\hline $\begin{array}{l}\text { ESPECIFICA 1: Las transferencias } \\
\text { monetarias realizadas por el Programa } \\
\text { JUNTOS, en Huánuco, no se otorgan a } \\
\text { toda la población objetivo por una } \\
\text { subcobertura de los hogares } \\
\text { seleccionados por parte de dicho } \\
\text { programa. }\end{array}$ & $\begin{array}{l}\checkmark \text { Se ha comprobado que los PTC } \\
\text { presentan limitaciones en sus } \\
\text { resultados en especial respecto a la } \\
\text { subcobertura; por esto es necesario un } \\
\text { sistema eficiente de monitoreo y } \\
\text { control de los beneficiarios. } \\
\checkmark \text { El programa JUNTOS presenta } \\
\text { dificultades a nivel de la focalización } \\
\text { de hogares y de la validación comunal } \\
\text { por problemas relacionados a la } \\
\text { recolección de la información } \\
\text { socioeconómica. } \\
\text { Una tercera parte de la población } \\
\text { objetivo del programa no está siendo } \\
\text { atendida por el programa en el } 2011 \text { a } \\
\text { pesar de que ese porcentaje ha } \\
\text { disminuido desde el } 2007 \text { y de la } \\
\text { incorporación de más hogares de la } \\
\text { región. }\end{array}$ \\
\hline $\begin{array}{l}\text { ESPECIFICA 2: Las transferencias } \\
\text { monetarias realizadas por el Programa } \\
\text { JUNTOS en Huánuco, en el 2007-2011, } \\
\text { explicarían el mayor consumo de } \\
\text { alimentos de las familias beneficiarias, } \\
\text { aunque no necesariamente más nutritivo. }\end{array}$ & $\begin{array}{l}\checkmark \text { Los PTC tienen un alto impacto en la } \\
\text { reducción de la pobreza, respaldándose } \\
\text { en la evidencia empírica e } \\
\text { internacional sobre sus resultados. } \\
\checkmark \text { La evidencia internacional demuestra } \\
\text { que las transferencias monetarias } \\
\text { generan un mayor consumo de } \\
\text { alimentos, aunque no necesariamente } \\
\text { más nutritivo, así como tampoco se } \\
\text { evidencia un uso productivo del dinero } \\
\text { recibido. } \\
\checkmark \text { En Huánuco, el dinero recibido por los }\end{array}$ \\
\hline
\end{tabular}




\begin{tabular}{|c|c|}
\hline & $\begin{array}{l}\text { hogares beneficiarios es destinado en } \\
\text { gran parte al consumo de alimentos y } \\
\text { vestimenta, y en una pequeña parte } \\
\text { destinado a pequeñas inversiones para } \\
\text { el desarrollo de sus familias. }\end{array}$ \\
\hline $\begin{array}{l}\text { GENERAL: Las transferencias } \\
\text { monetarias realizadas por el programa } \\
\text { JUNTOS en el período 2007-2011, en } \\
\text { Huánuco, afectan la economía regional, } \\
\text { por la subcobertura del programa } \\
\text { respecto de las familias beneficiarias y } \\
\text { por los cambios en los patrones de } \\
\text { consumo de las familias beneficiarias }\end{array}$ & $\begin{array}{l}\checkmark \text { A pesar de que las transferencias } \\
\text { otorgadas por el programa JUNTOS en } \\
\text { Huánuco han aumentado y mejorado el } \\
\text { consumo de los hogares beneficiarios, } \\
\text { aún existe un porcentaje de la } \\
\text { población objetivo que no recibe los } \\
\text { beneficios del programa a pesar de que } \\
\text { sus condiciones socioeconómicas los } \\
\text { hacen merecedores de las } \\
\text { transferencias. }\end{array}$ \\
\hline
\end{tabular}




\section{ANEXO 2: Entrevistas}

\section{Jefe de Equipo Regional de Huánuco: Edwin Olórtegui}

- ¿Ud. como observa a la población de JUNTOS, ha mejorado o sigue igual que antes?

- Lo que se sabe es que ha habido una mejora a nivel nacional, la meta del presidente es bajar a $15 \%$ la pobreza, hemos ingresado a distritos nuevos donde no habíamos ingresado, plan de expansión

- Mi pregunta va a ¿cómo controlan el ingreso de nuevos beneficiarios?

- Nosotros no focalizamos, sino lo hace el SISFHO (...) Te explicaba, antes que entre JUNTOS al país, las postas medicas eran muy poco usadas por los pobladores de las zonas, hoy en día en todas las poblaciones donde esta JUNTOS, asisten los niños entre 0 y 5 años a sus controles, a sus vacunas en el primer año, en el segundo año a sus controles de crecimiento y así hasta los 5 años. Por un asunto cultural las mujeres que se embarazaban no se controlaban, esto también ha cambiado obviamente ha sido progresivo, hoy en día podemos decir que más mujeres embarazadas que asisten a los establecimientos de salud y ya son atendidas por los médicos de las diferentes localidades. Otro de los logros de JUNTOS es que antes de que entre había una gran deserción escolar enorme sobre todo en las zonas rurales, hoy en día si bien no se ha acabado, tenemos indicadores que muestran que ha bajado la deserción y ha aumentado la asistencia, hoy en día solamente el programa permite que un joven pueda faltar 3 veces en un periodo de 2 meses, si falta más, ya no cumple las corresponsabilidades e inmediatamente se les suspende, el hogar sabe que si no van se les suspenden. Si bien es cierto hablamos de mejoramiento de asistencia, la calidad del servicio no lo damos nosotros lo da le sector, pero la asistencia si lo estamos controlando, y eso hace que a partir del semestre de setiembre-octubre, se ha ampliado eso, antes era de 6 a 14 años, ahora es de 6 a 19 años, que significa, que aquellos de más de 14 años que estaban abandonados, se puede entender que hay subempleo en los jóvenes, son empleados pero con sueldos bajos, porque al no tener certificado de 5to de secundaria el dueño no les paga el sueldo mínimo porque no cumple los requisitos, entonces estos jóvenes que no ha terminado secundaria se ven en desventaja, entonces para evitar esta situación y romper la figura de generación de pobreza en las zonas rurales el gobierno ha ampliado hasta 19 años con la finalidad de supervisar en las zonas rurales que los chicos terminen secundaria, de tal manera que haya nexo, van a venir a las ciudades, pueden acceder a los institutos superiores, a las universidades o a otra actividad, de todas maneras tienen otra ventaja y eso es lo q está promoviendo JUNTOS.

- ¿Uds. como controlan, a través de los promotores, que la gente cumpla con sus corresponsabilidades? porque me decían que a veces por problemas con el líder o de malos entendidos, el líder podía sacarlos y el promotor a veces no verificaba y los sacaba del programa ¿Cómo verifican realmente que la madre no esté cumpliendo las corresponsabilidades y que no se trate de temas de enfrentamiento?" 
- La filosofía del programa está basada en que los gestores son fedatarios, entiendo que eso se puede dar, reconozco que seguramente habrá lugares que se puedan haber dado esas cosas porque hay lugares muy alejados que la misma accesibilidad no les permiten a los gestores llegar y tenemos las llamadas madres líderes, que son aliados importantes; es cierto que este asunto de conflictos sociales se puede dar pero cuando ya hay una alerta, el gestor debe ir a verificar, el programa indica que debe ir al sitio, de esa verificación que hace va a sacar una conclusión, por ejemplo hemos estado en Chusqui y se presentan dos usuarias del programa y me informan: "señor he salido del programa y no sé porque". Para sacar del programa se tiene que cumplir tres requisitos: ausentarse más de 6 meses, basta que los usuarios se hayan ido a otro lugar a vivir y ya lo sacamos; la segunda razón es porque ya no hay miembro objetivo, porque no hay niños menores porque la razón del programa no son las madres sino los niños entre 0 y 19 años; y, la tercera es tener información de que la usuaria ya tiene ingresos superiores a los $\mathrm{S} / .300$ puede ser que tenga una bodega o un comercio, entonces como ya hay un autoabastecimiento un autofinanciamiento, se le visita a la señora y se le dice que se le va a desafiliar. Pero tienes que entender que cuando están allá se resisten, pero también tenemos que entender que hay zonas donde también hay personas que no tienen esa posibilidad y que necesitan ser atendidos, por lo que hoy en día el programa ha ampliado la cobertura, antes estábamos a nivel nacional con un promedio de 456 mil usuarios, hay una tentativa de llegar a unos 700 mil a final de año, para que en el 2013 se llegue a los 900 mil. Para abarcar más hogares, esos hogares deben encontrarse en lugares donde la pobreza es mayor al $40 \%$ si es menor no intervenimos. Bajo esa verificación se saca a la persona, no hay otra cosa

- ¿Pero Uds. verifican eso?

- Claro

- Porque en una comunidad me dijo una madre que no la querían atender, quería hablar con el promotor pero este le decía q solo hablaba con el líder, no sabía porque la habían sacado a pesar de tener sus controles cumplidos.

- Eso es lo mismo que me dijeron la señora no sabía por que la habían sacado, yo se lo puedo asegurar que efectivamente ese puede ser un indicador en muchas personas pero si saben, incluso hay una cuarta salida: cuando ha sido suspendida tres veces. Porque el usuario firma un acuerdo de compromiso donde como responsable se compromete a llevar a sus hijos a salud y al colegio, si no ha cumplido le suspendemos un pago, pero con el pasar del tiempo puede ser nuevamente suspendido, y así una tercera, entonces cuando una familia tiene tres suspensiones en el sistema por incumplimiento, entonces ya hay una desafiliación cancelatoria. Yo le aseguro que si me trae a esa persona que refiere, ellas saben sino que dicen que no. En el caso de la señora que te mencione, acepto que tenía una bodeguita. Las reglas del programa dicen que es un alivio temporal de la pobreza, la temporalidad esta en razón de que las personas que están en situación de pobreza puedan con el dinero del programa adquirir algunas cosas, por ejemplo en Loreto, las personas han sacado créditos en una entidad y han comprado un "peque peque" y con el pago que les da el programa han ido pagando su crédito y ya son propietarios de sus botes, con eso salen a los ríos y hacen su pesca, al hacer su pesca ya hay un medio por el que la familia puede trasladarse y vender su pescado, con el producto 
de su venta compra su combustible compra las necesidades que requiere para su hogar, su arroz su azúcar, etc. es un medio bien aprovechado, esa es la idea del programa, eso están tratando de hacerlo en Huánuco, que compren sus cuyes sus animalitos. Se está rompiendo esta generación de la pobreza pero con la gente que si quiere salir de la pobreza; pero también hay gente conformista que no quiere hacer nada que solo quiere recibir; no somos un programa asistencialista, somos un programa que impulsamos el desarrollo y el capital humano, la idea es esa. Si es cierto no se está llegando en un $100 \%$ pero si estamos teniendo acciones de ese tipo. Todo depende la población, cuando está muy bien organizada entonces el desarrollo se va a generar. Hoy en día tenemos proyectos con FONCODES, en 2 de mayo y en Pachitea. En 2 de mayo, dos distritos van a entrar a un asesoramiento, vamos a seguir dando los incentivos, pero FONCODES va a entrar a hacer lo que se llama chacras productivas o mejoradas, eso son pilotos que nosotros pensamos introducir a las familias con la finalidad de que sean emprendedoras y esos productos bajen a Huánuco o a las localidades más cercanas para que se pueda mover el capital, también hay un proceso que a esas personas que logran tecnificarse el estado les va a dar acceso a crédito con la finalidad de que a través de la inclusión financiera puedan crecer más. Es un asunto de personas y cultura, de voluntad. Pero falta más apoyo de los gobiernos regionales.

- ¿Uds. tienen alianzas con otros programas? ¿Uds. capacitan a las madres, las orientan sobre cómo invertir el dinero?

- Sí.

- ¿Qué criterio hay para que después de los 4 años el hogar salga del programa?

- Esa era la idea cuando se inició, pero dadas las circunstancias del desarrollo del país, algunas poblaciones de lugares alejados sienten que no les llega, pero esto también es problema de la descentralización. Terminado los 4 años hay un proceso de recertificación, hoy en día son 7 años ya en Huánuco, pero no se ha sacado a nadie, salvo por las razones que ya te explique. La idea es seguir otorgándole el bono hasta que la familia este acostumbrada a trabajar a través de los proyectos de FONCODES ahí es donde nos articulamos; inicialmente se hacen esos pilotos entonces los resultados de ese piloto lo vamos aplicando en diferentes sitios, obviamente van a participar las zonas donde haya para poder desarrollar porque hay otras zonas donde no hay y tenemos que ver otra forma de generar ingresos. En realidad la misión del gestor no es tanto eso sino básico en salud y educación, pero como actividad complementaria, y dentro de lo que articulamos con otros programas del MIDIS o de ONGs, y de acuerdo a las propias experiencias de los promotores, ellos recomiendan actividades, no es su trabajo pero es un plus.

- Entonces lo que me dice es que no solo buscan aliviar con la pobreza sino también promover el desarrollo

- El MIDIS se crea justamente para eso, yo he estado en una reunión en Lima para promover los pilotos de desarrollo de egreso para las personas que ya estén preparados para eso, estamos haciendo inclusión financiera, porque antes una persona que tenía un crédito no podía entrar al programa, hoy ese criterio ya ha terminado, porque una persona puede tener un crédito para mejorar su chacra, y eso no significa que ya no sea pobre.

- Entonces según Uds. existen fallas pero no son tan grandes 
Personalmente no creo que haya fallas sino dispersiones, de 5 arriba 5 abajo y así, pero no fallas, sino que acá ya lo magnifican.

\section{Entrevista a Madres beneficiarias}

\section{Entrevistada $\mathbf{N}^{\circ}$ 1: NNN (Huánuco)}

- ¿Ud. recibe Juntos?

- JUNTOS si recibí pero ya me han quitado de 9 meses ya no cobro ya

- ¿tiene hijos? ¿de cuántos años?

- $\mathrm{Si}, 4$ hijos menores. Uno tiene 9 uno 12 uno 15 y uno 13

- ¿Y no le quieren dar el programa?

- No ya pues, vecinos ahí no más envidiosos, vengativos.

- ¿Cuánto tiempo recibió el programa?

- 1 año

- ¿Y se ha quejado con los promotores?

- Sí, pero no están ahora

- ¿Los lleva a la posta y al colegio?

- Sí, todo está al día

- ¿Ud. con el dinero del programa que compraba?

- Yo compraba ropa de muchachos, sus alimentos, útiles, pero para cuatro muchachos falta pues.

- ¿Qué alimentos compraba?

- Nosotros comprábamos un poco aceite, arroz, fideo y su ropa, zapato, pantalón...comprábamos carne, gallinas, carnero y chancho también criamos, eso siempre comíamos en mi casa, están acostumbrados quieren comer carne de chancho carne de gallina huevo quieren comer

- ¿Hay posta en su comunidad? ¿Les ayudan los médicos?

- Si nos ayudan

- ¿Y sus hijos están sanos?

- Si, están bien

- ¿Y cuando estaba en el programa su hijo trabajaba? ¿No les decía nada la promotora?

- Si trabajaba, pero no le avisábamos nada a la promotora.

- ¿Y cuando no recibía lo de JUNTOS, cuánto ganaba?

- Nosotros vendíamos carnero, ganado, en 6 meses ganábamos S/. 500 así es la chacra. Las mujeres tejemos mantas, vendemos manta, una manta vendemos a 35 soles, 30 soles, 25 soles, así no más los he hecho estudiar.

- ¿Ud. sabe si sus hijos aprenden?

- Sí, no han repetido ni un año

- ¿Todos tienen DNI? ¿Ud. les saco antes o porque el programa se lo exigió?

- No yo le saque porque mi hijo quería estudiar(...) pero ricos más reciben tiene carro tiene casa en Huánuco más reciben, tiene carro tienen camión bodega tienen y están cobrando, a mi si no quieren apoyar digo yo

- ¿Y los promotores no les dicen nada?

- No pues, eso apoyan también, los promotores no suben a mi chacra, ellos dicen que solo van a hablar con el líder de mi pueblo.

- ¿Y la comunidad no dice nada?

- No la comunidad compran capaz la gente rica (...) 


\section{Entrevistada $N^{\circ}$ 2: Yovina (Vinchos)}

- ¿Tú recibes el programa desde cuándo?

- 3;4 años

- No te han suspendido

- No

- ¿Cuántos hijos tienes? ¿qué edades tienen?

- Dos. Uno de 7 años y de 1 año 6 meses

- ¿Uds. en que trabajan?

- Agricultor no mas no hay nada más, para consumir no más porque todo esta barato

- ¿con el dinero del programa que consumes?

- Es para niño, no da para más. Su alimento los traigo a la posta pasajes, así no mas es.

- ¿consumes otros alimentos?

- Compramos alimento de niño arroz su leche su carnecita, criamos animales también pero esas crías se acaban, compramos de Huánuco también

- ¿ropa le compras?

- Ropa para que vayan a estudiar, útiles también.

- ¿Tu hijo menor va al colegio? ¿en qué grado esta?

- $\mathrm{Si}$, en 2do grado

- ¿Tú lo notas que aprende?

- $\mathrm{Si}$

- ¿Lo traes a sus controles?

- Si cada mes, todos sus papeles los tengo

- Cuando estuviste embarazada ¿viniste a tus controles? ¿Nació sanita?

- $\quad \mathrm{Si}$, nació sanita

- ¿En la posta les enseñan planificación familiar? ¿Es del programa JUNTOS?

- $\mathrm{Si}$, con programa es.

- ¿No quieres tener más hijos?

- No, difícil ya es, uno siquiera es difícil, cuando es chiquito se enferma (...)

\section{Entrevistada $N^{\circ}$ 3: Ana, 35 años (Churubamba)}

- ¿Hace cuánto recibe el programa?

- Recién un año va a ser

- ¿Cuántos hijos tienen?

- Dos, ella tiene 3 años 8 meses y el 1 año ha cumplido

- ¿Qué compra con el dinero que recibe?

- Mayormente lo que falte, víveres, cuando le falta a ella que va a 1 jardín, su leche su ropa o cuando le falte cositas

- ¿Ud. trabaja? ¿Su esposo? ¿Cuánto gana su esposo?

- Yo no, mi esposo sí, es agricultor. No es diario el trabajo a veces son 2 semanas, s/. 200

- ¿El programa les ayuda?

- Aunque es poquito si nos ayuda

- ¿Y los traes a sus controles?

- Todos los meses los traigo

- ¿Al colegio van?

- Ella va al jardín

- $\quad$ iy tienen DNI?

- Si

- ¿Tú fuiste a tus controles prenatales cuando estabas embarazada?

- Si siempre 
- ¿Les enseñan planificación familiar? ¿tú ya has decidido cuantos hijos vas a tener?

- Los dos únicos, para que más, ya no quiero más.

- ¿Tú has visto si hay personas que reciben el programa y que tienen dinero o bodegas?

- Acá la mayoría no tiene, algunos conocidos tienen pero ellos no reciben, pero la mayoría que reciben son personas que necesitan

- ¿me dices que con el programa compras leche, cosas para ellos para el colegio, no necesariamente compras solo alimentos?

- no necesariamente porque tengo que hacer alcanzar, como mamá yo ya sé que le falta entonces voy y compro lo que les falta no solamente ropa, por decir este mes no le compro ropa pero compro lo esencial para su comida ya el otro mes ya bueno si le falta tengo que hacer el esfuerzo de comprar.

\section{Entrevistada $\mathbf{N}^{\circ}$ 4: NNN}

- ¿Hace cuánto tiempo recibe el programa?

- Desde que ha nacido el programa

- ¿Cuántos hijos tiene?

- Cuatro. Dos ha terminado secundaria uno está en segundo. El mayor tiene 19 y ha terminado el anteaño pasado, el menor tiene 9

- ¿Qué compra con el dinero?

- Le doy su propina le compro alimentos,

- ¿Qué alimentos compras?

- Le doy así habas, de alverja leche huevo

- ¿Le compras ropa?

- ropa, uniforme le compro

- ¿Sabes que alimentos son nutritivos?

- Nos dicen pescado leche huevos,

- ¿Y eso le compras?

- Si bueno lo que alcance

- ¿Antes del programa en que trabajabas?

- En la chacra sembramos productos

- ¿siempre los traes a sus controles?

- Si siempre

- ¿Y van a la escuela todos los días?

- Sí. Ahora estoy suspendida porque el segundo no le da baja, porque dice termina su secundaria un documento tienen que presentar $\mathrm{x}$ eso estoy suspendida. Todos los días van a la escuela, cuando se enferman presento su certificado.

- ¿tus hijos trabajan y estudian?

- No, solo en la chacra nos ayudan

- ¿Notas si tus hijos aprenden?

- Si aprenden

- ¿Antes de entrar al programa que alimentos comían?

- Siempre comíamos criábamos gallinas daba huevo siempre pues los animalitos

- Ahora con el dinero compran mas

- Si pero sigo trabajando no nos vamos a esperanzar en el dinero no mas

\section{Entrevistada $N^{\circ}$ 5: Marlinda Benancio (Churubamba)}

- ¿Desde cuándo recibes el programa?

- Desde que inició

- ¿Cuántos hijos tienes? ¿qué edades?

- Dos. El mayor tiene 12 y el menor tiene 10 
- ¿Todos los días van al colegio?

- Si, nunca falta

- ¿Y tus hijos trabajan?

- En casa, cuando no tienen tareas si nos ayudan

- ¿Y tú trabajas?

- Claro en chacra sembrando maíz

- ¿Qué compras con el dinero del programa?

- Lo que falte, sus uniformes, sus zapatos, sus alimentos, su manzana su plátano

- ¿Qué alimentos compras?

- Frijolito, lentejitas alverjitas partidas, verdura, y su pollo pescado, y con nuestros mismos animales también

- ¿Y antes que comían?

- Lo que producíamos vendíamos y con eso comprábamos

- ¿compras azúcar fideos?

- Muy poco

- ¿Traes mensualmente a tus hijos a la posta, a sus controles?

- $\quad$ Si siempre, puntual

- ¿Los promotores del programa los controlan?

- Si acá los doctores nos controlan

- ¿Tú notas si tus hijos aprenden en el colegio?

- Si aprenden, yo voy a preguntar a su profesora y me dice que si están aprendiendo

- ¿Antes del programa los mandabas todos los días al colegio? ¿Los traías a la posta?

- Si puntual iban. A la posta si siempre hemos sido puntuales antes.

- ¿Acá les enseñan planificación familiar?

- Si nos enseñan para cuidarnos

- El dinero que recibes, ¿has pensado ahorrarlo e invertirlo en algún pequeño negocio?

- Si, con eso hemos comprado cuyes para hacerlos aumentar

\section{Entrevistada $\mathbf{N}^{\circ}$ 6: Fernanda (Chrubamba)}

- ¿Desde cuándo recibe?

- Ya hace 3 años, por mi nieto recibo

- ¿No la han suspendido?

- No, porque le hago todo, con esa plata le compro su ropa le doy su peso, todo no le falta, bien atendidito esta.

- ¿Va todos los días al colegio?

- Va todos los días

- ¿Lo trae mensualmente aquí a la posta?

- Sí, su control es a tal hora tal mes, el 13 nació el 13 se controla cada mes.

- Ha notado si su nieto aprende

- Si, está bien, le pregunto a la profesora

- ¿en el programa no le piden nada más a cambio de los controles que siempre les piden?

- No nada.

- ¿Con el dinero que recibe que compra?

- Sus zapatos, sus útiles, comida también, su leche su sopa, y ahora también pasaje no más para trabajo porque eso también no nos va a aguantar dos meses, eso ahorita compro un pantalón un uniforme, una camisita, zapatos ya se fue todo

- ¿Y alimentos no compra mucho?

- No, si compro trabajando, para el diario siempre se compra 
- Ah pero el dinero más lo destina a la ropa, a sus útiles

- Si, ahora sus propinas para el colegio, ahora diario le doy un sol, porque si no, no hay nada más baratito para que coma el niño siempre antoja en el colegio

- ¿Cría animales?

- Si crio, de eso consumo un poco me voy a trabajar vendo comida eso

- Antes que entrara al programa ¿consumía alimentos distintos?

- Si leche, como siempre igual se come

- Entonces, su consumo no ha cambiado

- No

- ¿tiene chacra? ¿parte del dinero no lo ha destinado para mejorar su chacra?

- No pues, no alcanza el dinero.

\section{Entrevistada $N^{\circ}$ 7: Silveria, 65 años (Pacrapucro)}

- ¿Ud. es beneficiaria desde que comenzó el programa?

- Sí, pero estoy suspendida, porque perdí mi DNI

- ¿Ud. recibe solo por su nieto?

- Si por mi nieto porque no tiene ni mama ni papa

- Y ¿Ud. lo manda todos los días a la escuela?

- Si todos los días, a la posta al colegio, continuo

- Con el dinero que recibe que le compra

- Todo lo que es para su colegio

- Que alimentos le da

- Leche, carne, pollo pescado

- Antes que recibiera que alimentos consumía

- Lo mismo no más, antes vendíamos gallina, cuy para comprar

- ¿Su nieto aprende en el colegio?

- Si

- ¿Ud. el dinero que recibe lo destina a su nieto, y para Ud. o para su chacra?

- Si, para mi nieto, para mí no.

\section{Entrevistada $N^{\circ}$ 8: NNN (Pacrapucro)}

- (...)Si no vas a reunión por 1 día S/. 10 te hacen colaborar por ese día que no has ido

- ¿Quién les cobra?

- El líder nos dice: "Eso ha dicho el promotor para cobrarles así"

- ¿Ud. sigue recibiendo el programa?

- Si recibo pero ahora estoy castigada

- ¿Cuántos hijos tiene?

- Yo tengo 6 hijos, dos menores. El mayor tiene 27 y el menor tiene 5

- ¿Siempre los manda al colegio?

- Si todos los días, ahora pura lluvia igual los he mandado

- ¿Mensualmente los trae a su control?

- Si mensualmente

- ¿Antes del programa q alimentos consumía?

- Menestras arroz fideos leche, alverjas lo que producimos la leche si la compro.

- ¿Carne consume?

- Si eso es de gallina

- ¿Con el dinero que recibe del programa que compra?

- Eso es más que todo para el colegio colaboración al colegio, nos piden copia, un poco para su vestimenta, como son huérfanos son más para sus víveres, en esas cosas, huevos, cosas que no produce la chacra eso compramos 
- ¿Cuando estaba en el programa, venía a sus controles prenatales?

- Si venia

- ¿En la posta les dicen que alimentos son más nutritivos?

- Nos dice que para el bebe de 6 meses que aprende a comer nos enseñan para dar de comer hígado, sangre, eso. Yo sé también porque he trabajado 108 años de promotora de salud, yo les aviso también al resto.

\section{Entrevistado N9: líder comunal de Pacrapucro}

- ¿Ud. recibe el programa? ¿desde cuándo recibe?

- Sí. Recién recibo 3 años, pero primero recibí con mi hijo mayor de 15 años

- ¿Cuántos hijos tiene?

- Dos, uno de 5 años y el otro de 15

- ¿Ud. lo manda todos los días al colegio?

- En el Pronei está, cuando no hay clases no lo mando, o cuando está enfermo

- ¿Y también lo traes mensualmente a la posta?

- Sí, mi hijo es sano

- ¿Sabe que alimentos son nutritivos?

- $\mathrm{Si}$

- ¿Antes del programa sabía que alimentos eran nutritivos?

- Si, igual

- ¿Consumía lo mismo antes del programa y ahora?

- Si igual consumíamos, normal pues igual, osea no le dábamos golosinas, le dábamos menestras, frutas. En los pueblos la mayoría de mama saben.

- ¿Nota si su hijo aprende?

- Sí. Mensual tenemos reunión con la profesora. Como reciben alimentos del Pronaa siempre cada dos meses hacemos a reunión, ahí a veces las mamas hacen sopa también y nosotras no permitimos, hay mamas que no son de JUNTOS y dicen porque no reciben JUNTOS le pueden dar lo que quieran y eso no es así, sopa no es alimento.

- Antes del programa, ¿consumías pescado?

- Si, consumíamos. Pescábamos del rio

- ¿Ahora con el dinero del programa compran o siguen pescando?

- Pescamos pero a veces compramos cuando no hay, el pescado en el rio tiene su tiempo, no es todo el tiempo. Compramos su leche no se lo q no hay.

- Me comentaban que a veces hay líderes que por problemas con alguna persona o familias los sacan del programa, ¿tú has tenido esos problemas?

- No yo tengo años y nunca he tenido esos problemas.

- ¿Y en tu comunidad hay gente que realmente necesita el programa y que no recibe? ¿por qué?

- Si hay pero no entran, no sé porque será, pero se han censado se han escrito pero no entran.

- ¿Qué requisitos les piden?

- Censo, ahí te preguntan presentan tus papeles eso. A nosotros de JUNTOS también nos ha dicho que no es una plata que termines todo eso es para que inviertan también cuando ya no haya programa JUNTOS, no lo van a acabar, nos han dicho que pueden hacer aumentar más, sus animales, también en chacra pero más es en animales

- ¿Uds. invierten en su chacra?

- Criamos cuyes, la mayoría cuyes, ya tengo para que coman y a veces nos falta vendemos, invierto en cuyes, cuyes tienen la mayoría.

- ¿Eso se los dice el promotor del programa? 
- Mas antes así nos han dicho tenemos cada mes reunión. Algunos han puesto su tiendita un poco así. Por ejemplo hay mamas que no tenían su animales y ahora que han recibido su platita han recibido 200 y con 100 han comprado 10 cuyes, lo han hecho aumentar y ahora una parte venden una parte comen.

- Por cuando tiempo es el programa

- No se hay un contrato x 6 años, depende también, hay mamas que no cumplen con todo lo que les dicen y les quitan. Cuando no ha habido juntos la mayoría no tenía su DNI ni su partida, ahora con juntos la mayoría han sacado todos los niños ya casi tiene habrá poquitos que no tienen, antes no les importaba sacar, ahora con el programa juntos obligatoriamente todos hacen sacar y todos hacen estudiar también.

\section{Entrevistada $N^{\circ}$ 10: Domitila 28 años}

- ¿Ud. con el dinero cría animales?

- $\mathrm{Si}$, cuyes también compro, criamos. Ahí tenemos cuyes grandes aparte chiquitos para q no se mueran.

- ¿Y eso se lo enseñan en el programa JUNTOS?

- No eso también viene del programa CRECER, ahí nos han dicho que nosotros podemos criar nuestros animales, eso con lo que cobro con eso compro, cuando me falta dinero con eso vendo, con eso pongo de su colegio que piden colaboraciones, ya eso le doy

- Entonces, con el dinero compras alimentos, útiles y otra parte la inviertes

- Yo en verdad cuando he vivido en la chacra no tenía nada y ahora con el programa también como soy madre soltera, si en algún tiempo el programa se cierra de donde voy a mantener, entonces yo he juntado hasta 1000 soles agarre ese dinero y me he comprado abono y he hecho una sembrada, con eso puedo tener y con eso puedo alimentar. Yo decía si un día me dicen ya no van a cobrar ya acá se termina, entonces que hago, tanto que he recibido ese dinero, que ha habido oportunidad, entonces yo digo mejor voy a agarrar esa plata y voy a hacer una inversión y con eso yo me quedo ya para toda mi vida esa plata ya puedo salir a vender y ahí con ese dinero ya puedo hacerlo estudiar hasta la universidad, y eso muchas madres no entienden, cobran y se compran lo que quieran. Yo con eso debo hacer algo para la vida de mi hijo.

- Entonces tu ahorras el dinero

- Si yo estoy ahorrando

- ¿Solo tienes un hijo?

- $\quad$ Si, uno. Él tiene 7 cumplidos

- ¿Tú lo mandas todos los días al colegio?

- Si todos los días, por eso también el enfermero me ha dicho porque has llegado tarde, porque está estudiando y su profesora cuando yo lo hago fallar su profesora me dice que le van a hacer recuperación. Cuando lo hago fallar me requintan.

- ¿Todos los meses lo llevas a la posta?

- Si mensual

\section{Entrevistada $N^{\circ}$ 11: Carmen (Ambo)}

- ¿Recibe el programa JUNTOS?

- Si

- ¿Cuántos hijos tienes?

- Dos hijos, de 3 y 1 año

- ¿Los mandas al nido?

- Están en Wawawasi

- ¿porque el programa se lo exige? 
- $\mathrm{Si}$

- ¿Y los llevas todos los meses a sus controles de salud?

- Si

- Con el dinero que recibes, ¿qué compras?

- Compro sus alimentos, su calzado, su vestido

- ¿Y qué alimentos compras?

- Carne, azúcar, fideos

- ¿Leche compras?

- También

- ¿Y tú trabajas? ¿Tu esposo?

- Yo no, mi esposo si, en la chacra

- Antes del programa, ¿en que trabajaba?

- Igual también

- ¿Cuánto ganaba mensual o semanal?

- Semanal le pagan, 95 soles

- Ahora que vas a la posta, ¿te dicen que alimentos son nutritivos?

- Sí, porque cada que le llevaba me decían

- Y antes del programa, ¿sabías que alimentos eran nutritivos?

- Sí, porque cada que le llevaba me decían

- Y antes de entrar al programa, ¿consumías lo mismo?

- No

- ¿Qué consumías antes además de lo que consumes ahora o que ya no consumes?

- Aceite, así, alimentos mejores

\section{Entrevistada $N^{\circ}$ 12: Mercedes (Ambo)}

- ¿Recibes el programa JUNTOS?

- $\mathrm{Si}$

- ¿Cuántos hijos tienes?

- Tres tengo y 1 nieta

- ¿Qué consumes con el dinero del programa?

- Compramos su menestra pues, su pescado su leche, su yogurt, alimentos

- Antes ¿consumías lo mismo?

- No, en eso no más es.

- ¿Lo que comprabas antes es distinto a lo de ahora?

- Su ropita nada más, ahora ya estudia mi hija

- ¿A tus hijos los mandas todos los días al colegio?

- Si todos los días

- ¿Y trabajan tus hijos?

- No ninguno

- ¿Y antes trabajaban?

- Si cuando estaban en chacra si trabajaban. Ahora he venido a Ambo a hacer estudiar ya no trabajan, en su estudio no más, llega de colegio y sus libros leen

- ¿Y tú notas si tus hijos están aprendiendo?

- Sí, todo saben acá, pero en cambio en chacra no sabían nada. El estudio es fuerte en ciudad, porque arriba las profesoras en altura no es como en ciudad, a veces x una semana hay algo así acaso vienen, por eso yo me he traído a mis hijos acá, porque acá si todo han aprendido

- ¿Los traes mensualmente a tus hijos a los controles?

- $\mathrm{Si}$

- ¿Los notas mejor de salud? 
- Si, más sanos, ya no se enferman mucho

- Antes del programa, ¿los traías a la posta?

- Si, desde bebitos, antes de recibir el programa. de mi nieta su mama no le he hecho controlar, la posta no ha conocido, en chacra no más mi mama todo tenia, no conocía ni ciudad nada, en cambio ahora de mis chiquitos que tengo su papa ya dice ya llévelos a su control de mis hijos, por eso ahora ya están bien controlados todo

- ¿En la posta te capacitan te dan alguna información sobre nutrición o que le tienes que dar a tus hijos?

- De mi están bien, yo no recibo alimentos nada, otros reciben por peso bajo, de mi completo peso y talla igualito están bien, de otros no crecen así.

- ¿Con la pata que recibes algo lo inviertes o lo ahorras?

- No nada, mis hijos quieren comer su leche su mazamorrita, a pesar de estar grande 12 años quiere tomar leche no más el, entonces tengo que comprar su leche su menestra su pescadito, su carne quiere comer carne no más, a pesar de que ha venido acá a aprender, antes en chacra no sabía ni comer ni zanahoria ni nada no quería en cambio acá sí.

- Entonces tú has notado que ha habido cambio en tu hijo en cuanto a su alimentación.

- $\quad \mathrm{Si}$, ahora si todo quiere comer no más, yogurt también así, "compra, para que recibes plata, para comer para alimentarme yo" me dice mi hijo mayor. Ahora que se le ha roto un poquito su zapato, ya me dice "mamita ya está rompiendo mi zapato, mi plata tendrás todavía" así dice. "voy quejarme ah, sí me terminas tú, yo voy quejarme" así me dice

- ¿Y tú trabajas?

- No yo no trabajo, yo cocino lavo en mis hijos no más. Mi esposo va en chacra, pero medio enfermizo es también, no es sano

- ¿YY él no te pide el dinero?

- No, no me exige

- Y antes de ingresar al programa, ¿cuánto tenías de ingreso mensual o semanal?

- Mensual trabajando en chacra, s/. 20 S/. 15 es para diario no más, hay veces cuando hay trabajo va, cuando no hay trabajo no va pues

- ¿Tú crees que más adelante puedas ahorrar parte de la plata que te da el programa?

- No, nada. Con muchachos no se puede ahorrar nada. Mis hijos quieren comer cualquier cosa, quiere comer yogurt, jugos "hágame mi jugos mamita" me dicen. Hago pues en su juguito también hecho huevo leche

- ¿Pero no les das comida chatarra ni dulces?

- No, en la mañana en su desayuno hay veces no quiere quinua le cansa comer, "mamita yo quiero con mi jugo no más hágame" me dice entonces hecho 2 huevos su leche su papaya su piña su juguito hago y con su pan no más se viene al colegio no más, entonces con eso ya plata se va, plata es para ver no más.

\section{Entrevistada $N^{\circ}$ 13: Maribel (Canchacay)}

- ¿Hace cuánto recibes el programa JUNTOS?

- 8 años ya

- ¿Cuántos hijos tienes?

- Yo tengo 2 hijos, de 9 y el otro tiene 12 años

- ¿Tus hijos van todos los días a la escuela?

- Si

- ¿Y los llevas también a sus controles mensuales?

- $\mathrm{Si}$

- ¿Y qué haces con el dinero que recibes? 
- compramos sus menestras de nuestros hijos, para su propina, lo que le piden en la escuela para sus útiles, su leche

- ¿Y tú el dinero no se lo das a tu esposo? ¿No te lo pide?

- No para nada, eso es muy aparte.

- Entonces, ¿todo el dinero que recibes del programa es para tus hijos?

- Si todo es para mis hijos

- ¿Y cómo van tus hijos en el colegio? ¿Tienen buenas notas?

- $\mathrm{Si}$

- ¿Tú vas a preguntar por tus hijos? ¿Y qué te dicen los profesores?

- Si está bien me dicen, a veces está un poco bajo su nota, nos avisan que están bajando

- ¿Y están sanitos tus hijos?

- $\mathrm{Si}$

- En el puesto de salud si tus hijos están bajos de peso, ¿te dan alimentos?

- No, para desparasitar no más nos dan pastillas, es por eso que no sube de peso talvez $\mathrm{x}$ eso

- ¿Y del dinero que tienes, algo ahorras?

- Si lo ahorro

- ¿Lo ahorras y lo inviertes o solo ahorras?

- No lo ahorro no mas

- ¿Y qué vas a hacer con ese dinero?

- Para el otro año, para sus útiles de mis hijos, otra vuelta para que empiece a estudiar para su uniforme para sus útiles, así no mas ya me guardo, entonces el año viene ya le compro todo zapatos todito ya, porque a veces sin plata estamos empiezan las clases con que comprar útiles uniformes.

- Antes de entrar al programa, ¿qué alimentos consumías?

- Consumíamos así trigo, maíz, habas, papa

- ¿YY ahora consumes algo más?

- Ahora consumimos con eso recibiendo leche, lentejitas alverjitas frejol castilla maca avena, quinua, más cosas que antes no he consumido

- ¿Y tú trabajas ahora?

- No me dedico a mis hijos no más, mi esposo si trabaja en la chacra

- ¿Y antes del programa cuanto ganaba tu esposo?

- En la chacra mínimo ganas, depende hay veces pagan 15 soles 20 soles

- El jornal del día, pero no es todos los días entonces, ¿cuantos días?

- No, a la semana cuando hay trabajo más o menos para que dure se va 2 semanas 3 semanas se va y luego vuelve, otro trabajito se busca

- ¿Antes del programa tus hijos iban a la escuela?

- Si iban a la escuela, yo trabajaba así ayudaba

- ¿Iban todos los días?

- Todos los días, aunque no me alcanzara, aunque sea con 20 céntimos de su propina

- ¿Y también los llevabas a la posta igual antes del programa?

- Si igual, hasta ahora

- Entonces lo único que ha cambiado es tu alimentación

- $\quad \mathrm{Si}$, su alimentación su vestimenta, sus estudios

- Y en cuanto a planificación familiar, ¿en la posta les hablan de eso?

- $\mathrm{Si}$

- ¿Y tú ya decidiste no tener más hijos?

- Sí, yo ya decidí no tener, basta dos. Porque ahora todo cuesta pues, los niños al ver a sus compañeros quieren poner ropa buena quieren comer comida buena, de todo quieren, ellos no dicen así no más me voy a estudiar 
- ¿y tú a tus hijos les das golosinas, chizitos eso?

- no eso no le doy, galletas si le doy, porque yo he sufrido de gastritis por gaseosa, por eso no le doy, en vez de eso le doy agua de piña así haciendo hervir cascarita, le hago su jugo con betarraga su papaya, eso le hago, porque en televisión se ve que esas cosas tienen colorante intoxican por eso yo viendo eso no le doy, en la posta también nos capacita en la posta

- ¿pero eso es parte del programa o es porque salud así los capacita siempre?

- no, ahora recién, antes no nos capacitaban, y además antes ni para comprar eso no alcanzaba, ahora si me alcanza, ahora mis hijos quieren comer pollo así me dicen, le hago comer, pescado así

- ¿Y qué haces con el dinero que ahorras?

- yo dos carneritos he comprado, ahora ya su carnerito ya ha dado cría también, eso cuando aumenta ya vendemos ya también

- me imagino que no quieres depender siempre del programa, con el dinero ¿qué estás buscando?

- No, no. mantener sacar adelante a mi hijo tener un pequeño negocio para dejarle algún futuro a mi hijo porque yo también no voy a vivir todo el año, yo pienso yo digo como quisiera juntar esa plata dejarle algo a mi hijo siquiera cualquier cosita alguna bodeguita para que ellos también sepan mantenerse

- ¿Y para eso tu estas ahorrando?

- Eso rápido no alcanza también, hemos comprado cuyes, gallinas para criar, de machos cuatro no más he comprado

- Y si tú te atrasas en llevarlo un día a su control en la posta, ¿te suspenden?

- No, no nos suspenden. Acá hay veces suspenden porque el programa JUNTOS nos dan 4 cosas para cumplir pero acá hay veces nos dicen para limpiar la calle para bordar manteles nos dice para hacer el biohuerto

- ¿Quién les dice eso?

- La promotora pues

- ¿Y para q es eso? ¿No les dice?

- No de eso si han salido varias suspendidas 3 meses castigadas, luego de 3 meses recién van a cobrar

- Es decir, si el promotor les dice que deben bordar hacer limpieza y Uds. no lo hacen, ¿las suspenden?

- Nos suspenden

- Pero esa no es una condicionalidad del programa

- Eso también digo yo pues porque en el convenio eso no está en el convenio esta tan solo 4 cosas: identidad salud nutrición y educación, pero a nosotros de eso aparte fuera nos hacen hacer limpieza nos hacen bordar manteles

- ¿Y eso no les explican para qué es?

- No

- ¿Y me dices que si no lo hacen corren el riesgo que lo saquen del programa?

- $\mathrm{Si}$

- ¿Tú sabes de alguien que lo hayan suspendido por eso?

- No, pero en Sacsahuanca si varios han estado suspendidos

- ¿Por ese motivo?

- Si, x limpieza

- ¿Y Uds. no se quejan con alguien?

- Es q no sabemos pues donde quejarnos nada, tan solo al promotor nada más obedecemos, no sabemos dónde quejarnos, y así pues este mes mi mama estaba 
suspendida y no sabemos porque y su hijito va a 1 colegio no había cobrado el mes pasado y este mes recién va a cobrar

- ¿Y tú mama no trabaja?

- No, y de ella su hijito esta en 1ero de secundaria ya, de ella su hijito no falta. No nos ha dado explicación

- ¿El promotor no habla con Uds.?

- No, no nos ha dado explicación

\section{Entrevistada $N^{\circ}$ 14: Felicita (Maraypata)}

- ¿recibes el programa JUNTOS?

- si

- ¿hace cuánto recibes el programa?

- desde el inicio

- ¿y cuantos hijos tienes?

- Yo uno no mas

- ¿De qué edad?

$-7$

- ¿Y lo mandas todos los días al colegio?

- $\mathrm{Si}$

- ¿También lo mandas mensualmente a su control de salud?

- Si

- ¿Tú notas si tu hijo está aprendiendo? ¿En qué grado esta?

- Si, en 2do grado esta,

- ¿Y ya sabe leer sabe escribir sumar?

- Si, acá estudia en el colegio Virgen del Carmen. Arriba en Canchacay no hay escuela, acá también ha crecido mi hijito, acá ya vive y acá recibe también el programa

- ¿ ¿Tú vives acá?

- Si, acá ya vivimos, no quiere hacer volver ya a la chacra

- ¿Tú no trabajas tampoco?

- Yo no trabajo, soy madre soltera, cuando hay trabajo, trabajo, en casa trabajo a veces

- ¿Y antes del entrar al programa, como te mantenías tú con tu hijito?

- Trabajaba, cuando estaba chiquito trabajaba en casa, cuando estudia ya no puedo trabajar

- ¿Y cuánto ganabas?

- S/. 150 a veces S/. 100

- ¿Al mes?

- Al mes 100 no más te pagan en casa, así no puedo trabajar ya le llevo su almuerzo le cocino su almuerzo nadie que me ayude hay, tengo que hacer tejer así blondas, así bordo

- ¿Con el dinero que tienes del programa que le compras a tu hijo?

- Eso sus útiles, sus alimentos

- ¿Qué alimentos compras ahora que antes no podías comprar?

- Ahora compramos su leche su menestra, carne, pescado, hígado, pollo a veces

- ¿Y tú crías animales?

- Si criamos, cuy gallina

- ¿Antes que le dabas de comer antes?

- Cuando nos alcanzaba comprábamos. Primero comprábamos leche poco menestra también poco, pero antes así maíz trigo así lo que producíamos en la chacra, acá ahora si compramos todo alimentos, menestras leche soya avena, maca todo habas ahí todo ya pues 
- ¿Y para sus útiles? ¿Todo el dinero lo dedicas a tu hijo?

- Si

- ¿Y puedes ahorrar algo del dinero que recibes?

- Si ahorramos guardamos 50 así 60 soles por ahí no mas

- ¿Y qué haces con ese ahorro?

- Lo invierto así lo gasto

\section{Entrevistada $N^{\circ}$ 15: Zulema Paredes (31 años) Cuchacaya}

- ¿Hace cuánto tiempo recibes el programa JUNTOS?

- Yo 2 años no mas

- ¿Y por qué dejaste de recibir el programa?

- Porque me cortaron

- ¿Le dijeron por qué?

- Porque de mi chiquitín no presente su copia de DNI

- ¿Y cuántos hijos tiene?

- Uno de 4 y el otro de 12

- Con el dinero que recibía, ¿qué cosas compraba?

- Para ellos compraba sus menestras su ropa, para su educación para q estudia el otro sus cuadernos

- ¿Y los mandaba siempre al colegio?

- Si sin hacer faltar sino también estábamos suspendidas

- ¿Y siempre los traía puntualmente al centro de salud?

- Si, a Cuchacaya, todo está al día. Cuando estaba embarazada ya entrado al programa JUNTOS, a mi hijo, de un mes ya le he sacado su DNI también

- ¿Y antes de ingresar al programa lo mandabas todos los días al colegio?

- Si todos los días, para que se ponga al día difícil

- ¿Y acá al puesto de salud también lo traías antes?

- Si su control

- ¿Y antes de entrar al programa, que cosas consumías?

- Nosotros en chacra pues, alverja trigo maíz

- ¿Y con el dinero podía consumir más cosas?

- Si

- ¿Qué cosas podía comprar con el dinero del programa, en alimentos, que no consumía antes?

- Lentejitas, frijolito pallar

- ¿Eso no lo producías?

- No, no sembrábamos

- Y antes del programa, ¿en qué trabajabas tu o tu esposo?

- Así en chacra no más nosotros

- ¿Y vendías o solo para consumo?

- Así para consumir no más, un poquito de carnero tenía en chacra

\section{Entrevistada N$^{\circ}$ 16: NNN (Ambo)}

- ¿Cuántos hijos tiene?

- Tres

- ¿De qué edades?

- Uno 12, el otro 11 y la más chiquita va a cumplir 1 año

- ¿Desde cuándo recibe el dinero?

- Recién un año

- ¿Y con el dinero que compra? 
- Compramos ropa, para que coman todas sus menestras frutas, carnes, lo que falte pues siempre

- ¿Y Ud. trabaja o solamente recibe el programa?

- Si trabajamos, que va a alcanzar

- ¿Y en que trabajas?

- En agricultura

- Y antes del programa, ¿cuánto ganabas?

- Según que cuesta la papa pues

- ¿Según el precio de la papa? ¿No era diario ni semanal?

- Aja

- Y ahora que estas en el programa ¿los mandas todos los días a la escuela?

- Si, paran estudiando ahí, por eso cuando está yendo al día pero ahorita me han cortado

- ¿Y por qué les han cortado? ¿No les han dicho?

- Educación me han dicho, pero mis hijos están al día, he sacado lo que ha estado al día en escuela he presentado al coordinador, y me dice que te lo haga tu profesora vuelta

- ¿Y tú los traes mensualmente a sus controles?

- Si

- Y antes del programa ¿qué alimentos consumías?

- Normal compraba, lo que cosechaba

- ¿Tenías chacra?

- Si, chacra poco tenemos en altura

- ¿Y lo que cosechabas de eso le comprabas?

- Según que encontrábamos plata comprábamos

- De la plata que recibes, ¿algo puedes ahorrar?

- No en ellos no más se va toda la plata, cuando compras sus pantalones, sus zapatos ahí no más se va cuando compras sus alimentos, ahí no mas

- ¿Cómo les va a tus hijos en el colegio? ¿El profesor te dice que está yendo bien?

- Si, si voy, si está bien me dice.

- ¿Tus hijos no trabajan?

- Ellos no trabajan

- ¿No te ayudan tampoco en la chacra?

- Si, en chacra no, acá en casa si,

- ¿Y tú sabes si en tu comunidad hay personas que no tengan necesidad de recibir pero que aun así reciben el programa?

- $\mathrm{Si}$

- ¿Y el coordinador no dice nada?

- No dice nada, no te preguntan

- ¿Los del programa te capacitan? ¿Te dicen que hacer con el dinero que tienes?

- Si, alimenta a tus hijos te dicen

- ¿Pero en cuanto a ahorro?

- Que vas a ahorrar así, no puedes ahorrar, eso se va en su propina, en sus cositas se van

- El dinero te ayuda bastante pero no te alcanza

- Si, para ahorrar ya no pues.

\section{Entrevistada $N^{\circ}$ 17: Yolanda - Conchas}

- ¿Hace cuánto tiempo recibe el programa?

- Un año recién

- ¿Cuántos hijos tiene? ¿De qué edades?

- 5 hijos. El mayor tiene 22 y el menor 18

- Antes del programa ¿qué alimentos consumía? 
- Normal, mas menestras

- Y ahora con el dinero del programa ¿que consume?

- Eso es más para la educación de mis hijos, que necesito las cosas compro, lo que necesito compro, y útiles sus propinas

- Y respecto a alimentos, ¿qué alimentos compra ahora que antes no podía comprar?

- Ahora le vario con todo pues, mas leche más pescado, eso

- ¿Y algo de ahorro tiene con el dinero del programa?

- No

- ¿Y sus hijos trabajan y estudian?

- No, solamente estudiando

- ¿Y antes del programa trabajaban?

- Si, antes la mayor

- ¿Cuantos días van sus hijos al colegio?

- Toda la semana, de lunes a viernes

- Y al médico ¿los lleva siempre?

- $\quad$ Si a sus controles

- ¿Alguna vez la han suspendido del programa?

- No nunca

- Además de las condiciones que le exige el programa, ¿se les exige alguna otra más?

- No solamente el control de mis hijos y eso no mas

- ¿Y notas si tus hijos están aprendiendo? ¿Vas a las reuniones?

- Sí, todo

- ¿Los ves más sanos, mejor alimentados o igual que antes?

Bueno el programa que nos entrega plata es más ayuda, sí. Porque a veces trabajas pero no te alcanza y ahí ya cobras mes a mes

- Y antes de entrar al programa, ¿cuánto ganabas al mes?

- 400 soles, así no más.

- Y para 5 hijos me imagino que no te alcanzaba

- No pues

\section{Entrevistada N $^{\circ}$ 18: NNN (San Rafael)}

- ¿Cuántos hijos tiene?

- He tenido 3 pero uno ha terminado el año pasado, uno está en colegio el otro está en primaria

- ¿Y hace cuánto tiempo recibía el programa?

- Hace 3 años

- ¿Y le han cortado?

- Si en esta vez me han cortado, me ha dicho en primaria has tenido falta me ha dicho, pero no es que he tenido falta yo le he dicho en que tengo falta, en colegio, en posta o en primaria, "no solo en primaria" me ha dicho, "ha faltado tu hijo en mes de agosto", yo le he dicho no tengo ninguna falta en ningún lado de mi de todo están puntuales mis hijos, ahora en setiembre han ido los profesores de huelga, entonces él ha asistido en primaria si un mes y ,medio si no ha habido clase, entonces le he dicho promotor yo también puedo sacar mi asistencia de primaria porque me van a cortar mi dinero, entonces me ha dicho saca tu papel de asistencia, y el profesor se ha molestado porque te has quedado callada y no has dicho nada antes, ya va a ser fecha de cobro, y en el cuaderno de asistencia no tengo falta, ahora en setiembre sí, porque han estado de huelga. He llevado todo y me han dicho que lo van a enviar a Lima a evaluar, y para diciembre recién va a estar mi plata El promotor me dice en que gasto esa plata, y le he dicho que gasto en útiles, en uniformes en mercadería. 
- ¿Mercadería? ¿Qué mercadería?

- Así a veces saco fiado y me dicen Juntos vas a cobrar de ahí me pagas entonces yo saco leche

- ¿Y qué alimentos sacas con la plata que recibes del programa?

- Leche, saco maca saco quinua, soya, eso, café, quaker suelto, fideos aceite, eso saco

- ¿y por qué le das esos alimentos a tus hijos, porque tú sabes que son nutritivos?

- Porque las profesoras me dicen que tú le puedes dar esos alimentos a tus hijos

- ¿Y antes de que tú estuvieras en el programa le dabas los mismos alimentos o que consumías antes del programa?

- No, antes que no me daban JUNTOS no, probábamos siempre quacker leche así de vez en cuando nuestro café como siempre no, en la chacra nuestro machica nuestro cancha todo eso comíamos

- ¿Tú llevas a tus hijos a sus controles mensualmente?

- Si

- ¿Y tú notas si tus hijos están sanitos ahora?

- Si están bien

- Y antes del programa, ¿se enfermaban?

- Si estaban un poco bajo, estaban así fallando

- ¿Y los llevabas igual al centro de salud de la misma manera que los llevas a hora?

- Antes no lo llevaba mucho

- ¿Y ahora sí?

- Si

- Más que nada porque el programa te obliga

- $\mathrm{Si}$

- ¿Y si tú no lo llevas a un control el programa te suspende?

- $\quad$ Si, él tiene q tener sus citas que mes que mes que hora cuando

- ¿Tus hijos trabajan?

- No, sábado y domingo no más nos ayudan en la chacra

- ¿Y antes de que recibieras el programa tus hijos trabajaban?

- No, si me ayudaban así en la chacra en animales, como estudian sábado y domingo no más nos ayudan

- Y antes del programa itus hijos iban todos los días a la escuela?

- Sí, siempre iban, nunca han fallado

- Y antes de que recibieras el programa ¿tú trabajabas en algo?

- Si vendía mi pelado, mi motecito vendía mi triguito mi habas mi maicito vendía

- ¿Y cuánto sacabas a la semana o por día?

- Bueno a la semana 2 veces vendía mi pelado mi mote así

- ¿Y cuánto más o menos ganabas por semana?

- 10 soles 15 soles, a veces compran a veces no compran, a veces no sale por el día no vendes nada al siguiente día recién 1 sol 2 soles 3 soles

- ¿Y ahora con el programa te alcanza?

- No, a veces no te alcanza, a veces yo tengo mi carnerito mi gallinita tengo mi chanchito a veces vendo ya ahí incluyo

- ¿Y el dinero que recibes del programa inviertes? ¿Compras unos cuantos cuyes o algún carnero para criar?

- $\mathrm{Si}$

- ¿Qué compras?

- Cuyes gallinita, patos, eso lo que va creciendo unos comemos otros vendemos para la propina pues

- Ah eso te ayuda a crear tu propio negocio 
- si

- ¿y los promotores te orientan, te dicen que puedes hacer con ese dinero?

- él nos dice esa plata es para sus zapatos de tu hijo para educación de tu hijo cuando pide cuota para que das cuota para cuando pide falta otra cosa para su útiles para eso nos dice nos explica eso no es para que compres tu zapatos no es para que compres tu ropa eso son para tus hijos tu marido no tiene derecho porque pedirte ni 10 céntimos dice

- ¿tu esposo no te pide? ¿Tú no le das tampoco?

- No

- ¿Qué cosas te exige el programa?

- Nos exige tener biohuertos criar animalitos, nuestro cojín nos pide para nuestro adorno tu casa, nuestra cocina mejorada

- ¿Eso les exige el programa JUNTOS? ¿Aparte de las condiciones que tienen que cumplir en salud y educación?

- Aparte

- ¿Quién les exige?

- Nos corrige, nos dice para hacer nuestro biohuerto para criar nuestro animalito para no estar mirando el JUNTOS no más criando gallina cuando pone huevo para vender también

- ¿Pero eso se los recomiendan o se los exigen? Por decir si así como si no cumplen en salud los sacan del programa, si Uds. no cumplen con los biohuerto de las gallinas también ¿los sacan del programa?

- Sí, nos sacan

- Es decir, si ellos te dicen tú tienes que tener tu biohuerto tus gallinas tus cuyes, si no cumples eso, ¿te sacan del programa?

- Te suspenden

- ¿Osea que no es solo que tengas que cumplir las condiciones de salud y de mandar a tus hijos a la escuela?

- No aparte de eso nos pide nuestro biohuerto, que hace obligación en el pueblo.

- Pero eso no es una obligación, ¿Uds. no están obligados a eso?

- Ellos no dicen eso, cuando no hacemos, en nuestro barrio hay una presidenta de juntos, ella nos dice "el coordinador ha dicho que tú tienes tu biohuerto que tú tienes tu animalito que tengas tu cojín tus bolsas bordados tus manteles bordados, que tus hijos no falta a la asistencia, así como dinero no puedes gastar en cualquier cosa"

- ¿A Uds. no les exigen ningún dinero a cambio del programa?

- No

- ¿Y tú líder de la comunidad tampoco te pide algún dinero?

- No tampoco

- ¿Y tú notas si tus hijos están aprendiendo en el colegio?

- Si yo voy a ver mensualmente, yo pregunto a la directora sino a la auxiliar y a sus profesoras por turno le toca y a ellas les digo en que está fallando mi hijo, está estudiando no está estudiando, a qué hora llega a qué hora sale, yo voy a controlar ahí

- Y en nutrición, ¿tú notas que tus hijos están más sanitos, mejor alimentados?

- Si están recuperados

- ¿Están en su talla en su peso?

- Sí. 


\section{ANEXO 3:Metodología para el cálculo del Índice de Focalización de Hogares (IFH)}

Para calcular el IFH se utiliza un procedimiento que cuenta de tres pasos que se detallan a continuación (MEF 2010, p. 10-12):

1. Selección de las variables

Para este primer paso se utiliza el test de Sommers, una prueba estadística que permite medir el grado de asociación entre variables ordinales, lo que permite determinar qué grado de correlación existe entre las variables y la pobreza monetaria. Se seleccionan aquellas variables que presenten significancia estadística o capacidad para discriminar la pobreza de los hogares.

El grupo de variables que se evalúan se toman de la Encuesta Nacional de Hogares (ENAHO) del año 2009 y se refiere a las características de la vivienda, educación, activos del hogar, condiciones laborales de los miembros de estos hogares, hacinamiento, perceptores de ingresos, carga familiar, etc.

\section{Construcción}

Para construir el Índice se utilizó, de acuerdo al MEF (2010) la “técnica estadística del Análisis de Componentes Principales (ACP) para datos categóricos, lo que permite reducir la matriz de correlaciones de las variables originales a un conjunto pequeño de componentes" (p. 11), con lo que se captura la mayoría de la información de las variables originales y se respeta las categorías/unidades de medida impuestas.

Cada uno de los componentes tiene la siguiente forma (MEF 2010, p. 10):

$$
Y_{i}=v_{1 j} X_{1}+\cdots+v_{p j} X_{p}
$$

Yi: componente de las puntuaciones de cada individuo vij: ponderadores de cada variable $\mathrm{Xj}_{\mathrm{j}}$

De todos los componentes que se generan por el ACP, se eligen para trabajar a aquellos que reproduzcan la mayor variabilidad de la matriz de datos. Para este caso, solo se trabaja con el primer componente, dada la significancia de su poder explicativo (en 
promedio $50 \%$ ) y muy superior al segundo componente (13\% en promedio). Es así que se define al primer componente como el IFH.

3. Determinación de Umbrales de corte del IFH

El IFH es un índice continuo o "puntaje"; sin embargo, la elegibilidad es una variable categórica, por lo que para determinarla se tienen que establecer umbrales de corte para el IFH. Así, los hogares que obtengan un IFH o puntaje menor al umbral son calificados como "elegibles" y los que tienen mayor puntaje al umbral se califican como "no elegibles"

Para determinar los umbrales de corte: primero se agrupan las áreas que presentan la misma línea de pobreza monetaria, a través del análisis estadístico de conglomerados con la finalidad de identificar aquellos conglomerados que tengan similares niveles de bienestar y así establecer criterios estandarizados de medición del bienestar del hogar; finalmente, dentro de cada conglomerado se establece el valor crítico que deberá servir para calificar a un hogar como elegible o no elegible.

Este método es utilizado en la mayoría de países latinoamericanos dado que es la técnica que normalmente "funciona mejor" que otras como la regresión Probit, la regresión lineal múltiple, el Análisis Discriminante, etc., pues estas imponen supuestos muy fuertes sobre las variables. Por el contrario, los requisitos que exige el ACP son mínimos: variables continuas o cualitativas ordinales y número de individuos observados mayor al número de variables originales; no se exigen los supuestos de normalidad u homoscedasticidad. (MEF 2010, p. 12). 